\title{
MEDIDAS E ESTIMATIVAS DO BALANÇO \\ DE ONDAS LONGAS, PARA A REGIÃO \\ DE PIRACICABA (SP)
}

JEAN PIERRE H.B. OMETTO

Orientador: Prof. Dr. Valter Barbieri

Dissetação apresentada à Escola
Superior de Agricultura "Luiz de
Queiroz", da Universidade de são
Paulo, para a obtenção do título de
Mestre em Agronomia. Área de
Concentração: Agrometeorologia.

\footnotetext{
PIRACICABA

Estado de são Paulo - Brasil

Fevereiro - 1995
} 


\section{CATALOGAÇÃO NA PUBLICAÇÃO \\ DIVISÃO DE BIBLIOTECA E DOCUMENTAÇÃO - CAMPUS "LUIZ DE QUEIROZ"/ USP}

\section{Ometto, Jean Pierre H.B.}

Medidas e estimativas do balanço de ondas longas, para a região de Piracicaba (SP). Piracicaba, 1995.

$87 \mathrm{p}$.

Diss. (Mestre) - ESALQ

BIBLIOGRAFIA.

1. Balanço de energia - Piracicaba (região) 2. Equação de Brunt-Geiger 3. Meterologia 4. Radiação solar 5. Radiação terrestre I. Escola Superior de agricultu ra Luiz de Queiroz. Piracicaba. 


\title{
MEDIDAS E ESTIMATIVAS DO BALANÇO DE ONDAS LONGAS, PARA A REGIÃO DE PIRACICABA (SP)
}

\author{
JEAN PIERRE H.B. OMETTO
}

Aprovada em: 07/04/95

Comissão Julgađora:

Prof. Dr. Valter Barbieri

ESALQ/USP

Prof. Dr. Nilson Augusto villa Nova

ESALQ/USP

Prof. Dr. Miguel Angelo Maniero

UFSC

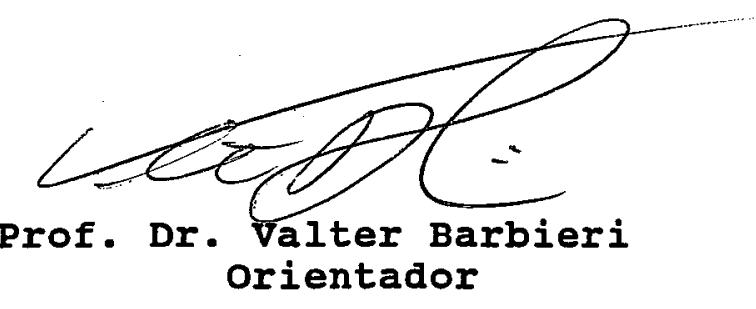


À minha filha ISABELA DEDICO 


\section{AGRADECIMENTO}

Ao Prof. Dr. Valter Barbieri, pela orientação, amizade e dedicação exemplar.

Aos Professores Doutores José Carlos Ometto e Nilson Augusto Villa Nova, pelas sugestões, orientações e preșividade, pelo grande apoio e sobretudo pela amizade pessoal e preocupação constante pelo aprimoramento dos trabalhos.

Aos outros professores do Departamento de Física e Meteorologia em especial à Luiz Roberto Angelocci e Antonio Roberto Pereira, pelas sugestões e apoio ao trabalho.

Ao Prof. Miguel Angelo Maniero pela presença e sugestões apresentadas à defesa do trabalho.

$\grave{A}$ ESALQ/USP, principalmente ao Departamento de Física e Meteorologia, pelo acolhimento amistoso e profissional, e pela qualidade na condução do curso de pós-graduação e de sua produção acadêmica.

À todos os funcionários do Departamento de Física e Meteorologia, em especial a Márcia e ao Robinson, pela prestatividade e amizade dedicadas ao longo do curso de pósgraduação.

À Coordenadoria de Aperfeiçoamento de Pessoal de Nível Superior (CAPES) pelo apoio financeiro. 
INDICE

Página

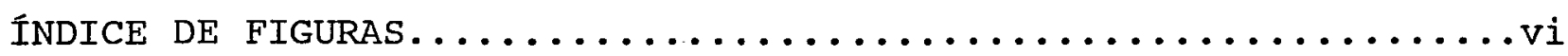

INDICE DE TABELAS............................

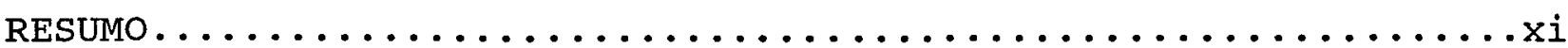

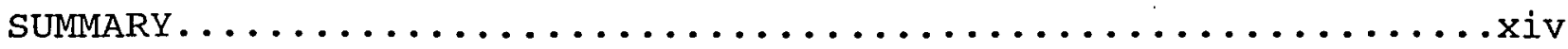

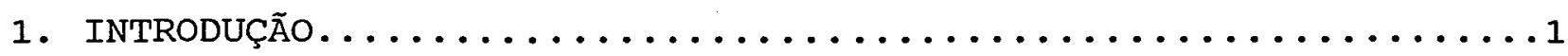

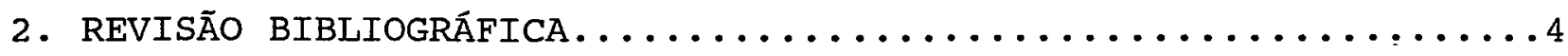

2.1. A Radiação Terrestre........................

2.1.1. Radiação de Corpos Negros................6

2.1.2. A Radiação de corpos naturais...............

2.2. Considerações sobre o papel da atmosfera terrestre......99

2.2.1. Considerações sobre cobertura de nuvens.........12

2.3. Balanço de Energia.........................

2.3.1. Radiação Líquida.......................

2.3.2. Radiação de Ondas Longas................... 15

2.3.3. Relação entre Balanço de Energia e Cobertura de Nuvens............................. 


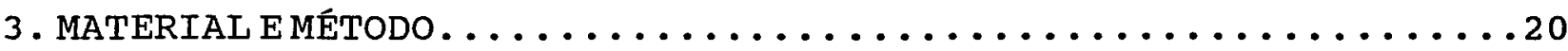

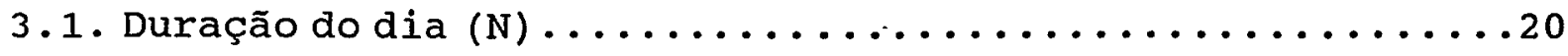

3.2. Horas de brilho solar medidas (insolação) (n) $\ldots \ldots \ldots \ldots 22$

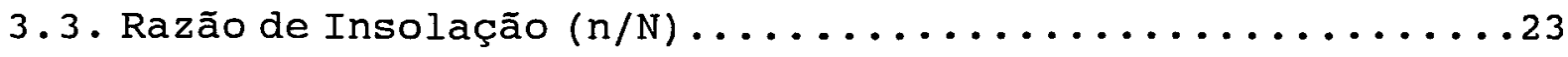

3.4. Radiação Solar Global Teórica (ausente à atmosfera).....23

3.5. Radiação Solar Global Medida (Roc) $\ldots \ldots \ldots \ldots \ldots \ldots$

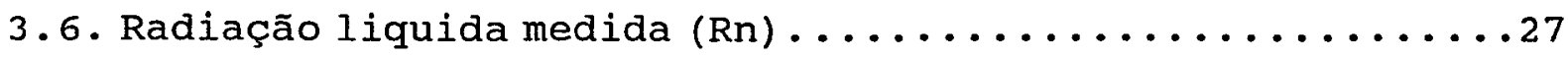

3.7. Pressão parcial de vapor d'água atmosférico (ve) ......29

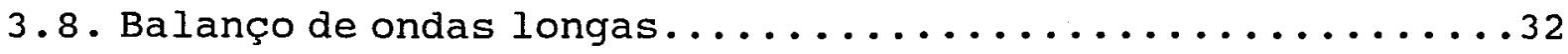

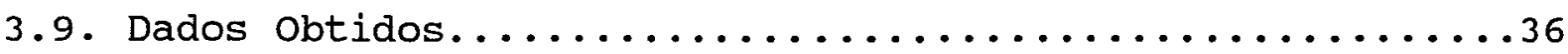

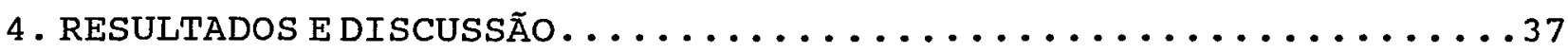

4.1. Análise dos dados............................

4.2. Resultados da radiação de ondas longas $\left(\mathrm{RL}_{0}\right)$ medida e estimadas............................. 49

4.3. Estimativa das equações de Balanço de ondas longas utilizando umidade absoluta................... 50

4.4. Balanço de ondas longas para diferentes períodos no

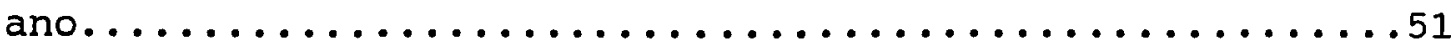

4.4.1. Primavera - Verão....................51

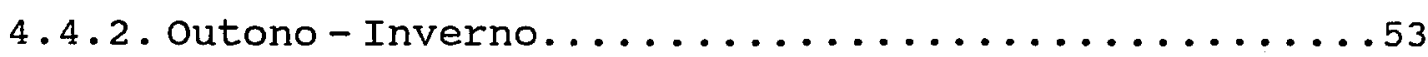


Página

5. CONCLUSÕES................................ 56

REFERENCIAS BIBLIOGRÁFICAS....................... 58

TABELAS E FIGURAS COMPLEMENTARES . . . . . . . . . . . . . . 66 


\section{ÍNDICE FIGURAS}

Página

Figura 1. Distribuição espectral da radiação solar, na ausência da atmosfera (Robinson, 1966) ............5

Figura 2. Emissão do corpo negro em função da temperatura.......7

Figura 3. Distribuição espectral das emissões de corpos negros $\mathrm{a}-33^{\circ} \mathrm{C}$ e $+27^{\circ} \mathrm{C} \ldots \ldots \ldots \ldots \ldots \ldots \ldots \ldots$

Figura 4. Aspectros da absorção solar pelos diferentes componentes da atmosfera (A) espectro de emissão do corpo negro à $6000^{\circ} \mathrm{k}$;

(B) Irradiância solar no topo da atmosfera;

(C) irradiância solar ao nível do mar.

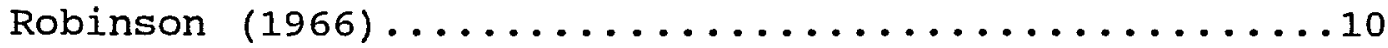

Figura 5. Absorção pela atmosfera vertical da radiação terrestre emitida pela superficie do solo.

Figura 6. Relação entre $R_{\mathrm{Lo}} / \sigma \mathrm{T}^{4}(0,56-0,092$ ve) em função da Razão de insolação para

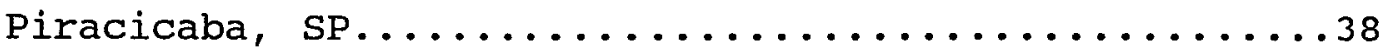


Figura 7. Relação entre $\operatorname{RLo}_{0} / \mathrm{T}^{4}(0,1+0,9 \mathrm{n} / \mathrm{N}) \mathrm{em}$ função da Pressão Atual de vapor para

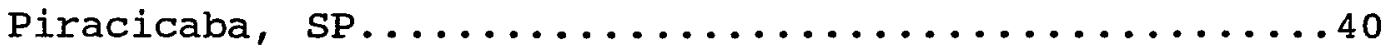

Figura 8. Relação entre $R_{L o}$ medidas em função da $R_{\text {Lo }}$ estimada pela equação: $R_{L_{0}}=\sigma T^{4} \quad(0,462-$ 0,0853 ve $\ldots \ldots \ldots \ldots \ldots \ldots \ldots \ldots \ldots \ldots \ldots \ldots \ldots \ldots \ldots \ldots \ldots$

Figura 9. Relação entre $R_{\text {Lo }}$ medido em função da $R_{L o}$ estimado por Brunt pela seguinte equação: $R_{L o}=\sigma T^{4}\left(0,56-0,092 \sqrt{ }{ }^{2}\right) \ldots \ldots \ldots \ldots \ldots \ldots \ldots \ldots \ldots \ldots \ldots$

Figura 10. Relação entre Rlo estimado pela equação: $\mathrm{R}_{\mathrm{Lo}}=\sigma \mathrm{T}^{4} \quad(0,091-0,019 \mathrm{Ve}+0,42 \mathrm{n} / \mathrm{N}-$ $0,055 \mathrm{n} / \mathrm{N}$ ve) em função da $R_{\text {Lo }}$ observada, para Piracicaba, SP......................... 43

Figura 11. Relação entre RLo estimado pela equação: RLo $=\sigma \mathrm{T} 4 \quad(0,233-0,056$ vet $0,209 \mathrm{n} / \mathrm{N})$ em função do RLo do observado, para Piracicaba,

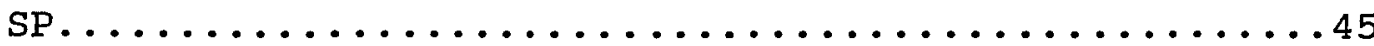

Figura 12. Relação entre $\mathrm{Rlo} / \sigma \mathrm{T}^{4}(0,44-0,056 \mathrm{ve}) \mathrm{em}$ função da razão de insolação para Piracicaba..... . . 44 
Figura 13. Relação entre $R_{\mathrm{Lo}}$ estimado pela equação:

$R_{\mathrm{Lo}}=\sigma \mathrm{T}^{4}(0,44-0,056 \mathrm{Ve}) \cdot(0,066+0,97 \mathrm{n} / \mathrm{N})$

em função da $R_{L_{0}}$ observado para Piracicaba, SP.......48

Figura 14. Relação entre $R_{\mathrm{Lo}}$ estimado pela equação de Brunt-Geiger e $R_{\mathrm{Lo}}$ observado para Piracicaba, SP . . . . 49

Figura 15. Histograma de frequência de $\mathrm{n} / \mathrm{N}$ (em valores) $\ldots \ldots \ldots 86$

Figura 16. Histograma de frequência n/N (percentual) $\ldots \ldots \ldots \ldots 86$

Figura 17. Histograma de frequência de pressão atual de

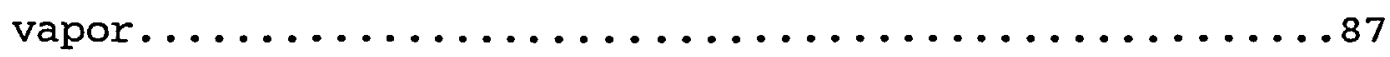

Figura 18. Histograma de frequência de pressão atual de

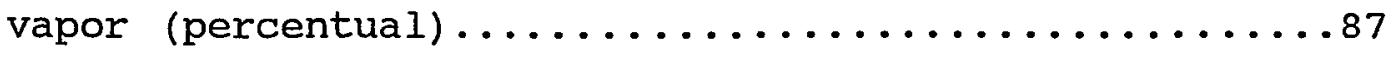




\section{INNDICE TABELAS}

Págira

Tabela 1. Valores medidos de: Qo = radiação solar global teórica $\left[\mathrm{cal} / \mathrm{cm}^{2} \cdot \mathrm{dia}\right] ;$ Roc $=$ radiação solar global medida (radiação de ondas curtas) [cal/ $\left.\mathrm{cm}^{2} \cdot \mathrm{dia}\right] ; \mathrm{N}=$ duração do dias [horas]; $\mathrm{n}=$ horas de brilho solar; $\mathrm{Ta}=$ temperatura do $\operatorname{ar}\left[{ }^{\circ} \mathrm{C}\right] ;$ UR $=$ umidade relativa; e(sat) $=$ pressão de saturação do ar à temperatura Ta $[\mathrm{mmHg}]$..........67

Tabela 2. Dados utilizados nos cáculos das regressões. Roc = Radiação de ondas curtas [cal/cm.dia]; Roc $(1-r)=$ Parcela refletida da radiação de ondas curtas [cal/cm.dia]; $\mathrm{Rn}=$ Radiação líquida medida [cal/cm.dia]; RLo = Radiação de ondas longas [cal/cm.dia]; $T=$ Temperatura absoluta $[\mathrm{K}]$; ea $=$ Tensão atual de vapor $[\mathrm{mmHg}] ; \mathrm{n} / \mathrm{N}=$ Razão de insolação; $\mathrm{Ea}=$ Emissividade atmosférica................... 
Tabela 3. Estimativa do Balanço de ondas longas, para dias limpos $(\mathrm{n} / \mathrm{N} 0,88): \operatorname{Roc}(1-r)=$ radiação de ondas curtas subtraída do albedo [cal $/ \mathrm{cm}^{2} \cdot$ dia] $\mathrm{Rn}=$ Radiação líquida medida $\left[\mathrm{cal} / \mathrm{cm}^{2} \cdot \mathrm{dia}\right] ;$ Rlo = Radiação de ondas longas medida [cal/ $\left.\mathrm{cm}^{2} . \mathrm{dia}\right] ; \mathrm{T}=$ Temperatura absoluta $[\mathrm{K}]$; $\mathrm{UR}=$ Umidade relativa; ea = Umidade absoluta [mmHg $; \mathrm{n} / \mathrm{N}=$ Razão de insolação; $\sigma=$ constante de stefan-Boltzmann $\left[1,19 \times 10^{-7} \mathrm{cal} / \mathrm{cm}^{2} . \mathrm{dia}\right]$; $\mathrm{Ea}=$ Emissividade atmosférica................ 75

Tabela 4. Dados estimados de radiação de ondas longas a partir da equação original de Brunt e equações 1,2 e 3 propostas neste trabalho. RLo(med) = Radiação de ondas longas medida $[\mathrm{cal} / \mathrm{cm}$.dia] ........77

Tabela 5. Valores da declinação solar - $\sigma$ Anuário Astronômico do Instituto Astronômico e Geofísico -USP, 1993 (grau e décimo) ...............82

Tabela 6. Pressão máxima de vapor à temperatura $\mathrm{T}(\mathrm{mmHg}) \ldots \ldots . . . .84$ 


\section{MEDIDAS E ESTIMATIVAS DO BALANÇO \\ DE ONDAS LONGAS, PARA A REGIÃO}

DE PIRACICABA (SP)

Autor: Jean Pierre H.B. Ometto Orientador: Prof. Dr. Valter Barbieri

RESUMO

Estudando a equação de Brunt-Geiger (1948) para determinação do balanço de radiação de ondas longas, $\mathrm{R}_{0} \mathrm{~L}=\sigma \mathrm{T}^{4}$ $\left(a-b\right.$ ve) $\left(a^{\prime}+b^{\prime} n / N\right)$, onde "a" igual a $0,56, "$ "b" igual à 0,092, "a"" igual à 0,1 e "b" igual a 0,9 e considerando, como citam diversos autores, que as características locais, sobretudo a cobertura de nuvens, influem no balanço de energia, fez-se uma análise em separado dos coeficientes da equação utilizando o método de regressão linear visando chegar a adequação desta expressão aos dados locais.

Os dados foram medidos para a região de Piracicaba SP. , coordenadas geográficas de $22^{\circ} 42^{\prime} \mathrm{S}, 47^{\circ} 37^{\prime} \mathrm{W}$ e $570 \mathrm{~m}$ de altitude, por Ometto (1968) e pelo Departamento de Física e Meteorologia da ESALQ USP. 
A partir disto, se propôs regressões múltiplas analisando a interrelação dos fatores atmosféricos vapor d'água e insolação, os quais interferem conjuntamente no balanço de radiação de ondas longas.

o primeiro estudo de regressão múltipla apresentou o seguinte resultado: $\operatorname{Rlo}=\sigma \mathrm{T} 4(0,091-0,019$ Ve $+0,42 \mathrm{n} / \mathrm{N}-0,55$ $\mathrm{n} / \mathrm{N}$ Ve). Com intenção de eliminar a interdependência entre as variáveis, desconsiderou-se o termo $n / N$ ve da regressão múltipla original, e assim refazendo a regressão obteve-se a seguinte expressão: RLO $=\sigma \mathrm{T} 4(0,233-0,056$ ve $+0,209 \mathrm{n} / \mathrm{N})$. Para esta equação assumiu-se $\mathrm{n} / \mathrm{N}$ igual a 1 , ou seja uma condição de céu completamente claro e aplicou-se uma regressão linear considerando todo o universo de dados de razão de insolação. Esta regressão linear apresentou a seguinte expressão como resultado: $\mathrm{RL}_{0}=\sigma \mathrm{T} 4$ $(0,44-0,56$ ve) $(0,06+0,97 \mathrm{n} / \mathrm{N})$

A proposta de se correlacionar diretamente $\mathrm{RL}_{0} / \sigma \mathrm{T}^{4} \mathrm{x}$ $f(\sqrt{ }$ ) foi considerada assumindo os valores de razão de insolação superiores à 0,88 encontrados no universo de dados medidos por Ometto (1968). A esses dados aplicou-se uma regressão linear obtendo-se resultados razoavelmente consistentes. No entanto, dado ao número muito pequeno de medidas, não se pode compara-lá, com um nível de confiança bom à equação original de Brunt.

Separou-se os dados em periodos e obteve-se para Primavera-Verão: $\quad R_{L o}=\sigma T^{4}(0,23-0,051$ ve $+0,19 \mathrm{n} / \mathrm{N})$, e para Outono-Inverno: $\mathrm{R}_{\mathrm{Lo}}=\sigma \mathrm{T}^{4}(0,23-0,062$ ve $+0,24 \mathrm{n} / \mathrm{N})$, mostrando a influência da nebulosidade no verão. Além disto, tentou-se a 
xiii

viabilidade da utilização da umidade absoluta em substituição da pressão parcial de vapor para os cálculos, com resultados que não justificam sua aplicação para a localidade. 


\title{
MEDIDAS E ESTIMATIVAS DO BALANÇO \\ DE ONDAS LONGAS, PARA A REGIÃo
}

\author{
DE PIRACICABA (SP)
}

Author: Jean Pierre H.B. Ometto

Adviser: Prof. Dr. Valter Barbieri

\section{SUMMARY}

studding the Brunt-Geiger 's (1948) equation for the determination of long wave balance, RLO $=\sigma T 4(a-b$ ve $)\left(a^{\prime}+b^{\prime} n / N\right)$ where "a" equal to 0,56 ; "b" equal to 0,092 , "a'" equal to 0,1 and "b" equal to 0,9 , and considering, like several authors mentions, the local caracteristics, especially cloudy skies, influence on the energy balance; by this an analisis were made in separeted for equation coeficients using the linear regression methods loocking for check the apropriation of this expression to locals data.

The messure were take to region of Piracicaba - SP, geographics coordenate of $22^{\circ} 42^{\prime} \mathrm{S}, 47^{\circ} 37^{\prime} \mathrm{W}$ and 570 height, by Ometto (1968) and Phisics and Meteorologic Department ESALQ - USP.

From this, multiples regression were proposed analysing the interelation between the atmosferic parameters, water vapor and insolation, wich interfere assembly on the long wave radiation balance. 
The first study of multiple regression show the folow result: $\mathrm{RLO}=\sigma \mathrm{T} 4(0,091-0,019 \mathrm{Ve}+0,42 \mathrm{n} / \mathrm{N}-0,55 \mathrm{n} / \mathrm{N}-0,55$ $\mathrm{n} / \mathrm{N}$ ve). Intending to eliminate the interdependency between the variables, the term $n / N$ e were desconsiderated from the original multiple regression, and them recalculating the regression the result was $\mathrm{RLO}=\sigma \mathrm{T4}(0,233-0,056 \mathrm{ve}+0,209 \mathrm{n} / \mathrm{N})$. To this equation were assumed $\mathrm{n} / \mathrm{N}=1$, other words, a condition of clearly skie, and than a linear regression were calculed considereting all universe of isolation values that was on the measures. This calculation show: $R_{L_{0}}=\sigma t^{4}(0,44-0,56$ ve $)(0,06+0,97 \mathrm{n} / \mathrm{N})$.

The propose of direct correlation $R_{L o} / \sigma T^{4} \times f(\sqrt{ })$, was considerated assuming valves of $n / N$ superiors to 0,88 , found in the universe of measuring data takes for Ometto (1968). A linear regression was applied founding resonables values, but not consistent to questionate the original equation Brunt.

The mesures were separeted in periods. To springsummer:

$\mathrm{R}_{\mathrm{Lo}}=\sigma \mathrm{T}^{4}(0,23-0,051 \mathrm{Ve}+0,19 \mathrm{n} / \mathrm{N})$, and to autonn-winter: $R_{L o}=\sigma T^{4}(0,23-0,062 \mathrm{Ve}+0,24 \mathrm{n} / \mathrm{N})$, showing the influence of clouds in summer. Tests of the viability of absolute umidity $\left(\mathrm{g} / \mathrm{m}^{3}\right)$ instead of strean pression on the calcules were take. The results didn't justify its application for the local. 


\section{INTRODUÇÃo}

Há milênios entende-se o sol como fonte vital à vida na terra. o conhecimento mais profundo dos fenômenos e dos processos que determinaram esta verdade sempre foi um desafio ao homem. Para tal a humanidade procurou desenvolver equipamentos que trouxeram o conhecimento real da energia solar incidente em qualquer ponto do globo, em qualquer instante que seja. No entanto era preciso também saber o quanto desta energia incidente a terra emitia para o espaço. Desde que era sabido que todo corpo emite energia em função de sua própria energia interna, era evidente que a terra quanto mais radiação recebesse mais radiação emitiria, e essa radiação não poderia ser computada no total da qual seria utilizada para os processos naturais, tais como evaporação, evapotranspiração, aquecimento do ar, metabolismo biológico, etc.

- físico stefan e o matemático Boltzman haviam levantado a proporcionalidade do modelo de emissão radiante proposto por Planck. O modelo dizia que a energia emitida por um corpo é proporcional à quarta potência de sua temperatura absoluta. A temperatura da superfície de emissão conhecida, a proporcionalidade levantada, seria simples determinar a perda de energia da superfície terrestre. Mas essa emissão também interagia 
com a atmosfera. Iniciou-se então estudos para determinar quais os elementos atmosféricos que mais interagiam coma radiação terrestre, isto é, os que mais absorviam a radiação do solo. Estes estudos levaram à direção do teor de água na atmosfera, fosse ela na forma gasosa (vapor), líquida ou sólida.

Estes estudos eram apoiados por equipamentos que mediam a emissão terrestre e que já começavam a ser desenvolvidos, no entanto eram caros, de dificil manuseio e altamente sensíveis. Com isso, valores obtidos por esses aparelhos associados à valores estimados pelo modelo teórico de emissão energética, obtinha-se o coeficiente de absorção atmosférico, em função do teor em água da atmosfera. Brunt $(1939)^{1}$ definiu valores de regressão, ou seja ajuste da emissão de ondas longas em função do vapor d'água, para condição de atmosfera limpa, livre de nuvens. Posteriormente Geiger $(1948)^{2}$ corrigiu com um segundo coeficiente para a condição de cobertura atmosférica (nuvens).

Essa expressão composta obtida na Inglaterra por Brunt (1939) e ajustada na Alemanha por Geiger (1948), perdura até hoje. Apesar dos fatores físicos e astronômicos considerados nas equações serem teoricamente imutáveis de região para região no globo terrestre, algumas condições geográficas, de movimentação do ar entre outras, acabam determinando alterações nas características de

${ }^{1}$ Brunt, D. Physical and Dinamical Meteorology, 2 a Cambrige University Press, 428p. 1939.

${ }^{2}$ Geiger, R. The climate near to the Ground. Bleu Hill Meteorology Observatory. Harvard University, Cambrige, $482 \mathrm{p}, 1948$. 
cobertura atmosférica que influenciam o balanço energético desta região específica.

$\mathrm{Na}$ importância do conhecimento, do estudo, da comprovação ou não das proposições já formuladas, reside o significado da ciência, e neste caso especifico, o conhecimento da expressão de emissão terrestre vem do fato de que o balanço de radiação, composto pela radiação solar incidente, sua parcela refletida e a própria emissão terrestre, é de vital importância aos processos físicos, químicos e sobretudo biológicos que ocorrem na natureza.

o objetivo deste estudo é propor uma alternativa à equação de Brunt-Geiger (1948), largamente utilizada para determinação do Balanço de ondas longas, baseada na proposição de que caracteristicas locais influenciam neste balanço. Robinson (1966) salienta que o albedo para ondas longas das bases das nuvens influencia determinantemente o balanço desta faixa espectral. O albedo é dependente da espessura das nuvens, e esta dependência é diferente para os vários tipos de nuvens. As características de cobertura para a região de Piracicaba são diferentes das existentes na Inglaterra, onde Brunt (1939) estabeleceu suas expressões, e da Alemanha onde Geiger (1948) a ajustou havendo portanto a possibilidade de determinação de valores diferentes para a equação. 


\section{REVISÃO BIBLIOGRÁFICA}

A radiação solar ocupa lugar de destaque e de primordial importância entre os elementos meteorológicos, pois além de ser o princípio básico da vida, é o motor que impulsiona a atmosfera (GEIGER, 1961). Quem primeiro publicou um trabalho sobre emissão da radiação eletromagnética pela matéria, inclusive observando que "para um dado comprimento de onda um corpo bom absorvedor de radiação é também um bom emissor", foi Kirchkoff em 1859, citado por Monteith (1973) .

A habilidade de emitir e absorver radiação é uma propriedade intrínseca de sólidos, líquidos e gases e é sempre associada com a mudança do estado energético de átomos e moléculas.

Grande parte da radiação emitida pelo sol está confinada à um comprimento de onda que vai de 0,3 à $3,0 \mu \mathrm{m}$ (MONTEITH); (1990). Segundo Wien, (1926) dentro deste espectro, o comprimento de onda de maior energia, ao qual está associado um maior número de fatores é próximo à $0,48 \mu \mathrm{m}$, pois é o comprimento de onda que mais existe no espectro e para este autor o produto desse comprimento de onda pela temperatura absoluta do corpo é constante e igual a $2897 \mu \mathrm{m} . \mathrm{K}$ (i.e $\lambda_{\max } \mathrm{T}=2897 \mu \mathrm{m} . \mathrm{K}$ ), e neste caso 
a estimativa da temperatura da atmosfera solar se aproxima a 6000 K. (Figura 1).

U.V. - Ultravioleta

V. - Visivel

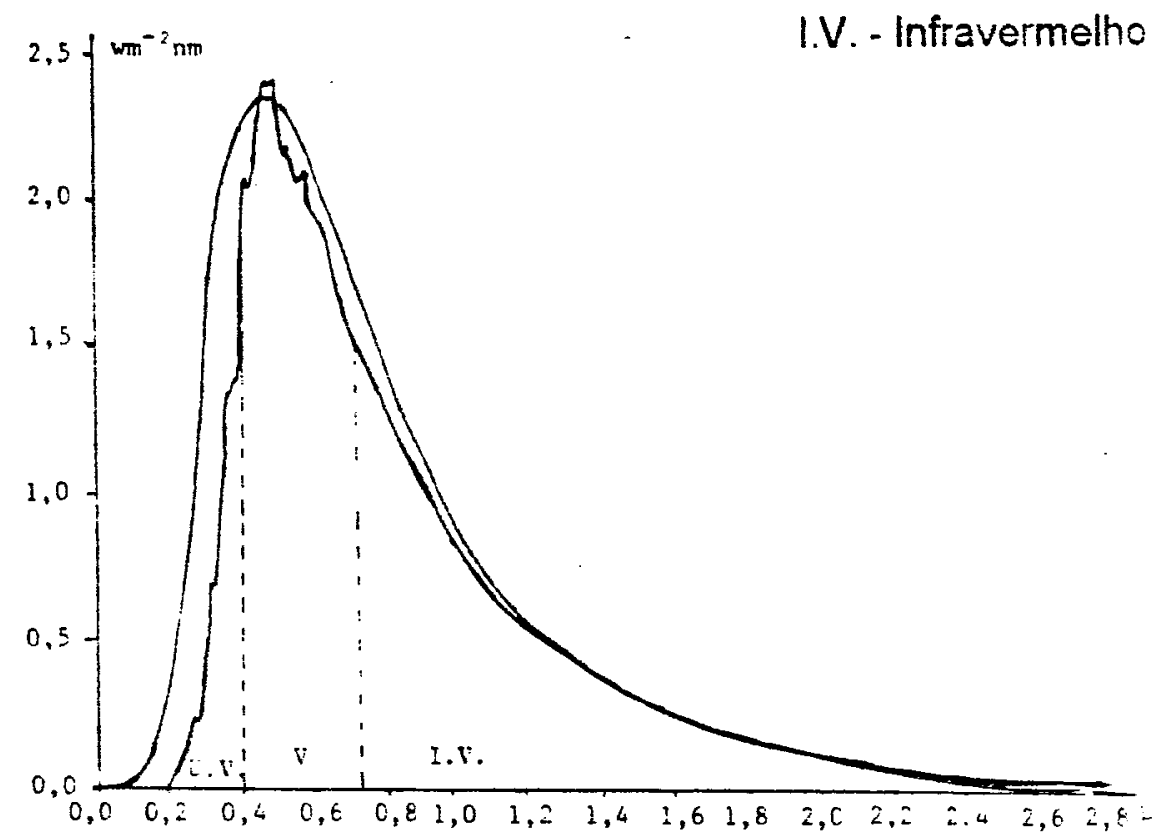

Figura 1. Distribuição espectral da radiação solar, na ausência da atmosfera (Robinson, 1966).

Para Geiger (1961), a distribuição espectral das intensidades de comprimento de onda em uma emissão se comporta de tal maneira que $25 \%$ do total da radiação estão abaixo de $\lambda_{\max }$ e $75 \%$ acima deste comprimento de onda acima considerado. o mesmo autor cita Hofmann ${ }^{3}$, que propõe que se considere um comprimento de onda $\lambda_{\mathrm{s}}$ que corresponda ao "centro de gravidade" da distribuição espectral, de tal forma que a cada lado de $\lambda_{\mathrm{s}}$ contenha $50 \%$ da radiação total emitida. o produto deste comprimento de onda $\lambda_{\mathrm{s}}$ pela temperatura absoluta é igual à $4100\left[i, e \mathrm{~T} \times \lambda_{\mathrm{s}}=4100 ;\right.$ (K $\left.\left.\mathrm{x} \mu \mathrm{m}\right)\right]$.

${ }^{3}$ Hofmann, G. Zue Darstellung der spektealen Verteilung de strahlungs energie. Arch f. Met (B) 6, 274-279. 1955. 
Conforme stefan-Boltzmann deduziram, integrando todo espectro da energia solar, o total de energia emitida é da ordem de 74 milhões $\mathrm{w} / \mathrm{m}^{2}$. Sendo a distância média terra-sol $1,5 \times 10^{8} \mathrm{Km}$, a irradiância em uma superficie plana no topo da atmosfera, chamada de constante Solar, foi estimada nos últimos 50 anos entre 1,94 à $2,00 \mathrm{cal} / \mathrm{cm}^{2}$ $\mathrm{x}$ min. Medidas mais recentes utilizando-se balōes ou nesmo com aeronaves voando acima da estratosfera tem corfirmado o valor de $1,94 \mathrm{cal} / \mathrm{cm}^{2} \times \mathrm{min}$.

\subsection{A Radiação Terrestre}

\subsubsection{Radiação de Corpos Negros}

Definido teoricamente como um corpo perfeitamente absorvedor de radiação de todos os comprimentos de onda, o corpo negro deu lugar à númerosos estudos termodinâmicos que salientaram as seguintes caracteristicas principais:

1 - o corpo negro sendo perfeito absorvedor é igualmente perfeito emissor (Drummond, 1968);

2 - emissão é unicamente função de sua temperatura, e é dada pela relação: $\mathrm{E}=\sigma \times \mathrm{T}^{4}$. Relação esta proposta por stefan-13oltzman, (Figura 2), onde E (energia emitida equivalente ao somatório da energia de todos os comprimentos de onda nela cortidos) é expressa em $\mathrm{W} / \mathrm{m}^{2}$ e $\mathrm{T}$ em graus Kelvin (temperatura absoluta) com $\sigma=5,62 \times 10^{-8} \mathrm{~W} / \mathrm{m}^{2} \times \mathrm{K}^{4}$. Esta relação só é válida interralmente para corpos negros; 


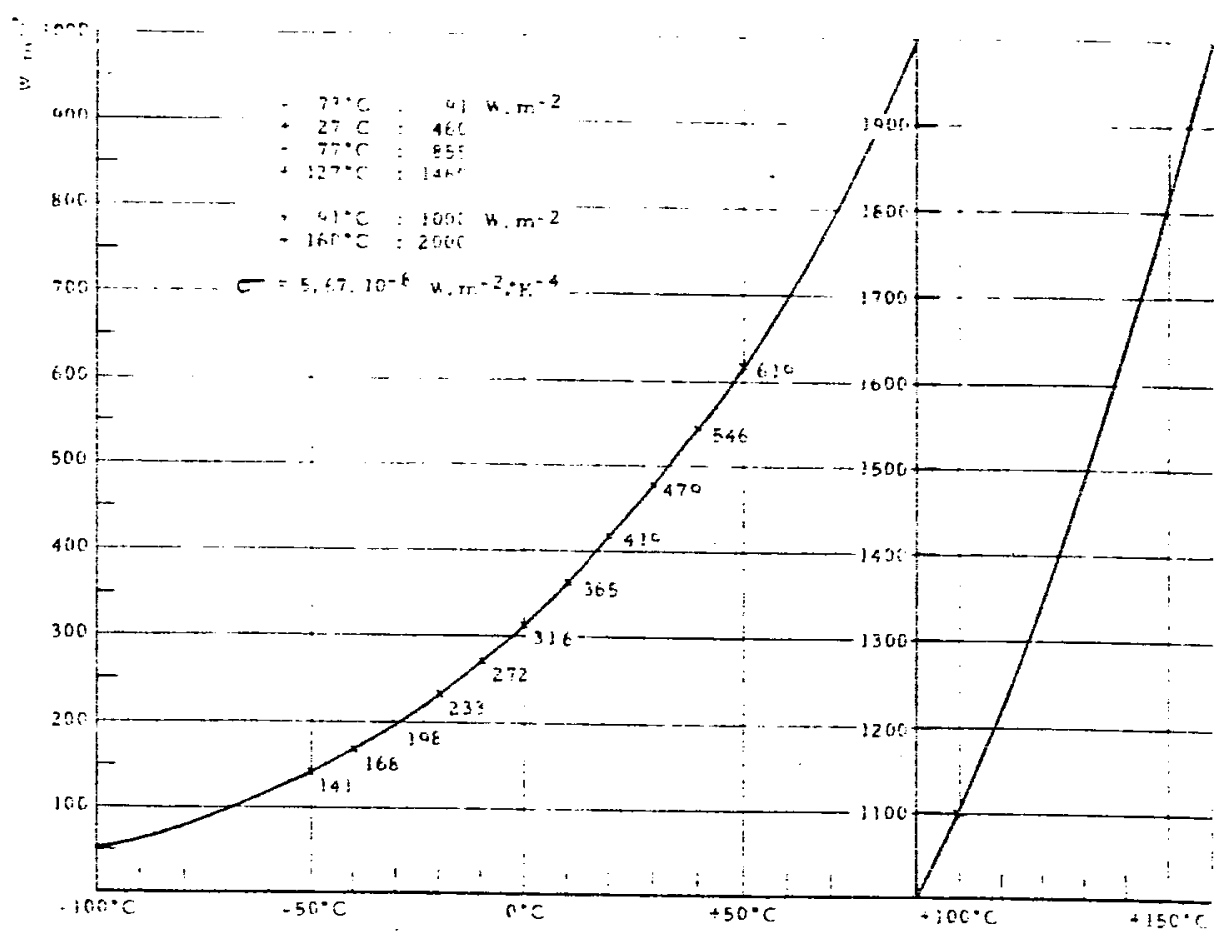

Figura 2. Emissão do corpo negro em função da temperatura.

3 - a radiância, fluxo de uma fonte por unidade de área em uma direção específica, de um corpo negro é a mesma em todas as direções (lei de Lambert) e sua emissão é igual ao produto de sua radiância por $\pi$ (pi), dentro de um sistema de unidade homogeneo; 4 - a lei de wien se aplica perfeitamente aos corpos negros; 5 - segundo Planck as curvas espectrais correspondentes à duas temperaturas diferentes nāo se remontam jamais (Figura 3), ou seja, "a radiação emitida por um corpo tem a distribuição dos seus comprimentos de onda de acordo com sua temperatura". 

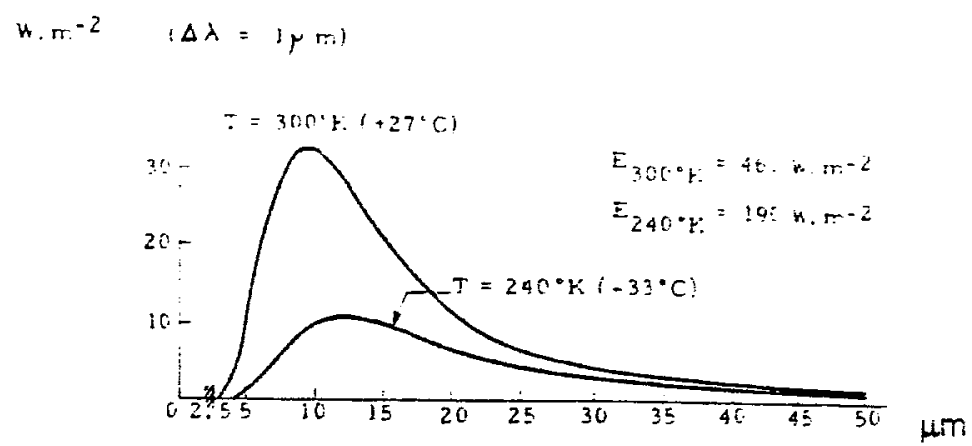

Figura 3. Distribuição espectral das emissões de corpos negros à $-33^{\circ} \mathrm{C}$ e $+27^{\circ} \mathrm{C}$.

Estas observações confirmam os limites energéticos dos comprimentos de onda da radiação solar, e com eles podemos afirmar que um corpo negro à temperatura de $288 \mathrm{k} \quad\left(15^{\circ} \mathrm{C}\right)$ emite um comprimento de onda de máxima energia em $10 \mu \mathrm{m}$ e os limites dos comprimentos de onda da emissão encontram-se entre 5 e $80 \mu \mathrm{m}$, sendo este praticamente o universo coberto pela radiação terrestre (Gates, 1980). Gole(1970) observa que a radiação emitida pela terra, e seu espectro de distribuição, apenas se aproxima da radiação emitida por um corpo negro à $288 \mathrm{~K}$. Ésta seria a média da temperatura absoluta da superfície terrestre, sendo portanto que seu espectro de emissão de radiação se situa na faixa do infravermelho.

\subsubsection{A Radiação de corpos naturais}

Para todo corpo negro cada temperatura corresponde à uma emissão energética bem definida, e sua característica espectral é também perfeitamente determinada, como visto anteriormente. 
Os corpos naturais, por sua vez, não são geralmente dotados destas características; normalmente eles refletem parcialmente certos comprimentos de onda, ou ao contrário se deixam atravessar por eles. Dentro do nosso domínio de temperatura, -50oc à $+800 C$, são os comprimentos na faixa do infra vermelho (entre 4 e $100 \mu \mathrm{m})$ que devem ser retidos. No entanto pode-se considerar que os corpos naturais são dotados de um poder de absorção ou emissão próxima do corpo negro para todo o universo de comprimento de ondas da radiação terrestre. Desta maneira pode-se frequentemente denominá-los corpos negros, pois o valor de absorção média para esses corpos está em torno de 0,95 (Maurain, 1937).

Deve-se salientar que para a maior parte dos corpos líquidos ou sólidos, estes fenomenos de emissão e de absorção são geralmente fenômenos se superfície, e assim sendo o estado e a temperatura da superfície são de extrema importância à emissão dos corpos naturais.

\subsection{Considerações sobre o papel da atmosfera terrestre}

A atmosfera é uma estrutura que absorve e emite ondas de forma seletiva, e um de seus principais componentes absorvedoremissor de ondas, o vapor d’água, é variável em quantidade e distribuição ao longo do planeta (Gole, 1970). Hunghton (1963), Barchewitz, Amat et Rosetti (1954), citam além do vapor d’água, o gás carbônico como elemento importante no balanço de energia da atmosfera. Outros autores entre eles Godoy (1964), Kondratiev 
(1965) e Robison (1966), também enfocam esses elementos em seus trabalhos. Além desses, outros como ozônio e poeira atuam na depleção atmosférica, que envolve processos de reflexão e desvios na faixa do visível no espectro da radiação solar e também absorção do infravermelho, este último com atuação mais marcante do vapor d'água. (Figura 4).

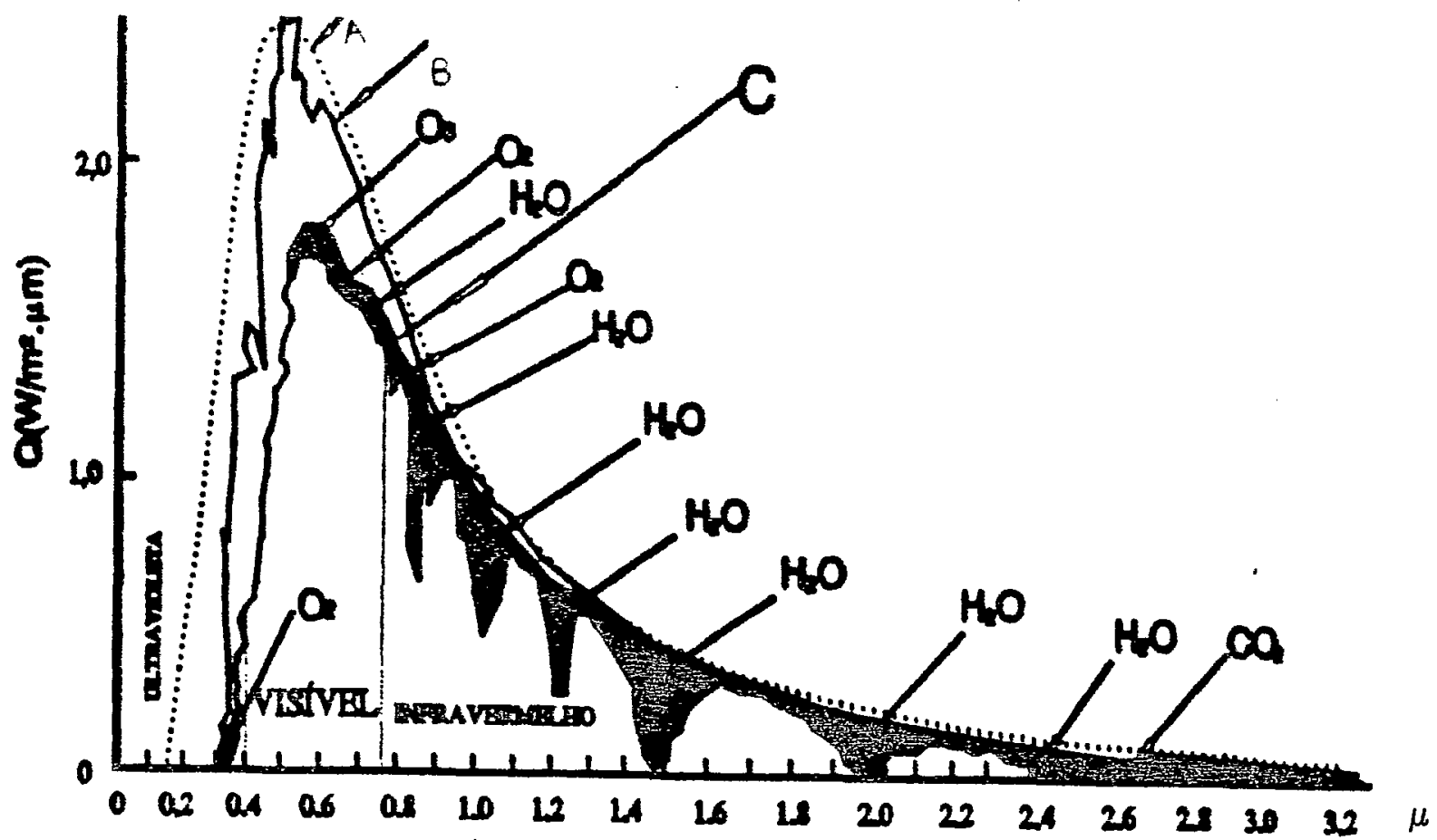

Figura 4. Aspectros da absorção solar pelos diferentes componentes da atmosfera (A) espectro de emissão do corpo negro à $6000^{\circ} \mathrm{k}$; (B) Irradiância solar no topo da atmosfera; (C) irradiância solar ao nível do mar. Robinson (1966).

Com relação à absorção, Gole (1970) salienta que a nível da estratosfera esta é basicamente efetiva na zona do ultra violeta, na qual atua o ozônio. Através da figura (Figura 5) pode- 
se ter uma idéia bem clara das bandas de absorção importantes na atmosfera.

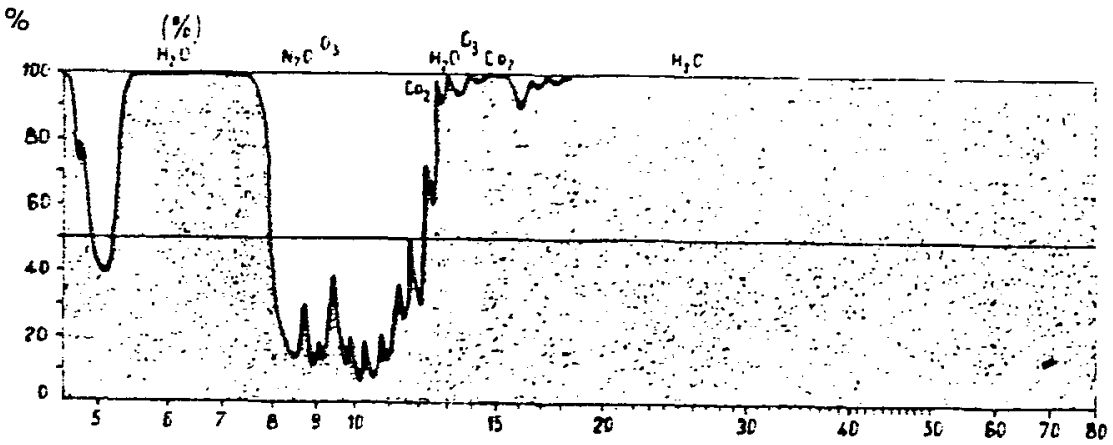

Figura 5. Absorção pela atmosfera vertical da radiação terrestre emitida pela superficie do solo.

Vários modelos de ábacos visando estimar a radiação terrestre emitida pela atmosfera foram propostos por Elsasser (1960), e Yamamoto (1952), no entanto fórmulas mais simples e estatisticamente válidas foram propostas. As mais utilizadas são a de Ängstron e Brunt, (1939) ambas comparam a emissão atmosférica à um corpo negro, considerando a temperatura do ar ao nível do solo e um fator levando em consideração o vapor d'água. Estas fórmulas são particularmente importantes no cálculo do balanço de energia radiante ao nível do solo. A temperatura, aspecto importante no fator emissivo da atmosfera, situa-se, em média, a $293^{\circ} \mathrm{K}$ na troposfera, camada na qual se concentra o vapor d’água e o gás carbônico. Nesta camada devido a presença predominante destes componentes o comprimento de onda de maior concentração na emissão energética é de 9,6 $\mu \mathrm{m}$ (Gates, 1980). A temperatura média da estratosfera, camada da atmosfera situada a cerca de 22 kilometros da superficie terrestre, é cerca de $235^{\circ} \mathrm{K}$. 


\subsubsection{Considerações sobre cobertura de nuvens}

As considerações feitas para o céu sem nuvens retrata apenas uma parcela dos dias em uma determinada localidade. Normalmente a presença de nuvens aumenta o fluxo de radiação recebida pelo solo, a irradiação do gás carbônico e sobretudo do vapor d'água da camada atmosférica compreendida entre o solo e a base das nuvens é suplementada pela irradiação das próprias nuvens (Usworth, 1990). Segundo Vassy (1966) uma nuvem normal deve ter ao menos $30 \mathrm{~m}$ (metros) de espessura para começar a emitir como um corpo negro. Para outros autores esta espessura deve ser de no mímino $100 \mathrm{~m}$ para que se possa considerar a nuvem como um corpo negro, sendo sua temperatura de emissão um pouco diferente daquela de sua base (Godoy, 1964). Dentro destas condições as nuvens emitem na direção da superfície da terra uma radiação infravermelha facilmente calculável, mas que é parcialmente absorvida pela atmosfera interposta entre o solo e a base das nuvens. Boltz citado por Kondratiev (1965) propôs uma fórmula para calcular o acréscimo ao balanço de radiação em direção ao solo provocado por uma cobertura de nuvens, esta fórmula é a seguinte: Ln $=\mathrm{L}(1+\mathrm{kn})$, onde:

L: Radiação em direção ao solo;

Ln: Radiação em direção ao solo acrescida do fator de nebulosidade; Kn: Fator nuvem, varia de: 0,04 para cirrus; 0,08 para Cirrustratus; 0,17 para Alto Cumulus; 0,20 para Alto Estratus ou Cumulus; e 0,24 para stratus. 


\subsection{Balanço de Energia}

\subsubsection{Radiação Iíquida}

Durante o dia, parte da energia vinda do sol é refletida de volta ao espaço pela superfície, fração esta conhecida por albedo, e parte interage com o solo alterando seu estado de energia; a radiação de onda longa emitida pelo solo, nuvens e atmosfera também contribuem ao fluxo de radiação líquida. Durante a noite, o resfriamento da superfície do solo, a emissão de radiação de ondas longas pelas nuvens e pela atmosfera é que determinam a radiação líquida (Berkowicz, 1982). o balanço de radiação de onda longa ao solo vem a ser a composição entre a radiação emitida pelo solo à atmosfera e a reirradiação desta em direção ao solo. A radiação líquida deste processo, que vem a ser - saldo de radiação sobre uma superfície, representa a principal fonte de energia aos processos naturais, tais como metabolismo biológico, perda d’água, decomposição orgânica entre outros (Azevedo et AL, 1991; Ometto et AL, 1972; Critchfield, 1974). Villanueva (1987), apresenta considerações sobre a importância do balanço de energia e a radiação líquida na determinação do fluxo de vapor d'água na atmosfera. Villa Nova (1973) cita Penman, dizendo que o balanço de energia é responsável por três quartos do processo de evaporação na natureza, e apenas uma quarta parte é devida ao déficit de saturação associada ao efeito da transferência de massa. Além de Penman, Villa Nova cita também os trabalhos de Budyko (1956 
e 1963), Lemon(1962), Priestley (1959), Rider (1954) e Robinson (1956), os quais demonstram a importância do balanço de energia nos processos evaporativos naturais.

A radiação líquida pode ser medida através de equipamentos, normalmente caros para o uso rotineiro e usados quase que exclusivamente para pesquisas, ou através de estimativas utilizando equações considerando a radiação líquida Rn, como sendo, uma composição entre o fluxo de radiação incidente à superfície do solo (positivo) e o fluxo de radiação incidente refletido pela superfície mais fluxo de radiação emitida pela superfície do solo. (negativo)

Ometto (1991) correlacionou valores medidos de radiação líquida com radiação solar incidente na superfície do solo, supondo atmosfera ausente, e razão de insolação. Utilizou para tal, dois períodos distintos caracterizados por declinações solares, positivas e negativas. Isto porque na região as características são altamente diferenciadas nos períodos citados. Desta maneira encontrou uma expressão para representar cada um dos períodos.

Atualmente os estudos passaram a ter uma especificidade bastante grande, Hage (1993) argumenta em seu trabalho que a radiação global, definida em termos climatológicos e sendo o componente básico na determinação da energia líquida do meio, é um "parametro pobre" para descrever o ambiente radiativo das plantas, ou seja, a radiação global não é apenas uma irradiância da energia solar em uma superfície horizontal, o que vista desta maneira se torna um parâmetro unidirecional em um ambiente, na realidade, 
tridimensional. Hage (1993) propõe a consideração de um parâmetro horizontal de distribuição de energia no meio ambiente, inclusive cita o trabalho de Ballare, scopel e Sanchez (1990) ${ }^{4}$, que identificaram em experimento uma influência significativa na distribuição horizontal da radiação entre plantas.

\subsubsection{Radiação de Ondas Longas}

Segundo Azevedo(1991) o termo de maior dificuldade de determinação na equação đo balanço de energia líquida é o termo referente à radiação de ondas longas incidentes na superfície do solo, Rol (+), dependente sobretudo do vapor d'água da atmosfera e a cobertura de nuvens.

A radiação de ondas longas é frequentemente estimada por fórmulas empíricas, em função da temperatura e/ou da pressão de vapor d'água da atmosfera. Monteith e Unsworth (1990), propuzeram uma equação utilizando medidas das terras centrais da Inglaterra, sob uma faixa de temperatura de $-6{ }^{\circ} \mathrm{C}$ à $+26{ }^{\circ} \mathrm{C}$, e obtiveram 0 seguinte resultado:

$$
\mathrm{Rla}=\mathrm{c}+\mathrm{d} \sigma \mathrm{T}^{4} \text { sendo } \mathrm{c}=(-119 \pm 16), \mathrm{d}=(1.06 \pm 0.04),
$$

e os valores de $\sigma$ e $\mathrm{T}$ em $\mathrm{W} / \mathrm{m}^{2}$ e ${ }^{\circ} \mathrm{C}$ respectivamente. Monteith(1990), cita que Swinbank (1963) na Austrália obteve valores semelhantes mas com uma significância menor. Muitas fórmulas complexas tem sido

${ }^{4}$ Ballere, C.L., Scopel, A.L. and Sanchez, R.A. Far-red radiation reflected from adjacent leaves: an earty signal of competition in plant canopies. Science, 247: 329-331, 1990. 
derivadas para ajustar as observações da radiação de onda longa sob céu sem nuvens e as mais precisas são as que consideram além da temperatura a pressão de vapor d'água da atmosfera, isto com intenção de determinar diferenças na água preciptável (Hatfield, 1983)

Bernard (1956), relata que vários autores tem procurado exprimir a radiação de onda longa atmosférica (Rla) em função do poder emissivo da atmosfera (Ea) partindo de uma fórmula empirica com a seguinte forma:

$$
\mathrm{Ea}=\mathrm{Rla} / \sigma \mathrm{T}^{4}=\mathrm{f}(\mathrm{e}) \text {, sendo } \mathrm{T} \text { a temperatura absoluta do }
$$
ar medida em abrigo meteorológico, e e a pressão atual de vapor medida igualmente sob o abrigo, onde a vantagem é que esta fórmula permite a determinação de Rol com dados meteorológicos correntes. Bernard (1956) cita as fórmulas de Ängstron (1915) $\mathrm{f}(\mathrm{e})=\mathrm{Rla} \mathrm{T}^{4}=$ $A-B \times 10^{-a e}$, sendo os válores empíricos para $A=0,81 ; B=0,52$ (sendo e em mb), também estudada por Boltz e Falckemberg (1949) que obtiveram os seguintes valores para as constantes: $A=0,82$; $B=0,25$ e $\sigma=0.0945$, que forneceram dados de 4 à $7 \%$ mais elevados para a radiação atmosférica em direção ao solo, e a fórmula de Brunt (1939).

$$
f(e)=R l a / \sigma T^{4}=a+b V e, \text { citada também por Azevedo }
$$
(1991), sendo os valores de $\mathrm{a}=0,44 \mathrm{e} \mathrm{b}=0,080$, e a pressão de vapor em mb. Brichambaut (1963) cita as fórmulas destes autores para a estimativa da radiação atmosférica, onde a fórmula de Ängstron (1924) para céu claro, ou seja sem nuvens é: $L=\sigma T^{4}$ $\left(a+b^{-c e}\right)$ sendo $a=0,18 ; b=0,25 ; c=0,095$ e e a pressão atual 
de vapor expressa em mb (milibars), e a fórmula de Brunt (1939) é definida como: $\quad L=\sigma T^{4}\left(a^{\prime}+b^{\prime} e^{0,5}\right)$ sendo, $a=0,40$ e $b=0,05$; e e a pressão atual de vapor d'água (em mb).

Azevedo et $\mathrm{AL}$ (1991) cita em seu trabalho mais alguns autores e suas respectivas propostas de equações para determinação do fluxo de ondas longas atmosférica em direção à superfície do solo (Rla): - Swinbank (1963): Rla $=\sigma \mathrm{T}^{4}\left(0,92 \times 10^{-5} \mathrm{~T}^{2}\right)$ - Idso \& Jackson (1969): $\operatorname{Rla}=\sigma \mathrm{T}^{4}\left(1-0,261 \exp \left[-7,77 \times 10^{-4}(273-\mathrm{T})^{2}\right]\right)$

- Brutsaert (1975): Rla $=\sigma \mathrm{T}^{4}\left(1,24(\mathrm{ea} / \mathrm{T})^{1 / 7}\right.$

- Satterlund (1979): Rla $=\sigma \mathrm{T}^{4}\left\{1,08-1,08 \exp \left(-\mathrm{e}^{\mathrm{T} / 1206}\right)\right\}$ sendo todos em condições de céu claro (sem nuvens), e a temperatura em graus Kelvin (absoluta). Através de erro padrão de estimativa Azevedo determinou as calibraçōes locais para cada uma das equações (inclusive a equação de Brunt citada anteriormente). Funari et ALLI (1985) apresenta um estudo comparativo entre a equação de Brunt, e a formulação proposta por Linacre(1967), ambas para a determinação de que chamou de radiação efetiva terrestre (Rb) (balanço de ondas longas). A equação proposta por Linacre é: Rb = $0,00032(1+4 \mathrm{n} / \mathrm{N})(100-\mathrm{T}) \quad 1440$, onde $\mathrm{T}$ é a temperatura do ar em graus celcius.

\subsubsection{Relação entre Balanço de Energia e Cobertura de Nuvens}

o aspecto de cobertura da atmosfera pelas nuvens é de extrema importância na determinação do balanço de energia ao nível 
do solo, sobretudo com relação aos aspectos quantitativos deste parâmetro. A grande variabilidade quanto à espessura, forma e ocorrência dos tipos de nuvens denota a grande complexidade na determinação desta influência. Culson (1975) cita Ängstron, o qual propõe uma relação linear entre insolação, ou seja a quantidade de luz solar que chega ao solo (n) com relação ao máximo que poderia chegar aquele dia (N) e a irradiância solar diária (Qg), sendo (QC) a irradiancia global no dia sem a presença de nuvens: $Q=Q C[a+(1-a) n / N]$.

Black et AL (1954) cita Prescott, que considerando o fato de que a irradiância solar global em um dia sem nuvens pode variar com a transmissividade atmosférica, propôs uma alteração à equação de Ängstron. Trabalhando com a irradiância solar global em uma superfície horizontal sem a presença da atmosfera, e fatores "a" e "b" determinados a partir de equações de regressão linear sobre dados medidos obteve a seguinte equação: $Q=Q_{0}(a+b n / N)$. Geiger (1948) propôs uma atenuação à equação de Brunt para a determinação do balanço de ondas longas, considerando o aspecto da cobertura de nuvens.

Senna (1992), chama a atenção para o grande número de trabalhos que buscam a determinação dos parâmetros "a" e "b" nas equações que consideram o aspecto da cobertura de nuvens nas estimativas do balanço de radiação, para as diversas regiōes do planeta. Com isto as deficiências e erros com relações as medidas e estimativas foram se evidenciando. Masteer (1955) citado por Senna observa a ineficácia do heliógrafo para registrar a insolação 
para pequenas elevações do sol com relação ao horizonte. Ometto (1991) salienta que com a passagem de nuvens, o que faz com que incida sobre o aparelho apenas radiação solar difusa, o heliógrafo nada registra. o erro que isto acarreta baseia-se no fato de que a radiação difusa contribui para o balanço energético e, sobretudo, tem influência sobre inúmeros processos biológicos. Perlat (1961) observa que a coloração da tira de leitura do heliógrafo, sendo esta mais fosca ou menos fosca, pode acarretar problemas na medida. Além destes, outro aspecto importante a se observar com relação às medidas do heliógrafo, é a fato de que a marca produzida na tira pode apresentar descontinuidades devido à nebulosidade passageira, além de ser uma marca grosseira, o que faz com que normalmente se apele para o bom senso de quem efetua a leitura. Estas observações não distituem a importância do heliógrafo como aparelho de medida e como ferramenta prática para os cálculos estatísticos de determinação aproximada da radiação solar global incidente, além de, como foi objeto deste estudo, estimar o balanço de ondas longas em um dado local. 


\section{MATERIAL E MÉtodo}

As informações teóricas utilizadas foram obtidas por intermédio de modelos matemáticos e por instrumental especifico, quando medidas.

\subsection{Duração do dia (N)}

- tempo transcorrido do nascer ao por do sol, em qualquer lugar do globo, é chamado de duração máxima do dia (N). A obtenção dessa informação é a partir de modelo matemático, utilizando conceitos astronômicos. Em virtude disso, a duração máxima do dia obtida dessa maneira é considerada um valor teórico. Ela é perfeitamente valida quando assume-se atmosfera ausente.

A obtenção do valor teórico de duração máxima do dia e utilizado na razão de insolação, baseia-se na teoria de deslocamento do ângulo zenital(Z). Essa teoria é fundamentada apoiando-se nos conceitos de: latitude $(\psi)$ (no caso de Piracicaba $\left.22^{\circ} 42^{\prime} \mathrm{S}\right)$; declinação solar $(\delta)$ (ver Tabela 6), que caracteriza a posição que a terra ocupa no plano da ecliptica, e ângulo horário (h), ângulo formado entre o plano meridiano do local e o plano meridiano que contém o sol. o modelo que relaciona o zenite do 
local com os parâmetros acima citados é dado pela expressão:

$$
\cos Z=(\operatorname{sen} \psi \operatorname{sen} \delta+\cos \psi \cos \delta \cos h)
$$

Por definição, ângulo zenital (z) é aquele formado pela vertical do local com a imaginária linha ligando esse local ao centro do sol. Isso posto, no momento do nascer ou pôr do sol esse ângulo é exatamente $90^{\circ}$.

Sendo o ângulo de $90^{\circ}$, o coseno desse ângulo no instante é 0 logo, a expressão (1) igualar-se-ia a 0, para situações do nascer e pôr do sol.

$$
0=\operatorname{sen} \psi \operatorname{sen} \delta+\cos \psi \cos \delta \cos h
$$

A latitude $(\psi)$ é um parâmetro determinado e constante para cada local no globo, a declinação solar $(\delta)$ é parâmetro conhecido e considerado constante para o período de um dia, e dessa maneira, procura-se obter o valor de (h). Pela expressão (3.1.2) obtêm-se:

$$
\cos h=-\frac{\operatorname{sen} \psi \operatorname{sen} \delta}{\cos \psi \cos \delta}(3.1 .3)
$$

A expressão (3.1.3), pode ainda ser escrita como:

$$
\cos h=-\operatorname{tg} \Psi \operatorname{tg} \delta
$$

a partir da equação (3.1.4), obtêm-se o valor do ângulo horário (h) 


$$
h=\operatorname{arc} \cdot \cos -(\operatorname{tg} \psi \cdot \operatorname{tg} \delta)
$$

o termo $h$ encontrado em (3.1.5) refere-se ao ângulo horário que o sol tem para aquele dia, no momento do nascente ou poente. Supondo ser o nascer, a medida que o sol vai aumentando sua altura, vai diminuindo o h até ser zero na passagem meridiana, isto é, ao meio do dia. Após esse instante vai crescendo novamente até - valor do poente, igual ao nascente. Logo, durante o dia o sol descreve dois semicirculos, e como sendo a velocidade angular da terra igual a 15 graus por hora, tem-se que:

$$
N=\frac{2 h}{15}
$$

ou seja $N=0,1333 \mathrm{~h}$ sendo a duração máxima do dia (N) expresso em horas e de décimos de hora (cada decímetro de hora equiivale a 6 minutos). As informações sobre o calculo estão na tabela 1.

\subsection{Horas de brilho solar medidas (insolação) (n)}

o registro do tempo em que o sol brilhou durante um dia, é feito por um equipamento simples, que tem por nome heliógrafo. Como sua finalidade é somente registrar o tempo de brilho do sol, existe alguns tipos de heliógrafos. o que foi utilizado para a obtenção das informações do presente trabalho, foi do tipo Campbell-stokes. Possui uma esfera de cristal, altamente polida que tem por finalidade concentrar os raios solares. Essa esfera é sus- 
pensa em um suporte com especificações. Deve ficar em posição que os hipotéticos eixos, tanto o da esfera como o da terra fiquem paralelos. Ajusta-se isso a partir de latitude do local de instalação. Perpendicular ao eixo e concentricamente a esfera fica a peça onde são colocados as tiras de registro. No momento em que o sol incide na esfera, esta concentra e focaliza a tira de papel, queimando-a. Como só existe a queima, quando há incidência de sol, torna-se simples o conhecimento de quanto tempo o sol brilhou naque le dia. os dados registrados no período estudado estão na tabela 1 .

\subsection{Razão de Insolação $(n / N)$}

A razão de insolação é a existente conceitualmente entre o número de horas de brilho solar que realmente houve (n), com o valor teórico do número máximo de horas de brilho solar que deveria haver no dia (N). Essa relação é importante sobre radiação solar, pois exprime a fração do brilho solar que houve, em relação ao máximo que poderia ter havido. É em verdade, um coeficiente de atenuação para o valor máximo.

os valores para a relação de insolação dos períodos estão na tabela 2 .

\subsection{Radiação Solar Global Teórica (ausente à atmosfera)}

Para se conhecer a quantidade máxima de energia que alcançaria uma superfície horizontal, em qualquer ponto ou local do 
globo, dever-se-á trabalhar considerando a atmosfera ausente. Como se calcula sempre para um determinado local, o modelo deve ser associado ao Zênite do local, sendo portanto o ângulo zenital. 0 modelo matemático abrangendo as variaçōes do ângulo zenital e a constante solar, para todo o dia deve ser utilizado. Logo: o modelo abrange, em valor instantâneo

$$
d Q=\left(\cos Z \cdot I_{0} / R^{2}\right) d t
$$

onde $d Q=$ valor infinitesimal de energia

$$
\cos Z=(\operatorname{sen} \psi \operatorname{sen} \delta+\cos \psi \cos \delta \cos h)
$$

$I_{0}=$ constante solar $=2,0 \mathrm{cal} \cdot \mathrm{cm}^{-2} \cdot \mathrm{min}^{-1}$

$\mathrm{R}^{2}=$ raio vetor terra-sol (correção diária da constante solar) $d t=$ variação infinitesimal de tempo

Então; preparando a expressão 1

$$
\int_{0}^{Q} d Q=\left.\int_{t n}^{t p}\right|_{0} / R^{2}(\operatorname{sen} \psi \operatorname{sen} \delta+\cos \psi \cos \delta \cos h) d t
$$

Na análise dos componentes da expressão 2, tem-se a latitude $(\psi)$ como valor determinado, a declinação solar $(\delta)$ tomados corretamente para o dia, logo simplificando (2) em

$$
\int_{0}^{Q} d Q=\left.\right|_{0} / R^{2}\left[k_{1} \int_{t n}^{t p} d t+k_{2} \int_{t n}^{t p} \cos h d t\right]
$$


Como o ângulo horário descreve dois semi-arcos durante o dia, isto é o primeiro do nascer à passagem meridiana e o segundo da passagem meridiana até o por do sol, e por serem idênticos, calcula-se um deles e soma-se ao resultado o outro. A expressão (3.4.3) mostra ainda a necessidade de troca de variáveis, pois $h$, está expresso em radianos, enquanto dt está expresso em minutos. Ajustando o valor do tempo em radianos, vamos encontrar,

$$
d t=\frac{720}{\pi} \cdot d h
$$

Substituindo a expressão (3.4.4) em (3.4.3), temos

$$
\int_{0}^{Q} d Q=\frac{\left.720 \cdot\right|_{0} \cdot 2}{\pi \cdot R^{2}}\left[k_{1} \int_{h m}^{h p} d h+k_{2} \int_{h m}^{h p} \cos h d h\right]
$$

resolvendo $(3.4 .5)$

$$
Q_{0}=\frac{\left.1440 \cdot\right|_{0}}{\pi \cdot R^{2}}\left[k_{1} \cdot(h p-h m)+k_{2} \cdot \operatorname{sen}(h p-h m)\right]
$$

$$
\text { como: } \begin{aligned}
\mathrm{I}_{0} & =2,0 \mathrm{cal} \cdot \mathrm{cm}^{-2} \cdot \mathrm{min}^{-1} \\
\pi & =3.1416 \\
\mathrm{R}^{2} & =\text { muito próximo de um, portanto considera-se um } \\
\mathrm{K}_{1} & =\operatorname{sen} \psi \operatorname{sen} \delta \\
\mathrm{K}_{2} & =\cos \psi \cos \delta \\
\mathrm{hp} & =\text { ângulo horário no pôr do sol em radianos } \\
\mathrm{hm} & =\text { ângulo horário na passagem meridiana, igual a } 0
\end{aligned}
$$


Substituindo os termos na expressão (3.4.6), ficará

$$
\begin{gathered}
Q_{0}=916,73(\operatorname{sen} \psi \operatorname{sen} \delta h p+\cos \Psi \cos \delta \operatorname{sen} h p) \quad(3.4 .7) \\
Q_{0}=x p r e s s o \mathrm{em} \mathrm{cal.} \mathrm{cm}^{-2} \cdot \mathrm{dia}^{-1}
\end{gathered}
$$

Os valores de $Q_{0}$ obtidos por intermédio da expressão (3.4.7), encontram-se na tabela 1 .

\subsection{Radiação Solar Global Medida (Roc)}

o aparelho destinado a indicar a intensidade do fluxo incidente, no caso a radiação solar global, é chamado de Piranômetro ou Solarímetro. O aparelho utilizado para indicar a energia solar incidente, foi um piranômetro Eppey. Esse instrumento tem como pares termo-elétricos os metais ouro e palladium. Tem no total dez junções desses elementos. Esses citados elementos têm respostas à diferença térmica. As junções desses elementos são dispostas em anéis separados de material altamente isolante, horizontais e pintados de preto e branco. Uma serie de junções encontra-se no anel sob a pintura de branco absolutamente brilhante, e outra em outro anel sob pintura de negro absolutamente opaco. As características absorvidas e refletidas dos elementos é que irão determinar as diferentes temperaturas nas junções. Essas diferenças de temperatura que irão determinar a grandeza da diferença de potencial instantânea a qual pode ser e é medida. Esses anéis estão contidos em uma ampola de vidro, lacrada tendo em 
seu interior gaz inerte, no caso hélio. Esses anéis ficam absolutamente nivelados entre si, e o vidro que reveste a ampola é caracterizado por homogeneidade impecável, afim de não provocar sombreamento, por menor que seja, no elemento sensível. A diferença de potencial estabelecida entre junções, à partir dos níveis térmicos é associada ao fluxo energético incidente, e causador da variação térmica. Dessa maneira o piranometro é calibrado com seu Indice de conversão. o equipamento que foi utilizado tinha por constante de calibração o valor de $2,8 \mathrm{mv} \cdot \mathrm{cal} \cdot \mathrm{cm}^{-2} \cdot \mathrm{min}^{-1}$. 0 Piranômetro Eppley indicava a energia solar incidente e o registro desse fluxo energético foi efetuado por um potenciógrafo tipo "Speedomax", de fabricação "Leeds e Northupp". Os valores de radiação solar global medida para o período estudado estão contidos na tabela 1.

\subsection{Radiação liquida medida (Rn)}

- aparelho destinado a medir a radiação líquida ou saldo de radiação, chama-se pirradiometro ou simplesmente radiometro Iiquido. o elemento sensível é composto de uma placa de material termicamente isolante, e uma série de pares termoelétricos enrolados sobre ela, de maneira que um conjunto de junções fique em um dos lados da placa e outro conjunto similar e absolutamente igual de junções fique simetricamente em outro lado da placa. Esse conjunto é recoberto de tinta negra altamente absortiva, que lhe dá características de absorvidade próxima a unidade. Em condições de 
trabalho essa placa é colocada em posição de perfeita horizontalidade com a superfície a ser estudada, quando recebe os diferentes fluxos energéticos em suas faces. Na face superior radiação solar global em forma de ondas curtas e radiação atmosférica em forma de ondas longas, e na inferior radiação solar global refletida pela superficie em ondas curtas, e emissão radiante da superficie em ondas longas. Isto resulta em diferentes temperaturas entre as placas, estabelecendo dessa maneira uma diferença de potencial elétrico que é proporcional ao fluxo líquido de energia em jogo.

Com o aquecimento da placa origina-se sobre ela movimentos convectivos do ar na tentativa de dissipação de calor. Essa transferencia é proporcional a raiz quadrada do produto da velocidade do vento pela diferença de temperatura entre a placa e - ar próximo, resultando sêr o parametro medido função do vento, Tubelis (1974). A solução desse inconveniente estabelece dois tipos de radiometros. Um dos tipos é com capsulas de proteção de polietileno de total transmissividade para ondas curtas e longas, e outro é com ventilação forçada, possibilitando fluxo de ar laminar, paralelo a superfície da placa, de mesma intensidade em ambos os lados, e produzido por um ventilador colocado no corpo do aparelho.

o pirradiometro utilizado para obter as informações que estão sendo utilizadas no presente trabalho é do segundo tipo acima relacionado. Construido nos Estados Unidos pela Beckman e Whithey, tem como pares termo-elétricos prata- constantan e como constante 
de calibração $0,145 \mathrm{cal} . \mathrm{cm}^{-2} / \mathrm{min}^{-1} / \mathrm{mv}$ ou $6,90 \mathrm{mv} / \mathrm{cal} \mathrm{cm}^{-2} \cdot \mathrm{min}^{-1}$. Foi instalado com elemento sensivel a $1,20 \mathrm{~m}$ da superficie gramada no solo. As indicações de energia em jogo foram ampliadas e registradas por um potenciografo Phillips, doze pontos, tipo PR $4069 \mathrm{n} / 00$.

Os dados registrados e utilizados no presente trabalho constam da tabela 2 .

\subsection{Pressão parcial de vapor d’água atmosférico ( $\mathrm{V} e$}

o vapor d'água contido em condições naturais pode vir a ser determinado pela pressão parcial que exerce na massa de ar em que se encontra. Dependendo da temperatura e densidade da massa de ar a pressão parcial caminha para uma condição de saturação. A partir da relação com sua condição de saturação é possível determinar a pressão de vapor e consequentemente o teor de vapor d’água no ambiente. Para tal usa-se dois termometros absolutamente iguais, com um deles tendo o bulbo envolvido em delicado tecido constantemente umido. A energia contida no meio provoca a evaporação da água presente no tecido envolvente do bulbo úmido, logo:

$$
Q_{A}=Q_{E}
$$

onde: $Q_{\mathrm{A}}=$ calor absorvido pelo tecido úmido $\mathrm{Q}_{\mathrm{E}}=$ calor consumido na evaporação 


$$
Q_{A}=m \cdot C P(T-T u)
$$

e

$$
Q_{E}=m L\left(q^{\prime}-q\right)
$$

sendo iguais;

$$
m \cdot c p(T-T u)=m L\left(q^{\prime}-q\right)
$$

identificando:

$\mathrm{m}=$ massa de ar (g)

$\mathrm{cp}=$ calor específico a pressão constante $\left(\mathrm{cal} \cdot \mathrm{g}^{-1} \cdot{ }^{\circ} \mathrm{C}^{-1}\right)$

$\mathrm{T}=$ temperatura do ar $\left({ }^{\circ} \mathrm{C}\right)$

$\mathrm{Tu}=$ temperatura do termometro de bulbo úmido $\left({ }^{\circ} \mathrm{C}\right)$

$I=$ calor latente de evaporação $\left(\mathrm{cal} \cdot \mathrm{g}^{-1}\right)$

$q$ = umidade específica. É o produto da pressão parcial de vapor pela relação da massa de vapor por massa de ar seco dividido pela pressão atmosférica do local $(0,622 \mathrm{e} / \mathrm{P}) \cdot\left(\mathrm{gv} \cdot \mathrm{gu}^{-1}\right)$

$q^{\prime}=$ umidade específica do ar após passar pelo tecido úmido ( $g v \cdot g u^{-1}$ ) sendo a mesma massa:

$$
C p(T-T u)=L\left(q^{\prime}-q\right)
$$

como: $q=0,622$ ea $/ P \cdot q^{\prime}=0,622$ e's/P

substituindo em $\left(3 \cdot 7 \cdot{ }_{5}\right)$ 


$$
C p \cdot(t-T u)=L \cdot 0,622 / p \cdot\left(e^{\prime} s-e\right)
$$

Reposicionando os termos de $(3.7 \cdot 6)$

$$
e^{\prime} s-e / T-T u=C p \cdot P / L \cdot 0,622
$$

onde;

$(\mathrm{Cp} / \mathrm{L}, 0,622)$ é constante e chamada de constante psicrometrica $(\Delta)$ onde:

$$
e^{\prime} s-e / T-T u=A \cdot P=\gamma
$$

$\gamma=\mathrm{cp} \cdot \mathrm{P} / \mathrm{L} \cdot 0,622$

em condições naturais, para o campus da ESALQ (Lat $22^{\circ} 42^{\prime}$ S, Lon $47^{\circ} 37^{\prime} \mathrm{W}$ e Alt $\left.570 \mathrm{~m}\right)$

$\mathrm{Cp}=0,240 \mathrm{cal} \cdot \mathrm{g}^{-1} \cdot{ }^{\circ} \mathrm{C}^{-1}$

$\mathrm{I} \simeq 580 \mathrm{cal} \cdot \mathrm{g}^{-1}$

$\mathrm{P} \simeq 712 \mathrm{~mm} \mathrm{Hg}$

$$
\gamma=\frac{0,241 \times 712}{0,622 \times 580}=0,476 \mathrm{mmHg}{ }^{\circ} \mathrm{C}^{-1}
$$

Revendo $(3.7 .8)$

$$
\gamma=\frac{e^{\prime} s-e}{T-T u}
$$

extrapola-se este valor para a pressão parcial de vapor (e) 


$$
e=e^{\prime} s-\gamma(T-T u)
$$

onde

e $=$ pressão parcial de vapor da massa de ar (mmHg)

$e^{\prime} \mathbf{s}=$ pressão de saturação à temperatura do bulbo úmido (mmHg) (Tabela 1 e 7)

Os dados obtidos para a pressão parcial de vapor para - período estabelecido encontram-se na tabela 2.

\subsection{Balanço de ondas longas}

o balanço de ondas longas é assim definido:

$$
R L_{0}=E S-E a
$$

onde: $\mathrm{Es}=$ emissão da superfície do solo

Ea = emissão atmosférica em direção ao solo

A emissão de radiação da superfície terrestre obedece a seguinte expressão:

$$
E S=\varepsilon_{s} \sigma T_{s}^{4}
$$

onde,

$\mathbb{I}_{\mathrm{s}}=$ emissividade do solo (relação que existe entre a emissão do corpo e a emissão do corpo negro), valor próximo à $1 \sigma=$ constante 
de Stefan Boltzmann: $0,0827 \times 10^{-10} \mathrm{cal}^{\mathrm{cm}} \mathrm{cm}^{-2} \cdot \mathrm{min}^{-1}$

$\mathrm{T}_{\mathrm{s}}=$ temperatura da superficie do solo (graus Kelvin)

A emissão da radiação de ondas longas da superfície do solo interage com a atmosfera, sobretudo com o vapor d'água. Portanto, a expressão que apresenta a emissão atmosférica (Ea) em direção ao solo é a seguinte:

$$
E a=\varepsilon_{a} \sigma T a^{4}-r_{L s} \varepsilon_{a} \sigma T a^{4}
$$

$\mathbb{1 a}=$ emissividade da atmosfera do ar

$\sigma=$ constante de stefan-Boltzmann

$\mathrm{Ta}=$ temperatura do ar (em graus Kelvin)

$r_{\mathrm{Ls}}=$ representa a parcela da emissão de ondas longas atmosférica que é refletida pela superfície do solo.

Como: reflexão + absorção $=1$

as $=$ absorção

$$
r_{L S}+a s=1
$$

tem-se que

$$
a S=1-r_{L S}
$$

Admitindo-se que para corpos negros e absorção é igual a emissão, para uma dada temperatura, tem-se para a superficie do solo que: 


$$
a s=\varepsilon s
$$

Desenvolvendo a expressão $(3.8 .2)$; tem-se:

$$
\begin{aligned}
& E a=\varepsilon a \sigma T a^{4}-r_{L s} \varepsilon a \sigma T a^{4} \\
& E a=\varepsilon a \sigma a^{4}\left(1-r_{L s}\right) \quad \text { substituindo-se } \\
& E a=\varepsilon a \sigma T a^{4}(a s) \quad \text { substituindo-se } \\
& E a=\varepsilon a \sigma T a^{4}(\varepsilon s) \\
& E a=\varepsilon a \sigma T a^{4}(\varepsilon s) \\
& E a=\varepsilon a \quad \varepsilon S \quad \sigma T a^{4}
\end{aligned}
$$

substituindo-se $(3.8 .2)$ e $(3.8 .6)$ em (3.8.1) tem-se:

$$
R_{L O}=\varepsilon S \sigma T S^{4}-\varepsilon a \varepsilon S \sigma T a^{4}
$$

desenvolvendo e admitindo que numa situação de equilíbrio Ts = Ta, tem-se:

$$
R_{L O}=\varepsilon s \sigma T a^{4}(1-\varepsilon a)
$$

como Es 1

$$
R_{L O}=\sigma T a^{4}(1-\varepsilon a)
$$

portanto 


$$
\varepsilon a=1-\left(\frac{R_{L O}}{\sigma T a^{4}}\right)
$$

os valores de emissividade atmosférica calculados em função dos dados medidos de Radiação de ondas curtas (Roc), da Radiação líquida ( $R$ n) e da temperatura média do ar ( $\mathrm{Ta}$ ) por Ometto(1968), encontram-se na Tabela 2. Por outro lado salientamos anteriormente que Ea é função do vapor d'água atmosférico (e). Portanto, Ea $\mathrm{x} f(\sqrt{e})$ logo: $\mathrm{Ea}=\mathrm{a}+\mathrm{b}$ ve.

Desta maneira podemos escrever a equação acima como:

$$
\frac{R_{L O}}{\sigma T a^{4}}=1-(a+b \sqrt{e} \rightarrow)
$$

onde

$$
R_{L O}=\sigma T a^{4}[1-(a+b \sqrt{e})]
$$

A expressão que define a relação entre radiação líquida $(\mathrm{Rn})$ radiação global $(\mathrm{Rg})$ e radiação de ondas longas $\left(\mathrm{R}_{\mathrm{Lo}}\right)$ é a seguinte:

$$
R n=R g(1-I)-R_{L O}
$$

sendo $\tau$ o Albedo da superfície do solo para ondas curtas. $\mathrm{Rg}=$ Radiação Solar Global incidente no solo. 


\subsection{Dados Obtidos}

Os dados obtidos encontram-se nas Tabelas 1, 2, 3 e 5 . Para as análises e cálculos foram utilizados os dados do ano todo conjuntamente, assim como os dados separados entre Primavera Verão e Outono - Inverno, uma vez que as características das nuvens nestas duas épocas são diferentes.

$$
\text { Considerando-se também a umidade absoluta (UA - g/m }
$$

além da pressão parcial de vapor (e - mmHg) como um elemento importante da emissividade atmosférica no que diz respeito a ondas longas.

Na tabela 1 a relação Roc/Qo mostra a porcentagem da energia solar global que atinge o solo na forma de ondas curtas. Pode-se identificar na ação da atmosfera atenuando a energia incidente. 


\section{RESULTADOS E DISCUSSÃo}

\subsection{Análise dos dados}

4.1.1. Partiu-se do princípio de que os coeficientes determinados por Brunt para correlação do balanço de ondas longas com a umidade atmosférica, fossem válidos para a região de Piracicaba. Para confirmar esta suposição selecionou-se dados medidos por Ometto (1968) os dias que continham todas as medidas necessárias ao trabalho (Tabela 2) e aplicou-se uma regressão simples considerando portanto a seguinte relação:

$$
\frac{R_{L O}}{\sigma T a^{4}(0,56-0,092 \sqrt{e})}=a+b \frac{n}{N}
$$

os valores obtidos para a regressão com os dados medidos foram:

\begin{tabular}{|lc|}
\hline VARIÁVEL INDEPENDENTE & COEFICIENTE \\
\hline \hline Constante $\mathrm{a}$ & 0,098 \\
Coeficiente $\mathrm{x}=\mathrm{b}$ & 0,963 \\
$\mathrm{R}$ quadrado & 0,885 \\
\hline $\mathrm{N} \cong$ de observações $=74$ &
\end{tabular}

№ de observações $=74$ 
A equação resultante foi:

$$
\frac{R_{L O}}{\sigma \operatorname{Ta}^{4}(0,56-0,092 \sqrt{e})}=0,098+0,96 \frac{n}{N}
$$

e como pode-se ver na Figura 6, a aproximação foi bastante significativa.

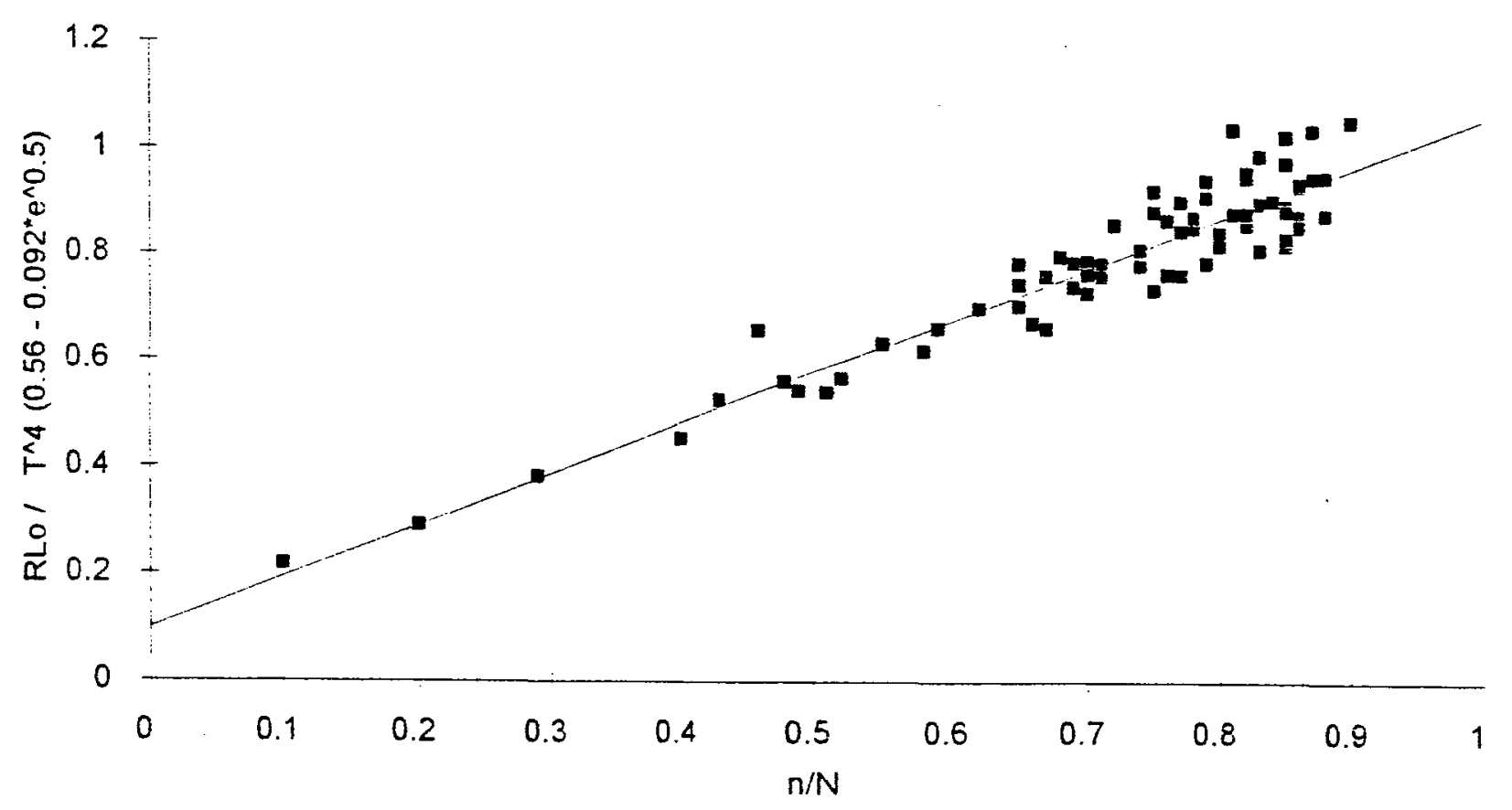

Figura 6. Relação entre $\mathrm{R}_{\mathrm{Lo}} / \sigma \mathrm{T}^{4}(0,56-0,092$ ve) em função da Razão de insolação para Piracicaba, SP.

4.1.2. O mesmo tipo de consideração foi feita admitindo que os valores dos coeficientes do termo referente à nebulosidade sejam bons para Piracicaba. Estes valores seriam: $(0,1+0,9 \mathrm{n} / \mathrm{N})$. Fez-se portanto uma regressão assumindo a seguinte condição: 


$$
\frac{R_{L O}}{\sigma \operatorname{Ta}^{4}\left(0,1-0,9 \frac{n}{N}\right)}=a+b \sqrt{e}
$$

- resultado obtido mostra valores semelhantes dos determinados por Brunt (1939) em sua equação. Regressão Linear:

\begin{tabular}{|lc|}
\hline VARIÁVEL INDEPENDENTE & COEFICIENTE \\
\hline \hline Constante $\mathrm{a}$ & 0,5358 \\
Coeficiente $\mathrm{x}=\mathrm{b}$ & $-0,0816$ \\
$\mathrm{R}$ quadrado & 0,082 \\
\hline
\end{tabular}

№ de dados $=74$

Obteve-se portanto a seguinte equação:

$$
\frac{R_{L O}}{\sigma \operatorname{Ta}^{4}\left(0,1-0,9 \frac{n}{N}\right)}=0,54-0,082 \sqrt{e}
$$

plotando os valores em gráfico pode-se observar a aproximação da reta referente a equação original de Brunt (1939), como verifica-se na Figura 7 .

Com estes estudos pode-se admitir uma boa correlação dos dados medidos em Piracicaba e utilizados na elaboração das equações propostas, à equação original de Brunt-Geiger (1948), uma vez que os coeficientes obtidos por estes autores foram muito próximos dos obtidos para esta localidade. 


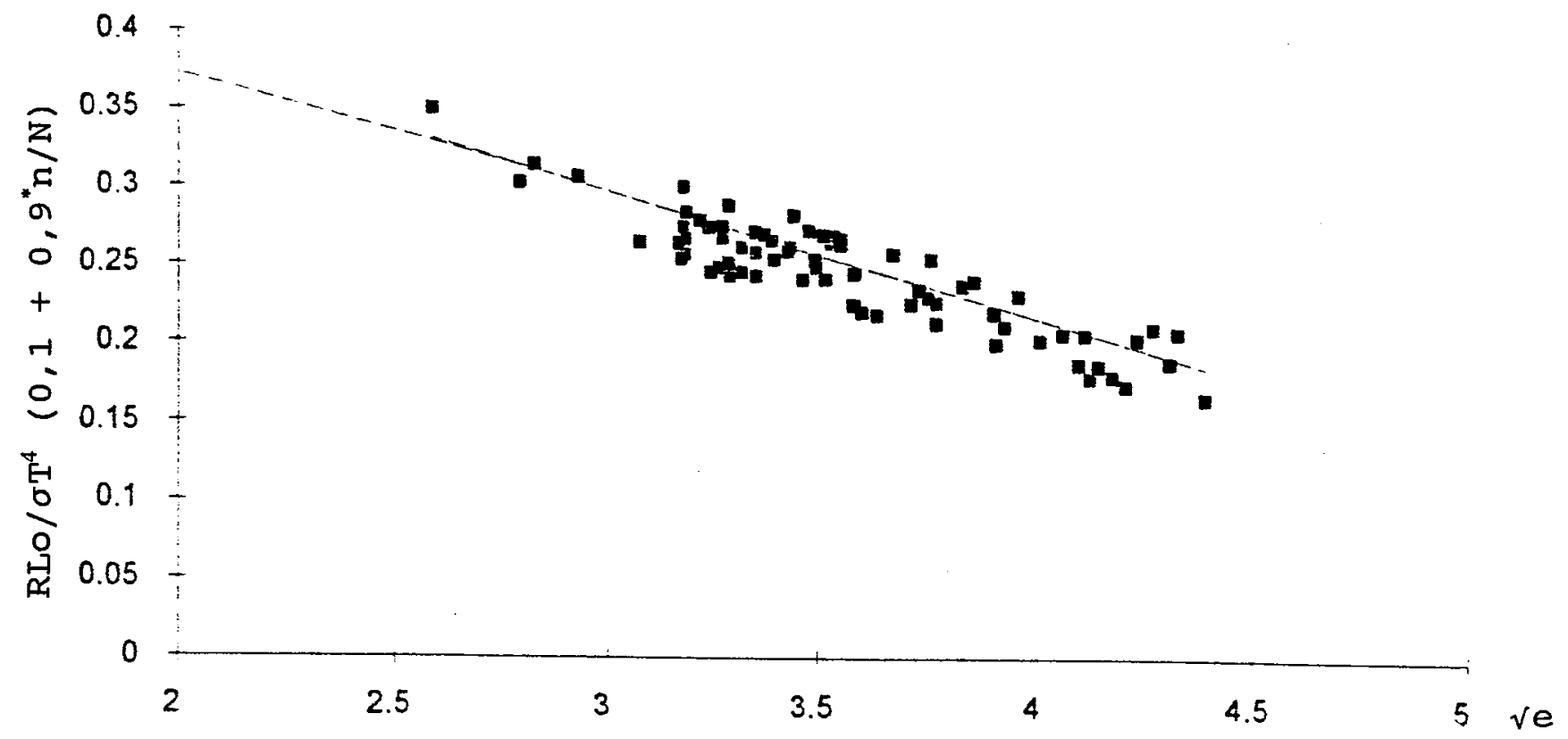

Figura 7. Relação entre $\operatorname{RL} 0 / \sigma \mathrm{T}^{4}(0,1+0,9 \mathrm{n} / \mathrm{N})$ em função da Pressão Atual de vapor para Piracicaba, SP.

4.1.3. Considerou-se a partir disto a hipótese de se propor uma equação alternativa, à de Brunt, perfeitamente ajustada às condições locais. Admite-se que as condições locais, físicogeográficas possam interferir no balanço de ondas longas.

Para esta análise procurou-se separar os dados com razão de insolação maior que 0,88 , ou seja, eliminando ao máximo o efeito da nebulosidade.

o resultado da análise, Tabela 3 e Figuras 8 e 9 não nos permite comparar com Brunt, já que o universo de dados admitidos para o cálculo foi muito reduzido. Entretanto, conforme pode ser observado naFigura 9, a equação proposta por BRUNT (1939) não se ajusta adequadamente aos dados medidos, sugerindo portanto, a necessidade de um ajuste local mostrado na Figura 8 . 


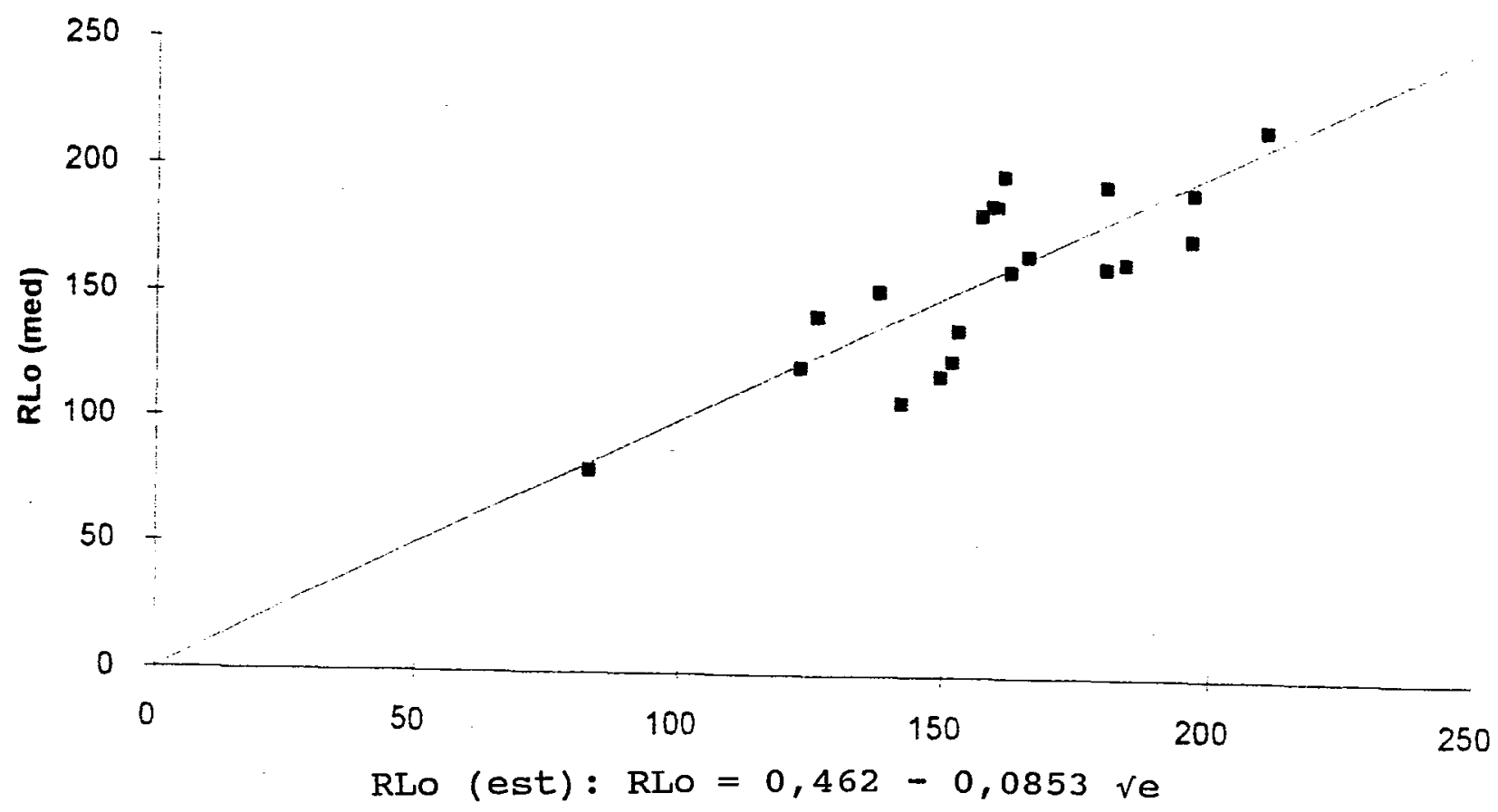

Figura 8. Relação entre $R_{L o}$ medidas em função da $R_{L o}$ estimada pela equação: $R_{\mathrm{Lo}}=\sigma \mathrm{T}^{4}(0,462-0,0853 \mathrm{Ve})$.

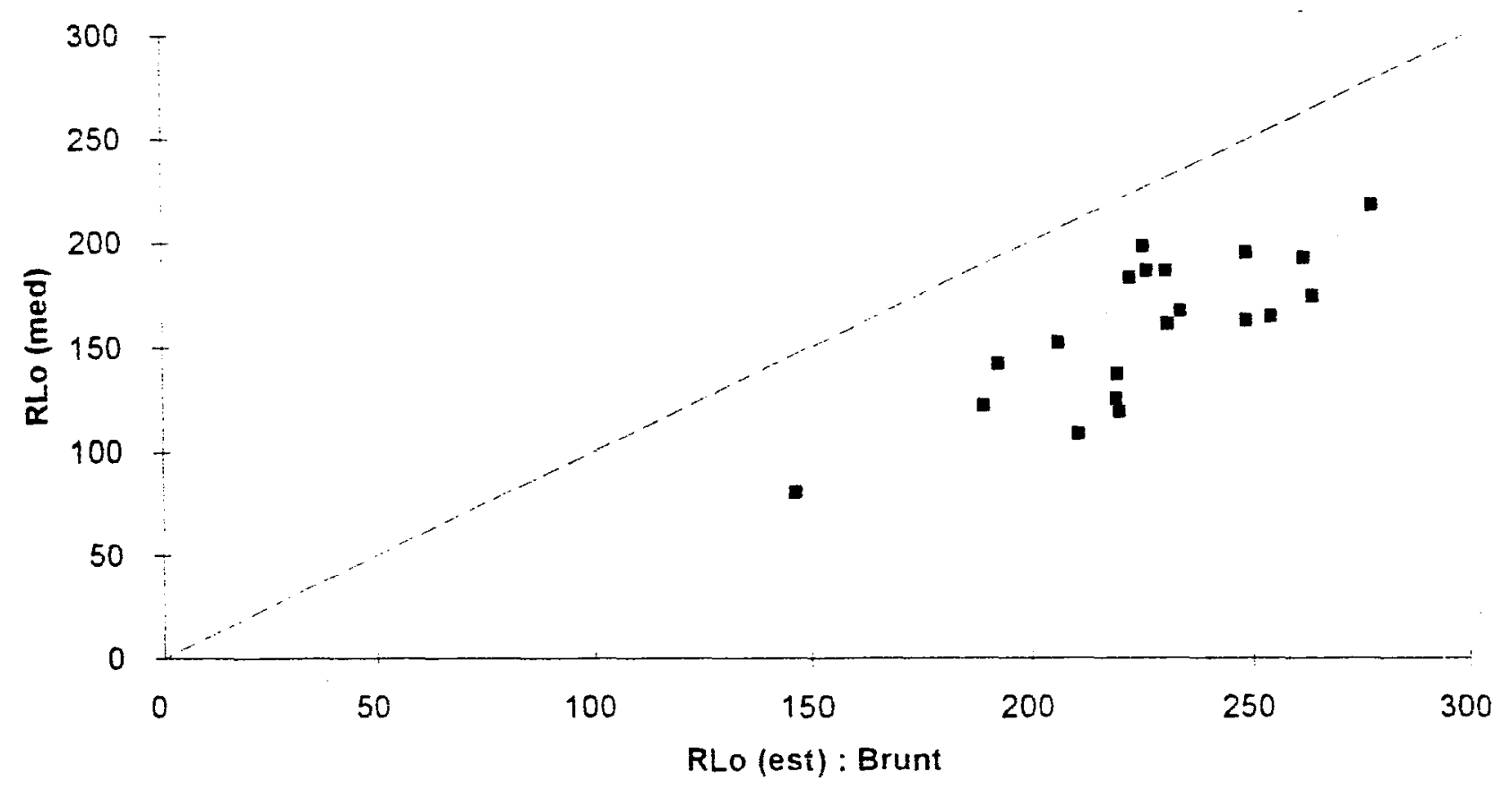

Figura 9. Relação entre $R_{\text {Lo }}$ medido em função da $R_{L o}$ estimado por Brunt pela seguinte equação: $R_{L o}=\sigma T^{4}(0,56-0,092$ ve $)$. 
4.1.4. Considerando o fato de que existe relação física entre a pressão de vapor da atmosfera e a razão de insolação, ou seja, a cobertura de nuvens, atuando no balanço de ondas longas, propôs-se uma regressão múltipla para estabelecer os coeficientes da equação, obtendo-se uma equação com a seguinte forma:

$$
\frac{R_{L O}}{\sigma T^{4}}=(a+b \sqrt{e})\left(a^{\prime}+b^{\prime} \frac{n}{N}\right)
$$

desenvolvendo:

$$
\frac{R_{L O}}{\sigma T^{4}}=a\left(a^{\prime}\right)+a b^{\prime} \frac{n}{N}+b\left(a^{\prime}\right) \sqrt{e}+b \cdot b^{\prime} \frac{n}{N} \sqrt{e}
$$

Regressão múltipla

$$
\frac{R_{L O}}{\mathbf{\sigma} t^{4}}=a_{1}+a_{2} \frac{n}{N}+a_{3} \sqrt{e}+a_{4} \frac{n}{N} \sqrt{e}
$$

\begin{tabular}{|lr|}
\hline VARIÁVEL INDEPENDENTE & COEFICIENTE \\
\hline \hline Constante a & 0,091596 \\
Coeficiente $\mathrm{n} / \mathrm{N}$ & 0,417424 \\
Coeficiente e & $-0,019042$ \\
Coeficiente e $\mathrm{n} / \mathrm{N}$ & $-0,054788$ \\
$\mathrm{R}^{2}=0,9361$ & \\
$\mathrm{~N} \cong$ de dados $=74$ &
\end{tabular}

A equação (4.1.4.3) fica, portanto definida da seguinte maneira: 


$$
\frac{R_{L O}}{\left(\sigma T^{4}\right)}=0,091-0,019 \sqrt{e}+0,42 \frac{n}{N}-0,055 \frac{n}{N} \sqrt{e}(\mathbf{4 . 1 . 4 . 4 )}
$$

a resolução da equação é apresentada na Figura 10.

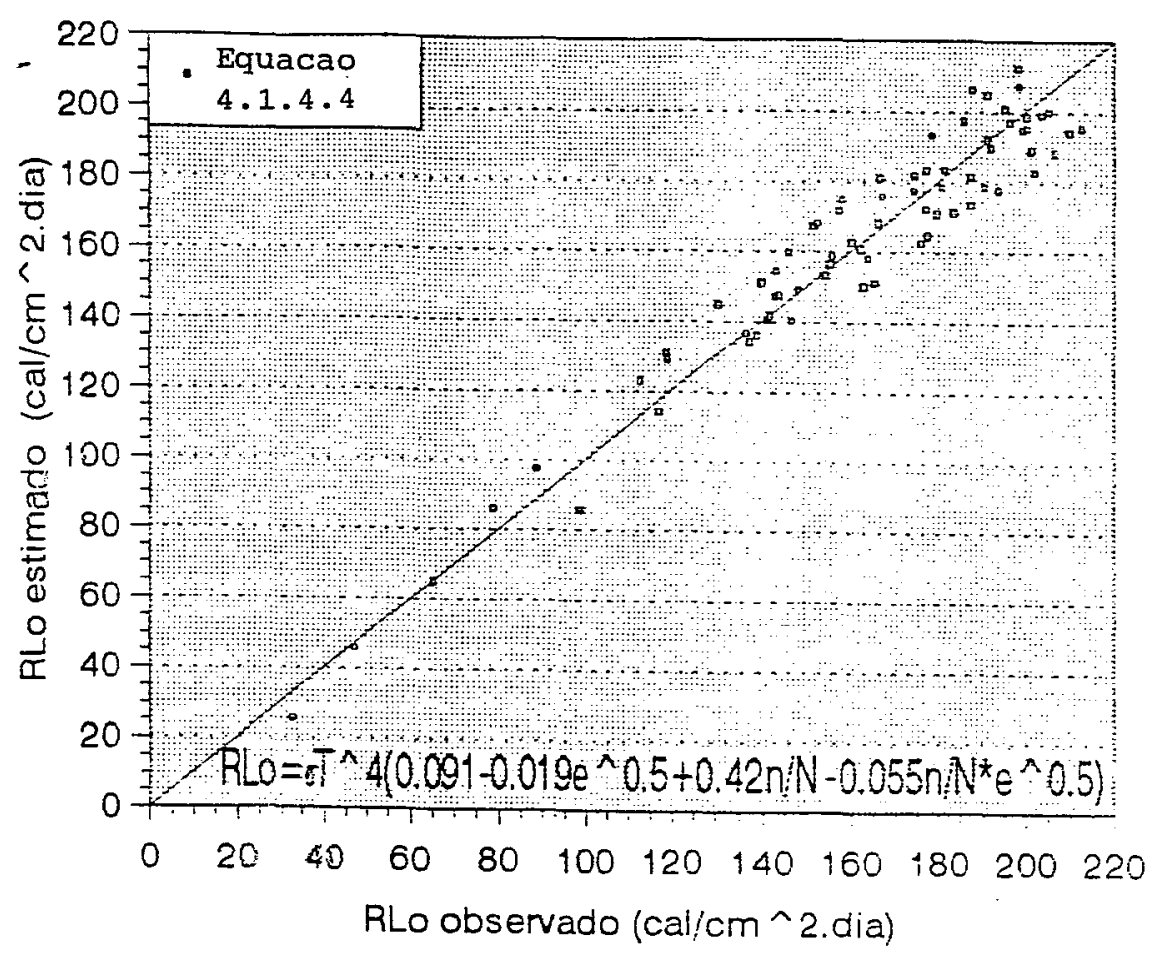

Figura 10. Relação entre Rlo estimado pela equação:

$\mathrm{R}_{\mathrm{Lo}}=\sigma \mathrm{T}^{4}(0,091-0,019 \mathrm{Ve}+0,42 \mathrm{n} / \mathrm{N}-0,055 \mathrm{n} / \mathrm{N} \mathrm{Ve})$ em função da $R_{L o}$ observada, para Piracicaba, SP.

4.1.5. Propôs-se a partir disto uma regressão múltipla eliminando-se o termo de interdependência, $n / N$ ve, que poderia ser, matematicamente, uma fonte de erro da estimativa. Obteve-se portanto a seguinte relação de dependência: 


$$
\frac{R_{L O}}{\sigma T^{4}}=\left(\sqrt{e}, \frac{n}{N}\right)
$$

a qual apresentou um resultado que pode ser considerado o mais viável para o local na estimativa do balanço de ondas longas. Estes valores estão em concordância com o princípio de que a contra emissão atmosférica depende conjuntamente da pressão atual de vapor d’água (ea) e a razão de insolação (n/N). ou seja, a regressão multipla considera esta ação conjunta.

A expressão encontrada, (4.1.5.1), foi:

$$
\frac{R_{L O}}{\sigma T^{4}}=0,233-0,056 \sqrt{e}+0,209 \frac{n}{N}
$$

e a regressão múltipla apresentou:

$\mathrm{R}^{2}=0,9299$ para o mesmo universo de 74 dados considerados (ver Figura 11).

\begin{tabular}{|lc|}
\hline VARIÁVEL INDEPENDENTE & COEFICIENTE \\
\hline \hline Constante a & 0,23305 \\
Coeficiente $\mathrm{e}$ & $-0,055812$ \\
Coeficiente $\mathrm{n} / \mathrm{N}$ & $-0,208929$ \\
$\mathrm{R}^{2}=0,9299$ &
\end{tabular}




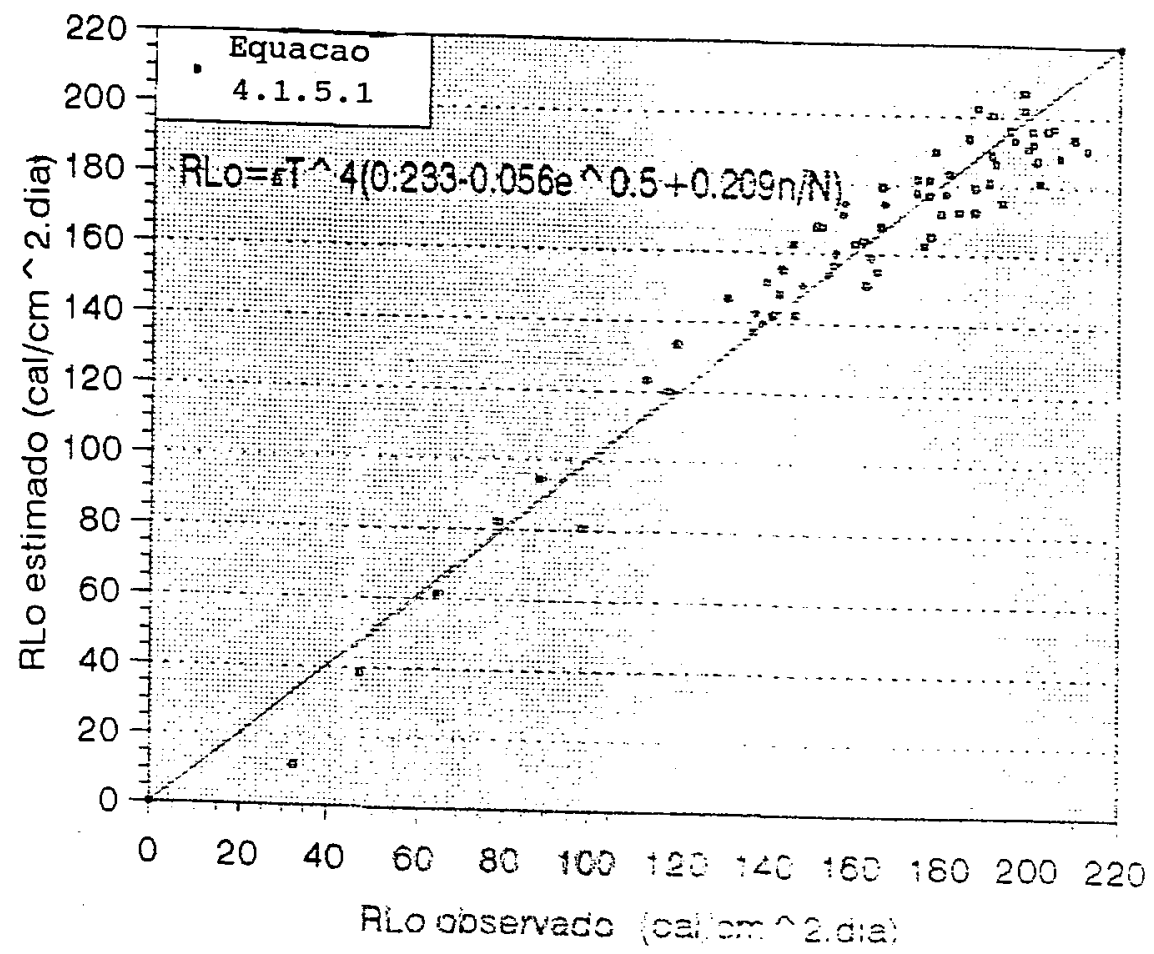

Figura 11. Relação entre RLo estimado pela equação:

RLo $=\sigma \mathrm{T} 4(0,233-0,056$ vet $0,209 \mathrm{n} / \mathrm{N})$ em função do RLo do observado, para Piracicaba, SP.

4.1.6. No calculo da equação anterior, considerou-se valores de insolação dentro de um universo de $0,1<\mathrm{n}<0,9$, (ver Figuras 16 e 17) ou seja, admitiu-se diversas condiçōes de cobertura por nuvens, associados à valores de tensão de vapor (ea), que para os dados coletados variavam de $6,68<$ ea $<19,70$ (ver Figuras 18 e 19), o que determina uma boa representatividade à equação, com isso propôs-se uma regressão linear admitindo a razão de insolação $(n / N)$ igual à 1. Desenvolveu-se a equação (4.1.5.1) da seguinte maneira: 


$$
\begin{gathered}
\frac{R_{L O}}{\sigma T^{4}}=0,233-0,056 \sqrt{e}+0,209 \frac{n}{N} \\
R_{L O}=\sigma T^{4}[0,33-0,056 \sqrt{e}+0,209 \text { (1) }]
\end{gathered}
$$

Rearranjando.

$$
R_{L O}: \sigma T^{4}(0,44-0,056 \sqrt{e})
$$

Procurando os parametros da função (n/N)

$$
\begin{gathered}
\frac{R_{L O}}{\sigma T^{4}(0,44-0,056 \sqrt{e})}=\frac{f(n)}{N} \\
\frac{R_{L O}}{\sigma T^{4}(0,44-0,056 \sqrt{e})}=a+b \frac{(n)}{N}
\end{gathered}
$$

encontra-se

coeficiente $=a=0,066$

coeficiente $x=b=0,97$

$\mathrm{R}^{2}=0,895$, para um universo de 74 dados (ver Figura 12)

Substituindo em 4.1 .5 .5$. , resulta

$$
\frac{R_{L O}}{\sigma T^{4}(0,44-0,056 \sqrt{e})}=0,066+0,97 \frac{n}{N}
$$




$$
\frac{R_{L O}}{\sigma T^{4}(0,44-0,056 \sqrt{e})}=0,066+0,97 \frac{n}{N}
$$

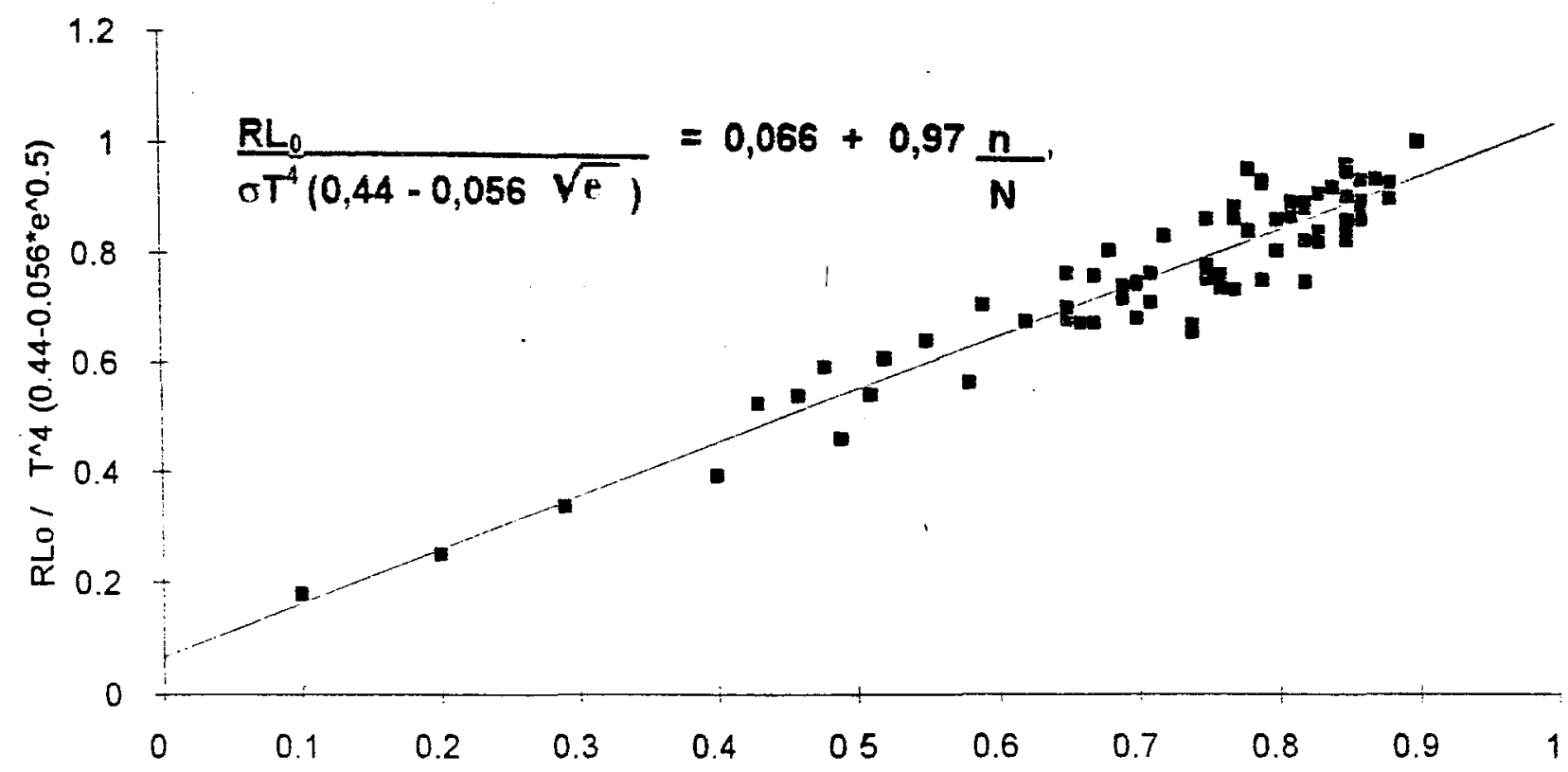

Figura 12. Relação entre $\operatorname{Rlo} / \sigma \mathrm{T}^{4}(0,44-0,056 \mathrm{Ve})$ em função da razão de insolação para Piracicaba.

portanto $\mathrm{RL}_{0}=\sigma \mathrm{T}^{4}(0,44-0,56 \mathrm{ve})(0,066+0,97 \mathrm{n} / \mathrm{N})$ com $\mathrm{R}^{2}=0,967$ para 74 dados (ver Figura 13). 


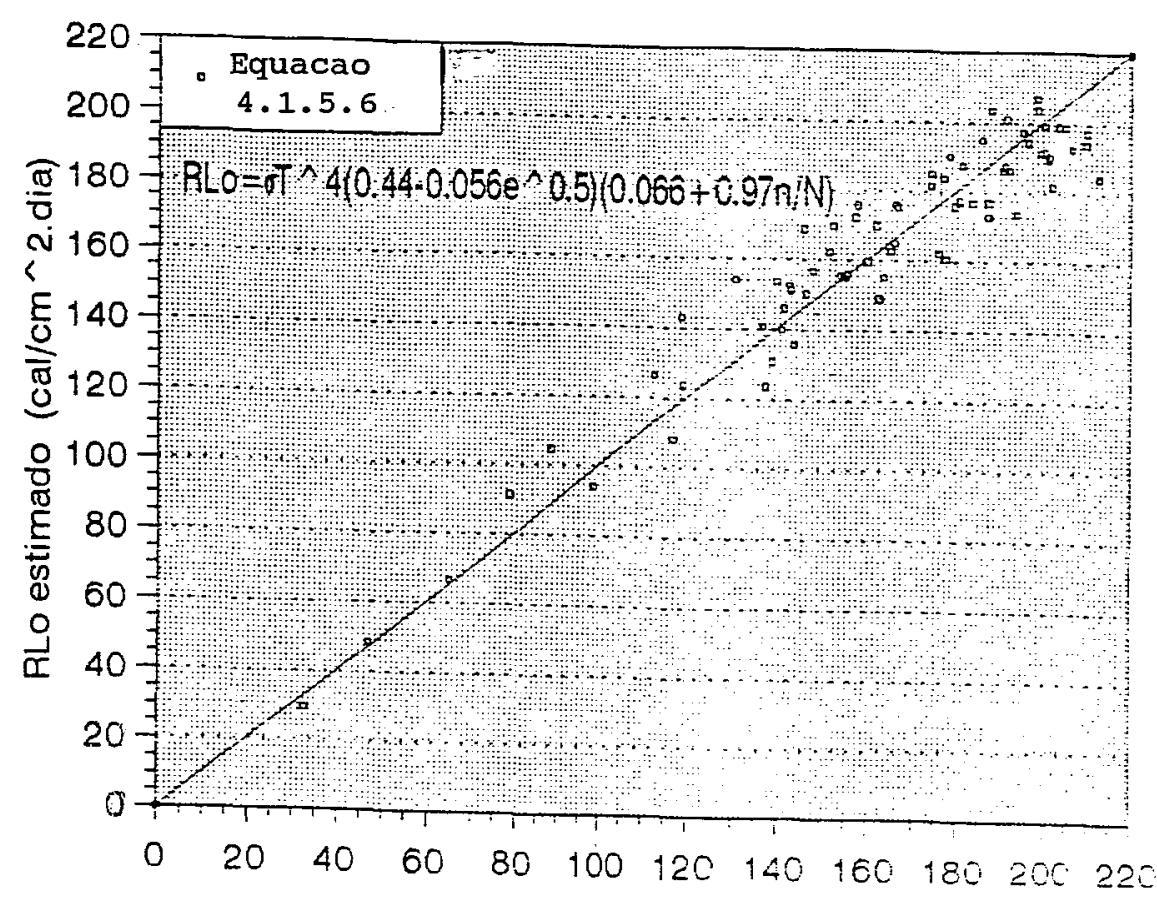

Figura 13. Relação entre $R_{L o}$ estimado pela equação:

$\mathrm{R}_{\mathrm{Lo}}=\sigma \mathrm{T}^{4}(0,44-0,056 \mathrm{Ve})(0,066+0,97 \mathrm{n} / \mathrm{N})$ em função da $\mathrm{R}_{\mathrm{Lo}}$ observado para Piracicaba, SP.

4.1.7. Plotando os valores de radiação de ondas longas estimados pela equação original de Brunt (1939), contra os valores observados obtém-se o seguinte gráfico (ver Figura 14) . Comparandose as figuras (11, 13 e 14) admite-se que a equação 2 seja a mais precisa em vista que a dispersão dos valores em torno da reta 1:1 é menor que na estimada com os coeficientes sugeridos por BruntGeiger (1948). 


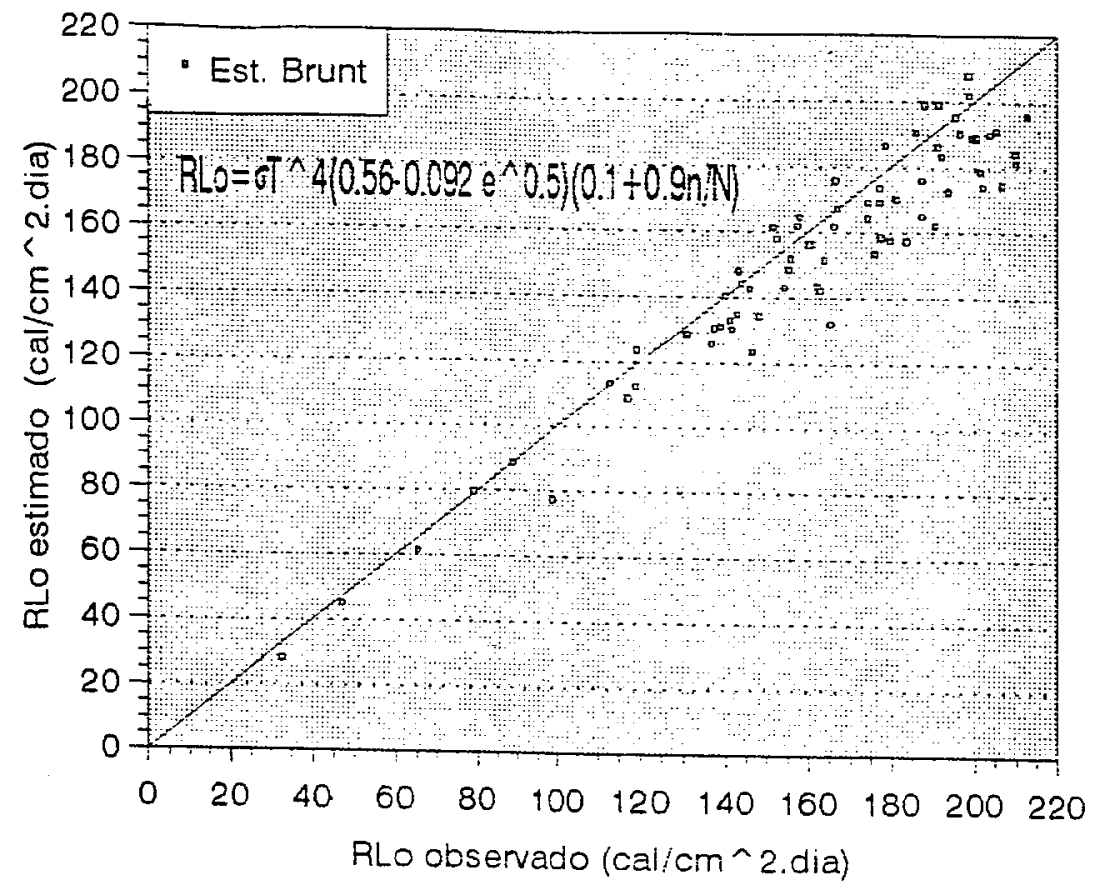

Figura 14. Relação entre $R_{\text {Lo }}$ estimado pela equação de Brunt-Geiger e $R_{L o}$ observado para Piracicaba, SP.

\subsection{Resultados da radiação de ondas longas $\left(R L_{0}\right)$ medida e estimadas}

Os resultados obtidos através da equação de Brunt e das equações propostas $(4.1 .4 .4,4.1 .5 .1$ e 4.1 .5 .6$)$ estão na Tabela 4 .

$$
\begin{gathered}
\text { Eq Brunt }=R_{L O}=\sigma T^{4}(0,56-0,092 \sqrt{e})\left(0,1+0,9 \frac{n}{N}\right) \\
E q(4.1 .5 .6)=R_{L O}=\sigma T^{4}(0,44-0,056 \sqrt{e})\left(0,066+0,97 \frac{n}{N}\right) \\
E q(4.1 .5 .1)=R_{L O}=\sigma T^{4}\left(0,2334-0,056 \sqrt{e}+0,209 \frac{n}{N}\right) \\
E q(4.1 .4 .4)=R_{L O}=\sigma T^{4}\left(0,091-0,019 \sqrt{e}+0,42 \frac{n}{N}-0,055 \frac{n}{N} \sqrt{e}\right)
\end{gathered}
$$




\subsection{Estimativa das equaçōes de Balanço de ondas longas utilizando umidade absoluta}

Com intuito de propor uma alternativa de cálculo para - balanço de ondas longas, substituiu-se na equação a pressão atual de vapor (ea) por umidade absoluta. Este parâmetro é dado em $\mathrm{g} / \mathrm{m}^{3}$ - o que se dá uma ideia da quantidade de água por volume de ar . Propôs-se então as seguintes regressões:

$$
\text { (A) } \frac{R_{L O}}{\sigma T^{4}}=(a+b U A)\left(a^{\prime}+b^{\prime} n / N\right)
$$

como o seguinte desenvolvimento

$$
\frac{R_{L O}}{\sigma T^{4}}=a a^{\prime}+b a^{\prime} U A+a b^{\prime} \frac{n}{N}=b b^{\prime} U A \frac{n}{N}
$$

\begin{tabular}{|lr|}
\hline VARIÁVEL INDEPENDENTE & COEFICIENTE \\
\hline \hline Constante aa' & 0,057 \\
Coeficiente ba' & $-0,003$ \\
Coeficiente ab' & 0,327 \\
Coeficiente bb' & $-0,008$ \\
\hline
\end{tabular}

$\mathrm{R}^{2}=0,9322$

No dados $=74$

A equação fica portanto:

$$
\frac{R_{L O}}{\sigma T^{4}}=0,057-0,003 U A+0,327 \frac{n}{N}-0,008 U A \frac{r}{N} \quad \text { (4.3.3) }
$$


(B) Eliminando-se o termo de interdepêndencia UA. n/N obteve-se a seguinte equação:

$$
\frac{R_{L O}}{\sigma T^{4}}=a a^{\prime}+b a^{\prime} U A^{\prime}+a b^{\prime} \frac{n}{N}
$$

com o seguinte resultado:

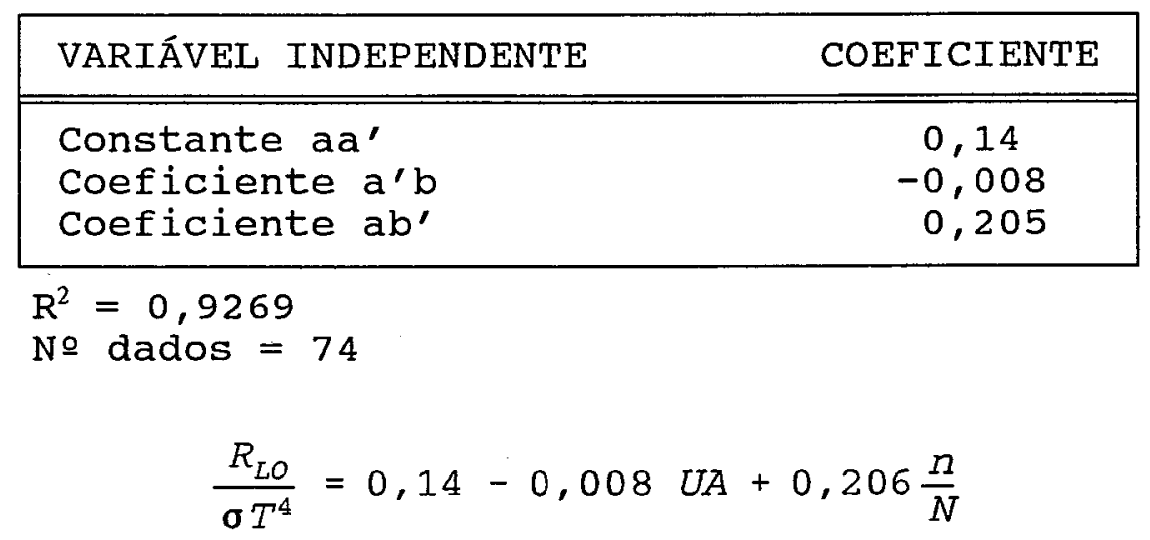

A precisão desta equação na estimativa dos valores de radiação de ondas longas está muito próxima à equação (4.1.5.1), determinada utilizando pressão atual de vapor, não justificando portanto, sua escolha para a localidade.

4.4. Balanço de ondas longas para diferentes períodos no ano

\subsubsection{Primavera - Verão}

o desenvolvimento estatístico de regressão múltipla para os dados da tabela dois, consentrados no período de 22 de 
setembro de 1966 até 21 de março de 1967, mostra o seguinte resultado:

\begin{tabular}{|lc|}
\hline VARIÁVEL INDEPENDENTE & COEFICIENTE \\
\hline \hline Constante a & $-0,046$ \\
Coeficiente ve & 0,014 \\
Coeficiente $\mathrm{n} / \mathrm{N}$ & 0,5247 \\
Coeficiente $\sqrt{ } \mathrm{n} / \mathrm{N}$ & $-0,08$ \\
\hline
\end{tabular}

$\mathrm{R}^{2}=0,9565$

No dados $=22$

Em equação tem-se:

$$
\frac{R_{L O}}{\sigma T^{4}}=-0,046+0,014 \sqrt{e}+0,52 \frac{n}{N}-0,08 \sqrt{e} \frac{n}{N} \quad(4.4 .1 .1)
$$

para dias totalmente limpos, quando $n / N$ se igual a 1 a expressão $(4.4 .1 .1)$ resulta em

$$
1: \frac{R_{L O}}{\sigma T^{4}}=0,474-0,066 \sqrt{e}
$$

Quando eliminou-se o termo de interdependência $\mathrm{n} / \mathrm{N} \sqrt{ } \mathrm{e}$ obteve-se a seguinte equação:

\begin{tabular}{|lc|}
\hline VARIÁVEL INDEPENDENTE & COEFICIENTE \\
\hline \hline Coeficiente a & 0,227 \\
Coeficiente $\mathrm{n} / \mathrm{N}$ & 0,19 \\
Coeficiente ve & $-0,051$ \\
\hline $\mathrm{R}^{2}=0,9556$ & \\
No dados $=22$ &
\end{tabular}




$$
\frac{R_{L O}}{\sigma T^{4}}=0,23-0,051 \sqrt{e}+0,19 \frac{n}{N}
$$

para dias limpos, quando $\mathrm{n} / \mathrm{N}=1$ tem-se:

$$
\frac{R_{L O}}{\sigma T^{4}}=0,42-0,05 \sqrt{e}
$$

e para dias completamente nublados, quando $n / N=0$, a expressão (4.4.1.3) ficará:

$$
\frac{R_{L O}}{\sigma T^{4}}=0,23-0,051 \sqrt{e}
$$

\subsubsection{Outono - Inverno}

Desenvolvendo-se equações para este período do ano (Tabela 2, de 23 março à 30 agosto 1967) e os resultados foram os seguintes:

(1)

\begin{tabular}{|lc|}
\hline VARIÁVEL INDEPENDENTE & COEFICIENTE \\
\hline \hline Constante a & 0,203 \\
Coeficiente ve & $-0,055$ \\
Coeficiente n/N & 0,281 \\
Coeficiente ve n/N & $-0,011$ \\
\hline
\end{tabular}

$\mathrm{R}^{2}=0,8609$

№ dados $=22$ 
A equação fica portanto:

$$
\frac{R_{L O}}{\sigma T^{4}}=0,203-0,055 \sqrt{e}+0,281 \frac{n}{N}-0,011 \sqrt{e} \frac{n}{N}(4.4 .2 .1)
$$

Para um dia de céu limpo, quando a razão de insolação igual à 1 tem-se:

$$
\frac{R_{L O}}{\sigma T^{4}}=0,48-0,066 \sqrt{e}
$$

(2) Eliminando-se o termo de interdependência $n / N$ ve obtém-se a

\begin{tabular}{|c|c|}
\hline VARIÁVEL INDEPENDENTE & COEFICIENTE \\
\hline Constante a & 0,229 \\
\hline Coeficiente $\sqrt{e}$ & $-0,062$ \\
\hline Coeficiente $n / N$ & 0,225 \\
\hline
\end{tabular}
seguinte equação:

$$
\frac{R_{L O}}{\sigma T^{4}}=0,23-0,062 \sqrt{e}+0,024 \frac{n}{N}
$$

Para dias limpos o (4.4.2.3) valor de razão de insolação igual à 1, resultando a equação em:

$$
\frac{R_{L O}}{\sigma T^{4}}=0,47-0,062 \sqrt{e}
$$

Para dias completamente nublados, quando $\mathrm{n} / \mathrm{N}=0$, a expressão $(4.4 .2 \cdot 3)$ ficará: 


$$
\frac{R_{L O}}{\sigma T^{4}}=0,23-0,062 \sqrt{e}
$$

Nas equações encontradas para os dois períodos considerados - Primavera-Verão e outono=Inverno - encontram-se os coeficientes para a razão de insolação $(\mathrm{n} / \mathrm{N})$ de 0,19 e 0,24 respectivamente para os períodos citados. Tais resultados sugerem que durante o inverno a perda de ondas longas é um pouco superior à perda durante o verão. Isto ocorre provavelmente, pelo fato de que no verão se tem uma característica de cobertura diferenciada tanto no tipo quanto na quantidade de nuvens (índice de cobertura do céu), com relação ao inverno. Todavia o número de dados analisados foi muito reduzido para que se possa tecer uma análise definitiva. Para que se tenha um melhor conhecimento dessas relações principalmente no que tange a umidade do ar, sugere-se que se utilise medidad honorárias do balanço de ondas longas, para obtenção de resultados mais consistentes. 


\section{CONCLUSÕES}

1. No estudo da Relação de onda longa em função da tensão atual do vapor (ea) $\mathrm{mmHg}$ e da razão de insolação $\mathrm{n} / \mathrm{N}$ considerando o ano todo encontra-se a seguinte equação:

$$
R_{L O}=\sigma T^{4}(0,233-0,056 \sqrt{e}+0,209 n / N) \quad(\text { eq } 4.1 .5 .1)
$$

a sendo considerada a mais adequada para a estimativa do balanço de onda longa na região de Piracicaba. Para valores baixos de razão de insolação, esta equação estima maiores valores de ondás longas que deixa a superfície do solo, quando comparado com a equação de Brunt-Geiger (1948), devido provavelmente as características da cobertura local.

2. Os resultados que considera os valores da pressão atual do vapor (e) e da razão de insolação separados entre Primavera-Verão e Outono-Inverno revelaram as seguintes equações:

\section{Primavera-Verão}

$$
R_{L O}=\sigma T^{4}(0,23-0,051 \sqrt{e}+0,19 n / N)
$$


outono-Inverno

$$
R_{L O}=\sigma T^{4}(0,23-0,062 \sqrt{e}+0,24 \mathrm{n} / \mathrm{N})
$$

Estas equações indicam que as nuvens predominantes nas épocas Primavera-Verão causam uma perda menor de ondas longas que na época outono-Inverno e isto vem a justificar o equacionamento da perda de ondas longas para épocas distintas do ano.

3. No estudo da Radiação de ondas longas em função da umidade absoluta $\mathrm{g} / \mathrm{m}^{3}$ e da razão de insolação $\mathrm{n} / \mathrm{N}$ considerando o ano todo encontrou-se a seguinte equação:

$$
R_{L O}=\sigma T^{4}(0,14-0,008 . U A+0,206 n / N)
$$

com precisão aproximadamente igual a equação (4.1.5.1), em vista disso não se justifica a sua escolha para localidades com características semelhantes a Piracicaba. A substituição da pressão atual do vapor (ea $\mathrm{mmHg}$ ) para umidade atual do ar ( $\mathrm{g}$ vapor $/ \mathrm{m}^{3}$ ) não mostra resultados melhores, não justificando a sua adoção na estimativa da radiação de ondas longas, para a região estudada.

4. No desenvolvimento de pesquisa foi possivel quantificar a emissividade atmosférica do local, para todos os dias estudados (equação 3.8 .7 e tabelas 2 e 3 ). 


\section{REFERENCIAS BIBLIOGRÁFICAS}

ABBOT, G.G. \& ALDRIEH, L.B. The pyranometer; an instrument for mesuring sky radiation. Smithsonian Miscellaneous Collections, Washington, $\underline{66}(7)$ 78-89, 1916.

ANGSTROM, A. A atudy of the radation of the atmosphere. Smithosonian Miscellaneous Collections, Washington, 65: 1-159, 1915

ANGSTROM, A. Solar and terrestrial radiation. Quartely Journal of the Royal Meteorological Society, London, $\underline{50}: 121-5,9124$.

AZEVEDO, P. V. de; RAO, T.V.R. ; LEITÃO, M.M.V.B.R. ; AMORIM, M.S.; PEREIRA, J.R.C.; ESPINOLA, J. Avaliação da radiação atmosférica sobre uma área cultivada com algodão. In VII CONGRESSO BRASILEIRO DE AGRONOMETEOROLOGIA, 7. ViçOsa, 1991. Resumos. UFV; SBA, 280-282, 1991.

ANUÁRIO ASTRONÔMICO, 1993. São Paulo, 1993. 
BALLERE, C.L.; SCOPEL, A.L.; SANCHEZ, R.A. Far-red radiation reflected from adjacent leaves: an earty signal of competition in plant camopies. Science, Washington, 247: 329-31, 1990.

BARCHEWITZ, J.P.; MAT, B.; ROSSETTI, C. Contribution à I'étude de la transmission dans la basse atmosfere. Paris, Ministére de L'air, 1954. 28 p. (Bolletin, 116) .

BERNARD, E.A. Le determinisme de l'évaporation dans la nature; étude des aspects ge'oplysique et ecologique du probléme dans le cadre du Bilan Energique. Paris, INEAC, 1956.

BERKOWICZ, R. \& PRATTN, L.P. Sensible heat flux estimated from Routine Meteorologica data by the registance method. Journal of the American Meteorological Society, Lancaster, 21: 1845-64, Dec. 1982 .

BLACK, J.N.; BONI, C.W.; PRESCOTT, S.A. Solar radiation and duration of sunstrime. Quarterly Journal of Royal Meteorological Society, London, $\underline{80}(344): 231-5,1954$.

BLANCK, A. Rayonnement (éclairage). Cahiers Association Francaise par l'étude et le Developpemente des Applications de L'énergie Solaire, Paris, (1): 112-119, jan. 1968 . 
BRICHENBANT, C.P de. Rayonnemant solaire et échanges radiatifs naturels. Paris, Gauthier-Villares, 1963300 p. (Monographies de Meteorologie).

BRUNT, D. Physical and dinamical meteorology. 2. ed. Cambridge, Cambridge University Press, 1939. 49 p.

BRUTSAERT, W. Evaporation into the atmosphere: theory, history, and applications. Dordrecht, D. Reidel, 1984. 299 p. (Environmental Fluid Mechanics).

CRITCHFIELD, H.J. General climatology. Englewood cliffs, Prentice - Hall, 1974 .

CULSAN, L.K. Solar and terrestrial radiation; methods and methods and measurements. New York. Academic Press, 1975. 322p

DRUMMOND, A.J. The extraterrestial solar spechaun. Caltiers Association Francaise par L'étude et le Développement des Applications de L'energie solaire, Paris, (1): 19-27, jan 1968 .

ELSASSER, W.M. \& CULBERTSON, M.F. Atmospheric radiation tables. Meteorological Monographs, Boston, $\underline{4}(23): 114-123,1960$. 
FUNLARI, F.L.; TARIFA; J.L.; SIMPSON, J.G.P. Estudo comparativo entre as equações de Brunt-Penman (1949) e a de Lineare (1967), para estimativa da radiação líquida. In: CONGRESSO BRASILEIRO DE AGROMETEOROLOGIA, 4., Londrina, 1985. Anais. Londrina, SBM, 1985. p. $129-31$.

GATES, D.M. Biophysical Ecology. Berlin, Springer-Verlag, New York. 1980 .

GEIGER, R. The climate near to the Graund Blen Hill Meteorology observatory. Cambridge, Harvard University, 1948. 482p.

GEIGER, R. Manual de microclimatologia. 4 ed. Lisboa, Fund. Calouste Gulbenkian, 1961. 556p.

GODOY, R.M.de. Atmosferic radiation. Oxford, Claredon Press, 1964. $436 \mathrm{p}$.

GOLE, F.W. Introduction to meteorology. New York, John Wiley, 1970. $388 \mathrm{p}$.

HAGE, J.C.H.van der. The horizontal component of solar radiation. Agricultural a Forest Meteorology, 67: 79-83, 1993. 
HATFIELD, J.L. Comparason of long wave radiation calculation methods over the United States. Water Resouses Research, Washington, 19: 285-8, 1983 .

HOUGHTON, B. The absorption of solar irradiation by the lower. Cahiers Association Francaise par l'etude et Devellopment des Applications de L'Énergi Solarie, Paris, (1): 34-42, jan. 1968.

IDSO, S.B.; JACKSON, R.D.; REGINATO, R.J.; KIMBALL, B.A. ; NAKAYAMA, F.S. The dependence of bare soil albedo on soil water content. Journal of Applied Meteorology, Lancaster, 14: 109-13, 1975.

KONDRATIEV, K.Y. Radiative heat exchange in the atmosphere. London, Pergamou Press, 1965.

LEMON, P.C. Field and laboratory quide for ecology. Minneapolis, Burgess, 1962. 180p.

LINACRE, E. \& HOBBS, J. Australian climatic environment. New York, John Wiley, 1977.

MAURAIN, P. Etude pratique des rayonnement solaires, atmosphérique et terrestre. Cahiers Association Francaise par l'etude et Devellopment des Applications de L'Énergi Solarie, Paris, (1): 66-74, jan. 1968 . 
MONTEITH, J.L. Principles of environmental physics. London, Edward Arnold, 1973. 241p. (Contemporany Biology).

MONTEITH, J.L. \& UNSWORTH, M.H. Principles of environmental physics. 2 ed. London, Edward Arnold, 1990. 291 p.

MOTA, F.S. Meteorologia Agricola. São Paulo, Nobel, 1986. $376 \mathrm{p}$.

OMETTO, J.C. Estudo das relações entre: radiação solar global, radiação líquida e insolação. Piracicaba, 1968. 64p. (Doutorado Escola Superior de Agriaultura "Luiz de Queiroz"/USP).

OMETTO, J.C. Bioclimatologia vegetal. São Paulo, Agronômica Ceres, 1981. $425 \mathrm{p}$.

OMETTO, J.C. Registro e estimativas de parâmetros meteorológicos da região de Piracicaba, SP. Piracicaba, FEALQ, $1991.76 p$.

OMETTO, J.C.; PERRIES, A.; ITIES, B. Sur la estimation de la radiation solaire globalle et radiation nete. Versailles, Centre National de Recherche Agronomique, 1973. 11p.

PENMAN, H.L. Natural evaporation from open water, bare soil, and grass. Proceedings of the Royal Society of London. Ser. A, London, 193: 120-45, 1948 . 
PERLAT, A.A.M. Petit mesures em méteorogie. Paris, Gauthier Villars, 1961. 393p.

PRIESTLEY, C.H.B. Turbulent transfer in the lower atmosphere. Chicago: University Press, 1959.

RIDER, N.E. Evaporation from an oat field. Quarterly Journal of the Royal Meteorological Society, London, 80: 198, 1954.

ROBINSON, N. Solar radiation. New York, Elsevier Publ., 1966. $347 p$.

SATTERLUND, D.R. Wildland watershed management. New York, Ronald Press, 1972. $370 \mathrm{p}$.

SENNA, R.C. Método para estimativa de irradiação solar global através de medidas de períodos de insolação. Piracicaba, 1992. 64p. (Mestrado - Escola Superior de Agricultura "Luiz de Queiroz"/USP) .

SWINBANK, W.C. Long wave radiation from clear skies. Quately Journal of the Royal Meteorological Society, 89: 339-48. 1963 .

TUBELIS, A. Radiômetro líquido evaporimetro de placas negras de Bellani. Botucatu, 1974. 87p. (Livre-Docência - Faculdade de Ciências Médicas e Biológicas de Botucatu/UNESP) • 
USWORTL, M.H. \& MONTEITH, J.L. Enviromental physics, Biddles Limited, London, 1990. 291p.

VILLA NOVA, N.A. Estudos sobre balanço de energia em cultura de arroz. Piracicaba, 1973. 78p. (Livre-Docência - Escola Superior de Agricultura "Luiz de Queiroz"/USP).

VILLANUEVA, J.G. Estudo do coeficiente de transferência do vapor d’água sobre cultura do feijão. Piracicaba, 1987. 58p. (Mestrado - Escola Superior de Agricultura "Luiz de Queiroz"/USP).

VASSY, E. Physique de l'atmosfhere. Paris, Gauthier-Villars, 1966.

YAMAMOTO, G. On a radiation chart. Tokyo. s. ed. 1952. (Reports, 4).

WIEN, W.C. \& HARMS, F. Handbuch der experimentl physik. Leipzig, Akademische Verlags gesellschat, 1926. 
TABELAS E FIGURAS COMPLEMENTARES 
Tabela 1. Valores medidos de: Qo = radiação solar global teórica [cal/ $\mathrm{cm}^{2} \cdot$ dia $]$ Roc = radiação solar global medida (radiação de ondas curtas) $\left[\mathrm{cal} / \mathrm{cm}^{2}\right.$.dia $]$; $\mathrm{N}=$ duração do dias [horas] $\mathrm{n}=$ horas de brilho solar; $\mathrm{Ta}=$ temperatura do ar $\left[{ }^{\circ} \mathrm{C}\right] ;$ UR = umidade relativa; e (sat) $=$ pressão de saturação do ar à temperatura Ta [mmHg].

\begin{tabular}{|c|c|c|c|c|c|c|c|c|}
\hline DATA & $Q_{0}$ & Roc & Roc $/ Q_{0}$ & $\mathrm{~N}$ & $\mathrm{n}$ & $\mathrm{T}(\mathrm{o} \mathrm{C})$ & UR\% & es \\
\hline 17 set 66 & 790 & 410 & 0,52 & 12,0 & 6,3 & 16,6 & 55 & 14,17 \\
\hline $27 \operatorname{set} 66$ & 831 & 408 & 0,49 & 12,2 & 5,3 & 20,8 & 61 & 18,42 \\
\hline 30 set 66 & 843 & 557 & 0,66 & 12,3 & 9,5 & 22,3 & 64 & 20,19 \\
\hline 12 nov 66 & 971 & 228 & 0,23 & 13,2 & 1,3 & 22,8 & 89 & 20,82 \\
\hline 20 nov 66 & 985 & 705 & 0,71 & 13,3 & 11,3 & 21,3 & 57 & 19,00 \\
\hline 23 nov6 6 & 989 & 664 & 0,67 & 13,4 & 11,4 & 19,1 & 57 & 16,58 \\
\hline 03 dez 66 & 1001 & 449 & 0,45 & 13,5 & 5,4 & 26,6 & 65 & 26,12 \\
\hline 09 dez 66 & 1006 & 698 & 0,69 & 13,5 & 11,5 & 25,1 & 59 & 23,90 \\
\hline 01 jan 67 & 1010 & 615 & 0,61 & 13,6 & 8,9 & 22,8 & 73 & 20,82 \\
\hline 02 jan 67 & 1010 & 652 & 0,64 & 13,6 & 10,3 & 23,2 & 77 & 21,37 \\
\hline 21 jan67 & 995 & 528 & 0,53 & 13,4 & 6,6 & 25,3 & 73 & 24,18 \\
\hline 23 jan67 & 992 & 580 & 0,58 & 13,3 & 9,2 & 21,5 & 79 & 19,23 \\
\hline 24 jan67 & 991 & 448 & 0,45 & 13,3 & 3,9 & 21,0 & 86 & 18,65 \\
\hline 25 jan 67 & 989 & 653 & 0,66 & 13,3 & 10,9 & 24,2 & 74 & 22,65 \\
\hline $27 j a n 67$ & 986 & 566 & 0,57 & 13,3 & 9,5 & 23,2 & 72 & 21,37 \\
\hline
\end{tabular}


continuação da Tabela 1

DATA $\quad Q_{0} \quad$ ROC ROC $/ Q_{0} \quad \mathrm{~N} \quad \mathrm{n} \quad \mathrm{T}(\mathrm{OC})$ UR\%

\begin{tabular}{|c|c|c|c|c|c|c|c|c|}
\hline 15 fev 67 & 946 & 642 & 0,68 & 12,9 & 11,2 & 24,7 & 67 & 23,34 \\
\hline 16 fev 67 & 943 & 323 & 0,34 & 12,9 & 6,0 & 24,1 & 83 & 22,51 \\
\hline 24 fev6 7 & 920 & 656 & 0,71 & 12,7 & 10,3 & 25,8 & 73 & 24,91 \\
\hline 27 fev6 7 & 910 & 622 & 0,68 & 12,6 & 10,3 & 25,0 & 71 & 23,76 \\
\hline 28 fev67 & 907 & 567 & 0,62 & 12,6 & 9,3 & 26,0 & 69 & 25,21 \\
\hline $02 \operatorname{mar} 67$ & 900 & 576 & 0,64 & 12,6 & 9,5 & 24,4 & 78 & 22,92 \\
\hline $04 \operatorname{mar} 67$ & 893 & 574 & 0,64 & 12,5 & 9,2 & 25,0 & 81 & 23,76 \\
\hline $09 \operatorname{mar} 67$ & 875 & 318 & 0,36 & 12,4 & 12,5 & 21,7 & 88 & 19,47 \\
\hline $20 \operatorname{mar} 67$ & 831 & 586 & 0,70 & 12,2 & 10,4 & 21,4 & 72 & 19,11 \\
\hline $21 \mathrm{mar} 67$ & 827 & 585 & 0,71 & 12,1 & 9,9 & 22,2 & 73 & 20,07 \\
\hline $22 \operatorname{mar} 67$ & 823 & 589 & 0,71 & 12,1 & 10,1 & 22,2 & 74 & 20,07 \\
\hline $23 \operatorname{mar} 67$ & 819 & 564 & 0,69 & 12,1 & 10,4 & 22,2 & 70 & 20,07 \\
\hline $06 a b r 67$ & 758 & 536 & 0,70 & 11,7 & 10,5 & 21,5 & 70 & 19,23 \\
\hline $07 a b r 67$ & 754 & 526 & 0,70 & 11,7 & 10,1 & 20,4 & 64 & 17,97 \\
\hline 09 abr 67 & 744 & 505 & 0,68 & 11,7 & 10,0 & 20,0 & 71 & 17,54 \\
\hline $11 \mathrm{abr} 67$ & 736 & 473 & 0,64 & 11,6 & 8,1 & 22,0 & 70 & 19,83 \\
\hline $14 \mathrm{abr} 67$ & 722 & 482 & 0,67 & 11,6 & 9,6 & 22,6 & 69 & 20,57 \\
\hline $15 \mathrm{abr} 67$ & 718 & 358 & 0,50 & 11,6 & 6,7 & 22,4 & 75 & 20,32 \\
\hline 17 abr 67 & 711 & 495 & 0,70 & 11,5 & 10,1 & 20,6 & 67 & 18,20 \\
\hline $18 \mathrm{abr} 67$ & 705 & 499 & 0,71 & 11,5 & 9,8 & 20,6 & 68 & 18,54 \\
\hline $19 a b r 67$ & 701 & 489 & 0,70 & 11,5 & 10,0 & 20,3 & 66 & 17,86 \\
\hline
\end{tabular}


continuação da Tabela 1

DATA

$\begin{array}{llllllll}\mathrm{Q}_{0} & \mathrm{ROC} & \mathrm{ROC} / \mathrm{Q}_{0} & \mathrm{~N} & \mathrm{n} & \mathrm{T}(\mathrm{OC}) & \mathrm{UR} \% & \text { es }\end{array}$

$20 a b r 67$

$696 \quad 428 \quad 0,61$

11,5

7,5

20,5

$69 \quad 18,90$

$22 \operatorname{abr} 67$

$688 \quad 475 \quad 0,69$

11,4

9,0

20,4

$66 \quad 17,97$

$25 a b r 67$

$675 \quad 357 \quad 0,53$

11,3

7,0

19,8

$74 \quad 17,32$

$26 a b r 67$

671408

0,61

11,3

8,7

19,1

$73 \quad 16,58$

27 abr 67

$667 \quad 427 \quad 0,64$

11,3

8,1

20,2

$71 \quad 17,75$

$30 a b r 67$

$655 \quad 406 \quad 0,62$

11,2

8,4

19,4

73

16,89

$01 \mathrm{mai} 67$

$651 \quad 445$

0,68

11,2

8,7

19,3

70

16,79

03 mai 67

$643 \quad 370$

0,57

$11,2 \quad 7,9$

21,9

72

19,71

$05 m a i 67$

635407

0,64

11,

7,6

18,9

$66 \quad 16,37$

$07 \mathrm{mai} 67$

$628 \quad 420 \quad 0,67$

$11,1 \quad 9,2$

17,5

$71 \quad 15,00$

$08 m a i 67$

$624 \quad 434$

0,69

11,1

9,4

18,6

63

16,07

$18 \mathrm{mai} 67$

$591 \quad 413$

0,70

10,9

7,7

18,5

69

15,97

$19 \mathrm{mai} 67$

$588 \quad 434$

0,74

10,9

8,8

19,0

63

16,48

$20 \mathrm{mai} 67$

$585 \quad 397$

0,68

10,9

7,3

18,8

70

16,27

$26 \operatorname{mai} 67$

$569 \quad 406$

$0,71 \quad 10,8$

8,7

17,6

$67 \quad 15,09$

$30 \mathrm{mai} 67$

$560 \quad 317$

0,57

10,8

5,5

19,2

$66 \quad 16,69$

09 jun 67

$544 \quad 428$

0,79

10,7

8,4

9 ,

75

8,91

15jun67

$538 \quad 375$

0,70

10,7

8,6

17,3

$81 \quad 14,81$

17jun67

$537 \quad 400$

0,74

10,7

8,8

16,4

75

13,99

19 jun 67

$536 \quad 399$

0,74

10,7

9,2

16,5

72

14,08

20 jun 67

$536 \quad 392$

0,73

$10,7 \quad 9,2$

17,

$73 \quad 14,81$ 
continuação da Tabela 1

\begin{tabular}{|c|c|c|c|c|c|c|c|c|}
\hline DATA & $\mathrm{Q}_{0}$ & RoC & $\operatorname{Roc} / Q_{0}$ & $\mathrm{~N}$ & $\mathrm{n}$ & $\mathrm{T}(\mathrm{OC})$ & UR\% & es \\
\hline 21 jun 67 & 536 & 390 & 0,73 & 10,7 & 9,1 & 17,6 & 71 & 15,09 \\
\hline 22 jun67 & 536 & 395 & 0,74 & 10,7 & 9,0 & 16,4 & 74 & 13,99 \\
\hline 23 jun67 & 536 & 394 & 0,74 & 10,7 & 9,4 & 17,0 & 69 & 14,53 \\
\hline 24 jun 67 & 536 & 343 & 0,64 & 10,7 & 7,4 & 18,6 & 70 & 16,07 \\
\hline 26 jun 67 & 536 & 313 & 0,58 & 10,7 & 7,1 & 17,5 & 75 & 15,00 \\
\hline 04 jul67 & 542 & 336 & 0,62 & 10,7 & 5,9 & 17,6 & 71 & 15,09 \\
\hline 05jul67 & 543 & 364 & 0,67 & 10,7 & 8,0 & 17,3 & 68 & 14,81 \\
\hline $13 j u 167$ & 555 & 560 & 0,65 & 10,8 & 7,6 & 18,0 & 79 & 15,48 \\
\hline $16 j u 167$ & 561 & 425 & 0,76 & 10,8 & 8,3 & 16,1 & 74 & 13,72 \\
\hline $17 j u l 67$ & 563 & 411 & 0,73 & 10,8 & 8,6 & 12,9 & 70 & 14,44 \\
\hline $21 j u 167$ & 572 & 347 & 0,61 & 10,9 & 5,2 & 17,0 & 59 & 14,53 \\
\hline $26 j u 167$ & 586 & 363 & 0,62 & 10,9 & 8,6 & 19,6 & 82 & 16,70 \\
\hline $28 j u 167$ & 591 & 426 & 0,72 & 11,0 & 9,4 & 17,6 & 82 & 15,09 \\
\hline 24 ago 67 & 689 & 401 & 0,58 & 11,5 & 7,5 & 21,5 & 60 & 19,23 \\
\hline 24 ago 67 & 693 & 442 & 0,64 & 11,5 & 8,7 & 21,4 & 67 & 19,11 \\
\hline 26 ago67 & 697 & 441 & 0,63 & 11,5 & 7,7 & 20,0 & 60 & 17,54 \\
\hline 28 ago67 & 706 & 452 & 0,64 & 11,5 & 6,8 & 21,3 & 42 & 19,00 \\
\hline
\end{tabular}


Tabela 2. Dados utilizados nos cáculos das regressões. Roc = Radiação de ondas curtas [cal/cm.dia]; Roc(1-r) = Parcela refletida da radiação de ondas curtas [cal/cm.dia]; $\mathrm{Rn}=$ Radiação líquida medida [cal/cm.dia]; RLo = Radiação de ondas longas [cal/cm.dia]; $\mathrm{T}=$ Temperatura absoluta [K]; ea $=$ Tensão atual de vapor $[\mathrm{mmHg}] ; \mathrm{n} / \mathrm{N}=$ Razão de insolação; Ea = Emissividade atmosférica.

DATA Roc Roc(1-r) Rn(med) RLo(med) $T(k)$ ve $n / N \quad$ Ea

\begin{tabular}{llllllllll}
\hline 17set66 & 410 & 315.7 & 172 & 143.7 & 289.6 & 2.79 & 0.52 & 0.83 \\
27 set66 & 408 & 314.2 & 197 & 117.2 & 293.8 & 3.35 & 0.43 & 0.87 \\
30set66 & 557 & 428.9 & 271 & 157.9 & 295.3 & 3.59 & 0.77 & 0.83 \\
12nov66 & 228 & 175.6 & 143 & 32.6 & 295.8 & 4.30 & 0.10 & 0.96 \\
20nov66 & 705 & 542.9 & 355 & 187.9 & 294.3 & 3.29 & 0.85 & 0.79 \\
23nov66 & 664 & 511.3 & 313 & 198.3 & 292.1 & 3.07 & 0.85 & 0.77 \\
03dez66 & 449 & 345.7 & 267 & 78.7 & 299.6 & 4.12 & 0.40 & 0.92 \\
09dez66 & 698 & 537.5 & 331 & 206.5 & 298.1 & 3.76 & 0.85 & 0.78 \\
01jan67 & 615 & 473.6 & 337 & 136.6 & 295.8 & 3.90 & 0.65 & 0.85 \\
02jan67 & 652 & 502.0 & 354 & 148.0 & 296.2 & 4.06 & 0.76 & 0.84 \\
21 jan67 & 528 & 406.6 & 318 & 88.6 & 298.3 & 4.20 & 0.49 & 0.91 \\
23jan67 & 580 & 446.6 & 305 & 141.6 & 294.5 & 3.90 & 0.69 & 0.84 \\
24jan67 & 448 & 345.0 & 280 & 65.0 & 294.0 & 4.00 & 0.29 & 0.93 \\
25jan67 & 653 & 502.8 & 357 & 145.8 & 297.2 & 4.09 & 0.82 & 0.84 \\
\hline
\end{tabular}


continuação da Tabela 2

DATA ROC Roc(1-r) Rn(med) RLo(med) $T(k)$ ve $n / N \quad$ Ea

\begin{tabular}{|c|c|c|c|c|c|c|c|c|}
\hline 27jan67 & 566 & 435.8 & 293 & 142.8 & 296.2 & 3.92 & 0.71 & 0.84 \\
\hline 15 fev 67 & 642 & 494.3 & 304 & 190.3 & 297.7 & 3.95 & 0.87 & 0.80 \\
\hline 16 fev67 & 323 & 248.7 & 150 & 98.7 & 297.1 & 4.32 & 0.46 & 0.89 \\
\hline 24 fev 67 & 656 & 505.1 & 340 & 165.1 & 298.8 & 4.26 & 0.81 & 0.83 \\
\hline 27 fev67 & 622 & 478.9 & 317 & 161.9 & 298.0 & 4.11 & 0.82 & 0.83 \\
\hline 28 fev67 & 567 & 436.6 & 306 & 130.6 & 299.0 & 4.17 & 0.74 & 0.86 \\
\hline $02 \operatorname{mar} 67$ & 576 & 443.5 & 297 & 146.5 & 297.4 & 4.23 & 0.75 & 0.84 \\
\hline $04 \operatorname{mar} 67$ & 514 & 395.8 & 277 & 118.8 & 298.0 & 4.39 & 0.74 & 0.87 \\
\hline $09 \operatorname{mar} 67$ & 318 & 244.9 & 198 & 46.9 & 294.7 & 4.14 & 0.20 & 0.95 \\
\hline $20 \operatorname{mar} 67$ & 586 & 451.2 & 277 & 174.2 & 294.4 & 3.71 & 0.85 & 0.81 \\
\hline $21 \operatorname{mar} 67$ & 585 & 450.5 & 271 & 179.5 & 295.2 & 3.83 & 0.82 & 0.80 \\
\hline $22 \operatorname{mar} 67$ & 589 & 453.5 & 270 & 183.5 & 295.2 & 3.85 & 0.83 & 0.80 \\
\hline $23 \operatorname{mar} 67$ & 564 & 434.3 & 253 & 181.3 & 295.2 & 3.75 & 0.86 & 0.80 \\
\hline $06 a b r 67$ & 536 & 412.7 & 203 & 209.7 & 294.5 & 3.67 & 0.90 & 0.77 \\
\hline $07 a b r 67$ & 526 & 405.0 & 200 & 205.0 & 293.4 & 3.39 & 0.86 & 0.77 \\
\hline $09 a b r 67$ & 505 & 388.9 & 188 & 200.9 & 293.0 & 3.53 & 0.85 & 0.77 \\
\hline $11 \mathrm{abr} 67$ & 473 & 364.2 & 210 & 154.2 & 295.0 & 3.73 & 0.70 & 0.83 \\
\hline $14 \mathrm{abr} 67$ & 482 & 371.1 & 197 & 174.1 & 295.6 & 3.77 & 0.83 & 0.81 \\
\hline $15 \mathrm{abr} 67$ & 358 & 275.7 & 163 & 112.7 & 295.4 & 3.90 & 0.58 & 0.88 \\
\hline $17 \mathrm{abr} 67$ & 495 & 381.2 & 181 & 200.1 & 293.6 & 3.49 & 0.88 & 0.77 \\
\hline $18 \mathrm{abr} 67$ & 499 & 384.2 & 183 & 201.2 & 293.6 & 3.55 & 0.85 & 0.77 \\
\hline
\end{tabular}


continuação da Tabela 2

DATA Roc Roc(1-r) Rn(med) RLo(med) $T(k)$ ve $n / N \quad$ Ea

\begin{tabular}{|c|c|c|c|c|c|c|c|c|}
\hline 19 abr 67 & 489 & 376.5 & 173 & 203.5 & 293.3 & 3.43 & 0.87 & 0.77 \\
\hline $20 a b r 67$ & 428 & 329.6 & 167 & 162.6 & 293.5 & 3.53 & 0.65 & 0.82 \\
\hline 22 abr 67 & 475 & 365.8 & 164 & 201.8 & 293.4 & 3.44 & 0.79 & 0.77 \\
\hline $25 a b r 67$ & 357 & 274.9 & 134 & 140.9 & 292.8 & 3.58 & 0.62 & 0.84 \\
\hline $26 a b r 67$ & 408 & 314.2 & 127 & 187.2 & 292.1 & 3.48 & 0.77 & 0.78 \\
\hline $27 \mathrm{abr} 67$ & 427 & 328.8 & 153 & 175.8 & 293.2 & 3.55 & 0.72 & 0.80 \\
\hline 30 abr 67 & 406 & 312.6 & 103 & 209.6 & 303.0 & 3.51 & 0.75 & 0.79 \\
\hline $01 \mathrm{mai} 67$ & 445 & 342.7 & 162 & 180.6 & 292.3 & 3.43 & 0.78 & 0.79 \\
\hline $03 \mathrm{mai} 67$ & 370 & 284.9 & 145 & 139.9 & 294.9 & 3.77 & 0.70 & 0.84 \\
\hline $05 \mathrm{mai} 67$ & 407 & 313.4 & 136 & 177.4 & 291.9 & 3.29 & 0.68 & 0.79 \\
\hline $07 \mathrm{mai} 67$ & 420 & 323.4 & 145 & 178.4 & 290.5 & 3.26 & 0.83 & 0.79 \\
\hline $08 \mathrm{mai} 67$ & 434 & 334.2 & 143 & 191.2 & 291.2 & 3.18 & 0.85 & 0.78 \\
\hline $18 \mathrm{mai} 67$ & 413 & 318.0 & 152 & 166.0 & 291.5 & 3.32 & 0.71 & 0.81 \\
\hline $19 \mathrm{mai} 67$ & 434 & 334.2 & 134 & 200.2 & 292.0 & 3.22 & 0.81 & 0.77 \\
\hline $20 \mathrm{mai} 67$ & 397 & 305.7 & 142 & 163.7 & 291.8 & 3.37 & 0.67 & 0.81 \\
\hline $26 \mathrm{mai} 67$ & 426 & 328.0 & 137 & 191.0 & 290.6 & 3.18 & 0.80 & 0.78 \\
\hline $30 \mathrm{ma}$ i 67 & 317 & 244.1 & 125 & 119.1 & 292.2 & 3.32 & 0.51 & 0.86 \\
\hline 09 jun 67 & 428 & 329.6 & 117 & 212.6 & 282.5 & 2.59 & 0.78 & 0.72 \\
\hline 15jun67 & 375 & 288.8 & 122 & 166.8 & 290.3 & 3.46 & 0.80 & 0.80 \\
\hline 17jun 67 & 400 & 308.0 & 116 & 192.0 & 289.4 & 3.24 & 0.82 & 0.77 \\
\hline 19jun67 & 399 & 307.2 & 112 & 195.2 & 289.5 & 3.18 & 0.86 & 0.77 \\
\hline
\end{tabular}


continuação da Tabela 2

DATA Roc Roc(1-r) Rn(med) RLo(med) $T(k)$ ve $n / N \quad$ Ea

\begin{tabular}{|c|c|c|c|c|c|c|c|c|}
\hline 20 jun 67 & 392 & 301.8 & 116 & 185.8 & 290.3 & 3.29 & 0.86 & 0.78 \\
\hline 21 jun 67 & 390 & 300.3 & 104 & 196.3 & 290.6 & 3.27 & 0.85 & 0.78 \\
\hline 22 jun 67 & 395 & 304.2 & 105 & 199.1 & 289.4 & 3.22 & 0.84 & 0.76 \\
\hline 23 jun 67 & 394 & 303.4 & 105 & 198.4 & 290.0 & 3.17 & 0.88 & 0.76 \\
\hline 24 jun 67 & 343 & 264.1 & 104 & 160.1 & 291.6 & 3.35 & 0.69 & 0.82 \\
\hline 26 jun 67 & 313 & 241.0 & 98 & 143.0 & 290.5 & 3.35 & 0.66 & 0.81 \\
\hline $04 j u 167$ & 336 & 258.7 & 120 & 138.7 & 290.6 & 3.27 & 0.55 & 0.84 \\
\hline 05jul67 & 364 & 280.3 & 114 & 166.3 & 290.3 & 3.17 & 0.75 & 0.80 \\
\hline 13 jul67 & 360 & 277.2 & 122 & 155.2 & 291.0 & 3.50 & 0.70 & 0.82 \\
\hline $16 j u 167$ & 425 & 327.3 & 140 & 187.3 & 289.1 & 3.19 & 0.77 & 0.77 \\
\hline 17jul67 & 411 & 316.5 & 123 & 193.5 & 285.9 & 3.18 & 0.79 & 0.76 \\
\hline $21 j u 167$ & 347 & 267.2 & 130 & 137.2 & 290.0 & 2.93 & 0.48 & 0.84 \\
\hline $26 j u l 67$ & 363 & 279.5 & 127 & 152.5 & 291.6 & 3.63 & 0.79 & 0.82 \\
\hline $28 j u 167$ & 426 & 328.0 & 151 & 177.0 & 290.6 & 3.52 & 0.85 & 0.79 \\
\hline 24 ago 67 & 401 & 308.8 & 153 & 155.8 & 294.5 & 3.40 & 0.65 & 0.83 \\
\hline 25 ago67 & 442 & 340.3 & 183 & 157.3 & 294.4 & 3.58 & 0.76 & 0.82 \\
\hline 26 ago67 & 441 & 339.6 & 188 & 151.6 & 293.0 & 3.24 & 0.67 & 0.83 \\
\hline 28 ago67 & 452 & 348.0 & 171 & 177.0 & 294.3 & 2.82 & 0.59 & 0.80 \\
\hline
\end{tabular}


Tabela 3. Estimativa do Balanço de ondas longas, para dias limpos $(\mathrm{n} / \mathrm{N} 0,88): \operatorname{Roc}(1-\mathrm{r})=$ radiação de ondas curtas subtraída do albedo $\left[\mathrm{cal} / \mathrm{cm}^{2} \cdot\right.$ dia $] ; \mathrm{Rn}=$ Radiação líquida medida [cal/ $\mathrm{cm}^{2}$. dia]; Rlo = Radiação de ondas longas medida $\left[\mathrm{cal} / \mathrm{cm}^{2} \cdot \mathrm{dia}\right] ; \mathrm{T}=$ Temperatura absoluta [K]; UR = Umidade relativa; ea = Umidade absoluta [mmg $] ; \mathrm{n} / \mathrm{N}=$ Razão de insolação; $\sigma=$ Constante de Stefan-Boltzmann $\left[1,19 \times 10^{-7} \mathrm{cal} / \mathrm{cm}^{2} . \mathrm{dia}\right] ; \quad \mathrm{Ea}=$ Emissividade atmosférica.

\begin{tabular}{|c|c|c|c|c|c|c|c|c|c|c|c|c|c|}
\hline DATA & $\operatorname{Roc}(1-r)$ & Rn & $\mathrm{RL}_{0}($ med) & $T$ & UR & ea & $\mathrm{n} / \mathrm{N}$ & $\sigma T^{4}$ & $\mathrm{RL}_{0} / \sigma \mathrm{T}^{4}$ & Ea & $E a($ Yest) & $\mathrm{RL}_{0}$ est (eq) & RLest(B) \\
\hline 18 set66 & 472.78 & 255 & 217.7 & 288.9 & 44 & 2.44 & 0.92 & 829.58 & 0.262 & 0.737 & 0.747 & 210.387 & 278.340 \\
\hline 23 set66 & 466.62 & 274 & 192.6 & 287.3 & 54 & 2.57 & 0.88 & 811.35 & 0.237 & 0.762 & 0.758 & 196.770 & 262.520 \\
\hline 10out66 & 477.40 & 340 & 137.4 & 294.0 & 62 & 3.40 & 0.88 & 889.72 & 0.154 & 0.845 & 0.829 & 152.807 & 219.938 \\
\hline $160 u t 66$ & 478.17 & 353 & 125.1 & 295.3 & 59 & 3.45 & 0.90 & 905.57 & 0.138 & 0.862 & 0.833 & 151.668 & 219.691 \\
\hline 20 out66 & 500.50 & 326 & 174.5 & 290.8 & 48 & 2.71 & 0.94 & 851.62 & 0.204 & 0.795 & 0.770 & 196.370 & 264.581 \\
\hline $240 u t 66$ & 512.05 & 317 & 195.0 & 293.2 & 51 & 3.01 & 0.91 & 880.08 & 0.221 & 0.778 & 0.795 & 180.419 & 249.133 \\
\hline 25 out66 & 529.76 & 365 & 164.7 & 295.6 & 45 & 3.04 & 0.91 & 909.25 & 0.181 & 0.819 & 0.798 & 184.073 & 254.880 \\
\hline $260 u+66$ & 521.29 & 335 & 186.2 & 298.5 & 48 & 3.43 & 0.96 & 945.46 & 0.197 & 0.803 & 0.831 & 159.962 & 231.108 \\
\hline 07 nov66 & 527.45 & 419 & 108.4 & 297.2 & 58 & 3.62 & 0.92 & 929.10 & 0.116 & 0.883 & 0.848 & 142.141 & 210.868 \\
\hline 19nov66 & 559.02 & 396 & 163.0 & 293.2 & 51 & 3.01 & 0.95 & 880.08 & 0.185 & 0.815 & 0.795 & 180.419 & 249.133 \\
\hline 21 nov66 & 530.53 & 344 & 186.5 & 294.4 & 58 & 3.33 & 0.89 & 894.58 & 0.208 & 0.813 & 0.823 & 158.981 & 226.901 \\
\hline 24 nov66 & 521.29 & 354 & 167.2 & 294.4 & 55 & 3.24 & 0.92 & 894.58 & 0.187 & 0.813 & 0.815 & 165.847 & 234.308 \\
\hline 26 nov66 & 525.14 & 364 & 161.1 & 295.0 & 55 & 3.30 & 0.95 & 901.89 & 0.178 & 0.821 & 0.820 & 162.588 & 231.244 \\
\hline 01 dez66 & 522.83 & 404 & 118.8 & 299.3 & 50 & 3.58 & 0.88 & 955.64 & 0.124 & 0.876 & 0.844 & 149.461 & 220.408 \\
\hline $29 \operatorname{dez} 66$ & 485.10 & 343 & 142.1 & 296.3 & 66 & 3.80 & 0.89 & 917.90 & 0.154 & 0.845 & 0.863 & 126.339 & 193.126 \\
\hline $30 \operatorname{dez} 66$ & 507.43 & 355 & 152.4 & 297.8 & 58 & 3.69 & 0.89 & 936.63 & 0.162 & 0.837 & 0.854 & 137.703 & 206.545 \\
\hline
\end{tabular}


cont inuação da Tabela 3

\begin{tabular}{|c|c|c|c|c|c|c|c|c|c|c|c|c|c|}
\hline DATA & $\operatorname{Roc}(1-r)$ & Rn & $\mathrm{RL}_{0}$ (med) & $T$ & UR & ea & $\mathrm{n} / \mathrm{N}$ & $\sigma T^{4}$ & $\mathrm{RL}_{0} / \sigma \mathrm{T}^{4}$ & $\mathrm{Ea}$ & $\mathrm{Ea}($ Yest) & $\mathrm{RL}_{0}$ est(eq) & RLest(B) \\
\hline 28 jan 67 & 445.83 & 324 & 121.8 & 295.9 & 70 & 3.83 & 0.88 & 912.95 & 0.133 & 0.866 & 0.865 & 123.323 & 189.564 \\
\hline 13 fev 67 & 367.29 & 287 & 80.2 & 297.3 & 84 & 4.37 & 0.88 & 930.35 & 0.086 & 0.140 & 0.912 & 82.8347 & 146.958 \\
\hline 17 mai67 & 354.97 & 172 & 182.9 & 291.8 & 66 & 3.28 & 0.95 & 863.39 & 0.211 & 0.788 & 0.818 & 157.120 & 222.961 \\
\hline 23 jun67 & 303.30 & 105 & 198.3 & 290.0 & 69 & 3.17 & 0.88 & 842.29 & 0.235 & 0.764 & 0.809 & 161.180 & 226.036 \\
\hline
\end{tabular}

Procurando os valores para a e b para o ajuste de le em função de $\mathrm{RL}_{0} / \sigma \mathrm{T}^{4}$.

\begin{tabular}{|lc|}
\hline VARIÁVEL INDEPENDENTE & COEFICIENTE \\
\hline \hline Constante a & 0,461666 \\
Coeficiente $\sqrt{ }$ e & 0,08527 \\
Coeficiente $\mathrm{n} / \mathrm{N}$ & 0,731387 \\
\hline
\end{tabular}

$\mathrm{N}$ ㅇ de Observaçōes $=20$

$$
\frac{R L_{0}}{\sigma T^{4}}=0,4617-0,0853 \sqrt{e}
$$


Tabela 4. Dados estimados de radiação de ondas longas a partir da equação original de Brunt e equações 1,2 e 3 propostas neste trabalho. RLo(med) - = Radiação de ondas longas medida $[\mathrm{cal} / \mathrm{cm} \cdot \mathrm{dia}]$.

$E_{q} B r$ rut $=R L O=\sigma T^{4}(0,56-0,092 \sqrt{e})\left(0,1+0,9 \frac{n}{N}\right)$

$E_{q}(4.1 .5 .6)=R L O=\sigma T^{4}(0,44-0,056 \sqrt{e})\left(0,066+0,97 \frac{n}{N}\right)$

$E_{q}(4 \cdot 1 \cdot 5.1)=R L O=\sigma T^{4}\left(0,233-0,056 \sqrt{e}+0,209 \frac{n}{N}\right)$

$E_{q}(4.1 .4 .4)=R L O=\sigma T^{4}\left(0,091-0,019 \sqrt{e}+0,42 \frac{n}{N}-0,055 \frac{n}{N} \sqrt{e}\right)$

\begin{tabular}{|c|c|c|c|c|c|}
\hline \multirow{2}{*}{ DATA } & \multirow{2}{*}{ RLo (med) } & \multicolumn{4}{|c|}{ RLo (est) } \\
\hline & & BRUNT & $\begin{array}{c}\text { EQUAC } \\
(4.1 .5 \cdot 6)\end{array}$ & $\begin{array}{c}\text { EQUAC } \\
(4 \cdot 1 \cdot 5 \cdot 1)\end{array}$ & $\begin{array}{c}\text { EQUAC } \\
(4.1 .4 \cdot 4)\end{array}$ \\
\hline 17 set 66 & 144 & 144 & 136 & 155 & 147 \\
\hline 27 set 66 & 117 & 109 & 108 & 120 & 114 \\
\hline 30 set 66 & 158 & 165 & 176 & 174 & 175 \\
\hline 12 nov6 6 & 33 & 28 & 30 & 12 & 25 \\
\hline 20 nov66 & 188 & 199 & 203 & 202 & 206 \\
\hline 23 nov66 & 198 & 208 & 207 & 207 & 212 \\
\hline
\end{tabular}


continuação da Tabela 4

\begin{tabular}{|c|c|c|c|c|c|}
\hline \multirow{2}{*}{ DATA } & \multirow{2}{*}{ RLo (med) } & \multicolumn{4}{|c|}{ RLo (est) } \\
\hline & & BRUNT & $\begin{array}{c}\text { EQUAC } \\
(4.1 .5 .6)\end{array}$ & $\begin{array}{c}\text { EQUAC } \\
(4.1 .5 .1)\end{array}$ & $\begin{array}{c}\text { EQUAC } \\
(4.1 .4 .4)\end{array}$ \\
\hline 03 dez 66 & 79 & 80 & 91 & 82 & 86 \\
\hline 09 dez 66 & 206 & 175 & 192 & 188 & 188 \\
\hline $01 j a n 67$ & 137 & 126 & 141 & 137 & 137 \\
\hline 02 jan 67 & 148 & 134 & 157 & 151 & 149 \\
\hline 21 jan 67 & 89 & 88 & 104 & 94 & 98 \\
\hline 23 jan 67 & 142 & 130 & 146 & 142 & 142 \\
\hline 24 jan 67 & 65 & 62 & 67 & 62 & 65 \\
\hline 25jan67 & 146 & 143 & 169 & 163 & 160 \\
\hline 27jan67 & 143 & 135 & 152 & 148 & 147 \\
\hline 15 fev67 & 190 & 162 & 186 & 181 & 179 \\
\hline 16 fev 67 & 99 & 77 & 94 & 81 & 86 \\
\hline $24 \mathrm{fev} 67$ & 165 & 132 & 163 & 155 & 151 \\
\hline 27 fev67 & 162 & 143 & 170 & 164 & 161 \\
\hline 28 fev67 & 131 & 129 & 154 & 147 & 145 \\
\hline $02 \operatorname{mar} 67$ & 147 & 123 & 150 & 143 & 140 \\
\hline $04 \operatorname{mar} 67$ & 119 & 113 & 143 & 133 & 131 \\
\hline $09 \operatorname{mar} 67$ & 47 & 45 & 49 & 39 & 46 \\
\hline $20 \operatorname{mar} 67$ & 174 & 169 & 185 & 182 & 182 \\
\hline $21 \operatorname{mar} 67$ & 179 & 158 & 176 & 172 & 171 \\
\hline $22 \operatorname{mar} 67$ & 184 & 157 & 177 & 172 & 171 \\
\hline $23 \operatorname{mar} 67$ & 181 & 170 & 187 & 183 & 183 \\
\hline
\end{tabular}


continuação da Tabela 4

\begin{tabular}{|c|c|c|c|c|c|}
\hline \multirow{2}{*}{ DATA } & \multirow{2}{*}{ RLo (med) } & \multicolumn{4}{|c|}{ RLo (est) } \\
\hline & & BRUNT & $\begin{array}{c}\text { EQUAC } \\
(4.1 .5 .6)\end{array}$ & $\begin{array}{c}\text { EQUAC } \\
(4.1 .5 .1)\end{array}$ & $\begin{array}{c}\text { EQUAC } \\
(4 \cdot 1 \cdot 4 \cdot 4)\end{array}$ \\
\hline $06 a b r 67$ & 210 & 181 & 197 & 193 & 194 \\
\hline 07 abr 67 & 205 & 191 & 199 & 197 & 200 \\
\hline $09 a b r 67$ & 201 & 179 & 189 & 187 & 189 \\
\hline 11 abr 67 & 154 & 143 & 155 & 154 & 153 \\
\hline $14 \mathrm{abr} 67$ & 174 & 164 & 181 & 178 & 177 \\
\hline $15 a b r 67$ & 113 & 113 & 126 & 123 & 123 \\
\hline 17 abr 67 & 200 & 188 & 199 & 196 & 189 \\
\hline $18 \mathrm{abr} 67$ & 201 & 179 & 190 & 187 & 189 \\
\hline $19 a b r 67$ & 204 & 190 & 199 & 196 & 199 \\
\hline $20 a b r 67$ & 163 & 142 & 149 & 151 & 150 \\
\hline $22 \mathrm{abr} 67$ & 202 & 174 & 182 & 181 & 183 \\
\hline $25 a b r 67$ & 141 & 133 & 140 & 142 & 141 \\
\hline $26 a b r 67$ & 187 & 165 & 173 & 173 & 174 \\
\hline 27 abr 67 & 176 & 154 & 162 & 163 & 163 \\
\hline 30 abr 67 & 210 & 184 & 194 & 194 & 194 \\
\hline $01 \mathrm{mai} 67$ & 181 & 171 & 177 & 177 & 179 \\
\hline $03 \mathrm{mai} 67$ & 140 & 140 & 154 & 152 & 151 \\
\hline $05 \mathrm{mai} 67$ & 177 & 159 & 161 & 165 & 165 \\
\hline $07 \mathrm{mai} 67$ & 178 & 187 & 190 & 190 & 193 \\
\hline $08 \mathrm{mai} 67$ & 191 & 199 & 201 & 200 & 205 \\
\hline $18 \mathrm{mai} 67$ & 166 & 162 & 165 & 168 & 168 \\
\hline
\end{tabular}


continuação da Tabela 4

\begin{tabular}{|c|c|c|c|c|c|}
\hline \multirow{2}{*}{ DATA } & \multirow{2}{*}{ RLo (med) } & \multicolumn{4}{|c|}{ RLo (est) } \\
\hline & & BRUNT & $\begin{array}{c}\text { EQUAC } \\
(4.1 .5 .6)\end{array}$ & $\begin{array}{c}\text { EQUAC } \\
(4.1 .5 .1)\end{array}$ & $\begin{array}{c}\text { EQUAC } \\
(4.1 \cdot 4 \cdot 4)\end{array}$ \\
\hline $19 \operatorname{mai} 67$ & 200 & 189 & 191 & 192 & 195 \\
\hline $20 \mathrm{mai} 67$ & 164 & 151 & 155 & 159 & 158 \\
\hline $26 \operatorname{mai} 67$ & 191 & 186 & 187 & 189 & 192 \\
\hline $30 \mathrm{mai} 67$ & 119 & 124 & 124 & 133 & 129 \\
\hline 09 jun67 & 213 & 196 & 184 & 191 & 195 \\
\hline 15jun67 & 167 & 167 & 175 & 174 & 176 \\
\hline 17jun67 & 192 & 183 & 186 & 186 & 189 \\
\hline 19jun67 & 195 & 195 & 197 & 196 & 201 \\
\hline 20jun67 & 186 & 190 & 195 & 193 & 197 \\
\hline 21jun67 & 196 & 190 & 194 & 193 & 197 \\
\hline 22 jun67 & 199 & 189 & 191 & 191 & 195 \\
\hline 23jun67 & 198 & 202 & 203 & 202 & 207 \\
\hline 24 jun67 & 160 & 156 & 160 & 163 & 163 \\
\hline 26jun67 & 143 & 148 & 151 & 155 & 154 \\
\hline $04 j u 167$ & 139 & 131 & 131 & 140 & 136 \\
\hline 05jul67 & 166 & 176 & 176 & 189 & 181 \\
\hline 13 jul67 & 155 & 149 & 155 & 157 & 156 \\
\hline 16jul67 & 187 & 176 & 177 & 179 & 181 \\
\hline $17 j u 167$ & 193 & 173 & 173 & 175 & 178 \\
\hline $21 j u 167$ & 137 & 130 & 124 & 143 & 134 \\
\hline 26jul67 & 153 & 158 & 170 & 168 & 168 \\
\hline
\end{tabular}


continuação da Tabela 4

\begin{tabular}{lccccc}
\hline \multirow{2}{*}{ DATA } & RLo(med) & \multicolumn{5}{c}{ RLO } \\
\cline { 3 - 5 } & & BRUNT & $\begin{array}{c}\text { EQUAC } \\
(4.1 .5 .6)\end{array}$ & $\begin{array}{c}\text { EQUAC } \\
(4.1 .5 .1)\end{array}$ & $\begin{array}{c}\text { EQUAC } \\
(4.1 .4 .4)\end{array}$ \\
\hline \multirow{2}{*}{28 jul67 } & 177 & 174 & 184 & 181 & 183 \\
24 ago67 & 156 & 152 & 156 & 160 & 159 \\
25 ago67 & 157 & 162 & 172 & 171 & 172 \\
26 ago67 & 152 & 161 & 162 & 168 & 167 \\
28 ago67 & 177 & 169 & 161 & 177 & 172 \\
\hline
\end{tabular}


Tabela 5. Valores da declinação solar - $\sigma$ Anuário Astronômico do Instituto Astronômico e Geofísico - USP, 1993 (grau e décimo) .

\begin{tabular}{|c|c|c|c|c|c|c|c|c|c|c|c|c|}
\hline \multirow[b]{2}{*}{ DIAS } & \multicolumn{12}{|c|}{ MESES } \\
\hline & JAN & FEV & MAR & ABR & MAI & JUN & JUL & AGO & SET & OUT & Nov & DEZ \\
\hline 01 & -23.1 & -17.3 & -7.9 & 4.2 & 14.8 & 21.9 & 23.2 & 18.2 & 8.6 & -2.9 & -14.1 & -21.7 \\
\hline 02 & -23.0 & -17.0 & -7.5 & 4.6 & 15.1 & 22.1 & 23.1 & 17.9 & 8.2 & -3.2 & -14.5 & -21.8 \\
\hline 03 & -22.9 & -16.8 & -7.1 & 4.9 & 15.4 & 22.2 & 23.0 & 17.7 & 7.9 & -3.6 & -14.8 & -21.9 \\
\hline 04 & -22.8 & -16.4 & -6.7 & 5.3 & 15.7 & 22.3 & 22.9 & 17.5 & 7.5 & -4.0 & -15.1 & -22.1 \\
\hline 05 & -22.7 & -16.1 & -6.3 & 5.7 & 16.0 & 22.4 & 22.9 & 17.2 & 7.1 & -4.6 & -15.4 & -22.2 \\
\hline 06 & -22.6 & -15.8 & -5.9 & 6.1 & 16.3 & 22.5 & 22.8 & 16.9 & 6.7 & -4.8 & -15.7 & -22.4 \\
\hline 07 & -22.5 & -15.6 & -5.6 & 6.5 & 16.6 & 22.6 & 22.7 & 16.6 & 6.4 & -5.2 & -16.0 & -22.5 \\
\hline 08 & -22.3 & -15.2 & -5.2 & 6.9 & 16.9 & 22.7 & 22.6 & 16.4 & 6.0 & -5.6 & -16.3 & -22.6 \\
\hline 09 & -22.2 & -14.9 & -4.8 & 7.3 & 17.1 & 22.8 & 22.5 & 16.1 & 5.6 & -5.9 & -16.6 & -22.7 \\
\hline 10 & -22.1 & -14.6 & -4.4 & 7.6 & 17.4 & 22.9 & 22.3 & 15.8 & 5.2 & -6.3 & -19.9 & -22.8 \\
\hline 11 & -21.9 & -14.3 & -4.0 & 8.0 & 17.7 & 23.0 & 22.0 & 15.5 & 4.9 & -6.7 & -17.2 & -22.9 \\
\hline 12 & -21.8 & -13.9 & -3.6 & 8.4 & 17.9 & 23.1 & 22.1 & 15.2 & 4.5 & -7.1 & -17.5 & -23.0 \\
\hline 13 & -21.6 & -13.6 & -3.2 & 8.7 & 18.2 & 23.1 & 21.9 & 14.9 & 4.1 & -7.5 & -17.1 & -23.1 \\
\hline 14 & -21.4 & -13.3 & -2.9 & 9.1 & 18.4 & 23.2 & 21.8 & 14.6 & 3.7 & -7.8 & -18.0 & -23.1 \\
\hline 15 & -21.3 & -12.9 & -2.4 & 9.6 & 18.7 & 23.3 & 21.7 & 14.3 & 3.3 & -8.2 & -18.3 & -23.2 \\
\hline 16 & -21.1 & -12.6 & -2.0 & 9.8 & 18.9 & 23.3 & 21.5 & 14.0 & 2.9 & -8.6 & -18.5 & -23.2 \\
\hline 17 & -20.9 & -12.2 & -1.7 & 10.2 & 19.1 & 23.4 & 21.3 & 13.7 & 2.6 & -8.9 & -18.8 & -23.3 \\
\hline 18 & -20.7 & -11.9 & -1.2 & 10.5 & 19.4 & 23.4 & 21.2 & 13.3 & 2.6 & -9.3 & -19.0 & -23.3 \\
\hline 19 & -20.6 & -11.5 & -0.9 & 10.9 & 19.6 & 23.4 & 20.0 & 13.0 & 1.8 & -9.7 & -19.2 & -23.4 \\
\hline 20 & -20.3 & -11.2 & -0.5 & 11.2 & 19.8 & 23.4 & 20.8 & 12.7 & 1.4 & -10.0 & -19.5 & -23.4 \\
\hline 21 & -20.1 & -10.9 & -0.1 & 11.6 & 20.0 & 23.4 & 20.6 & 12.4 & 1.0 & -10.4 & -19.7 & -23.4 \\
\hline 22 & -19.9 & -10.5 & 0.3 & 11.9 & 20.2 & 23.4 & 20.4 & 12.0 & 0.6 & -10.7 & -19.9 & -23.4 \\
\hline 23 & -19.6 & -10.1 & 0.7 & 12.2 & 20.4 & 23.4 & 20.2 & 11.7 & 0.2 & -11.1 & -20.2 & -23.4 \\
\hline 24 & -19.4 & -9.8 & 1.1 & 12.6 & 20.6 & 23.4 & 20.0 & 11.4 & -0.1 & -11.5 & -20.4 & -23.4 \\
\hline 25 & -19.1 & -9.4 & 1.5 & 12.9 & 20.8 & 23.4 & 19.8 & 11.0 & -0.5 & -11.8 & -20.6 & -23.4 \\
\hline
\end{tabular}


continuação da Tabela 5

\begin{tabular}{|c|c|c|c|c|c|c|c|c|c|c|c|c|}
\hline \multirow[b]{2}{*}{ DIAS } & \multicolumn{12}{|c|}{ MESES } \\
\hline & JAN & FEV & MAR & $A B R$ & MAI & JUN & JUL. & AGO & SET & OUT & NOV & DEZ \\
\hline 26 & -18.9 & -9.0 & 1.9 & 13.2 & 20.9 & 23.4 & 19.6 & 10.7 & -0.9 & -12.1 & -20.8 & -23.4 \\
\hline 27 & -18.6 & -8.6 & 2.3 & 13.6 & 21.1 & 23.4 & 19.4 & 10.3 & -1.3 & -12.5 & -20.9 & -23.4 \\
\hline 28 & -18.4 & -8.2 & 2.7 & 13.9 & 21.3 & 23.3 & 19.2 & 10.0 & -1.7 & -12.8 & -21.1 & -23.3 \\
\hline 29 & -18.1 & - & 3.1 & 14.2 & 21.5 & 23.3 & 18.9 & 9.6 & -2.1 & -13.2 & -21.3 & -23.3 \\
\hline 30 & -17.9 & - & 3.4 & 14.5 & 21.6 & 23.2 & 18.7 & 9.3 & -2.5 & -13.5 & -21.5 & -23.2 \\
\hline 31. & -17.6 & - & 3.8 & - & 21.8 & - & 18.5 & - & - & -13.8 & - & -23.2 \\
\hline
\end{tabular}


Tabela 6. Pressão máxima de vapor à temperatura $\mathrm{T}(\mathrm{mmHg})$.

\begin{tabular}{|c|c|c|c|c|c|c|c|c|c|c|}
\hline$(t)$ & 0.0 & 0.1 & 0.2 & 0.3 & 0.4 & 0.5 & 0.6 & 0.7 & 0.8 & 0.9 \\
\hline 0 & 4.58 & 4.61 & 4.65 & 4.68 & 4.72 & 4.75 & 4.79 & 4.82 & .86 & 4.8 \\
\hline 1 & 4.93 & 4.96 & 5.00 & 5.03 & 5.07 & 5.11 & 5.14 & .18 & .22 & .2 \\
\hline 2 & 5.29 & 5.33 & 5.37 & 5.41 & 5.45 & 5.49 & 5.53 & 5.57 & .61 & .6 \\
\hline 3 & 5.69 & 5.73 & 5.77 & 5.81 & 5.85 & 5.89 & 5.93 & 5.97 & 6.02 & 5.0 \\
\hline 4 & 6.10 & 6.14 & 6.19 & 6.23 & 6.27 & 6.32 & 6.36 & 6.41 & .45 & $c$ \\
\hline 5 & 6.54 & 6.59 & 6.64 & 6.68 & 6.73 & 6.78 & 6.82 & 6.87 & .92 & .9 \\
\hline 6 & 7.01 & 7.06 & 7.11 & 7.16 & 7.21 & 7.26 & 7.31 & 7.36 & .41 & 7.4 \\
\hline 7 & 7.51 & 7.57 & 7.62 & 7.67 & 7.72 & 7.78 & 7.83 & 7.88 & .94 & .9 \\
\hline 8 & 8.05 & 8.10 & 8.16 & 8.21 & 8.27 & 8.32 & 8.38 & 8.44 & 8.49 & 8.5 \\
\hline 9 & 8.61 & 8.67 & 8.73 & 8.79 & 8.85 & 8.91 & 8.97 & 9.03 & 9.09 & 9.1 \\
\hline 10 & 9.21 & 9.27 & 9.33 & 9.40 & 9.46 & 9.52 & 9.59 & 9.65 & 9.71 & 9.7 \\
\hline 11 & 9.84 & 9.91 & 9.98 & 10.04 & 10.11 & 10.18 & 10.24 & 10.31 & 10.38 & 10.4 \\
\hline 12 & 10.52 & 10.59 & 10.66 & 10.73 & 10.80 & 10.87 & 10.94 & 11.01 & 11.09 & 11.1 \\
\hline 3 & 11.23 & 11.31 & 11.38 & 11.45 & 11.53 & 11.60 & 11.68 & 11.76 & 11.83 & 110 \\
\hline 4 & 11.99 & 12.07 & 12.14 & 12.22 & 12.30 & 12.38 & 12.46 & 12.54 & 12.62 & 12 \\
\hline 15 & 12.79 & 12.87 & 12.95 & 13.04 & 13.12 & 13.21 & 13.29 & 13.38 & 13.46 & 13.5 \\
\hline 16 & 13.63 & 13.72 & 13.81 & 13.90 & 13.99 & 14.08 & 14.17 & 14.26 & 14.35 & 14.4 \\
\hline 17 & 14.53 & 14.62 & 14.72 & 14.81 & 14.90 & 15.00 & 15.09 & 15.19 & 15.28 & 15.3 \\
\hline 18 & 15.48 & 15.58 & 15.67 & 15.77 & 15.87 & 15.97 & 16.07 & 16.17 & 16.27 & 16.3 \\
\hline 19 & 16.48 & 16.58 & 16.69 & 16.79 & 16.89 & 17.00 & 17.11 & 17.21 & 17.32 & 17.4 \\
\hline 20 & 17.54 & 17.64 & 17.75 & 17.86 & 17.97 & 18.09 & 18.20 & 18.31 & 18.42 & 18.5 \\
\hline 21 & 18.65 & 18.77 & 18.88 & 19.00 & 19.11 & 19.23 & 19.35 & 19.47 & 19.59 & 19.7 \\
\hline 22 & 19.83 & 19.95 & 20.07 & 20.19 & 20.32 & 20.44 & 20.57 & 20.69 & 20.82 & 20.9 \\
\hline 23 & 21.07 & 21.20 & 21.37 & 21.45 & 21.58 & 21.71 & 21.85 & 21.98 & 22.11 & 22.2 \\
\hline${ }^{4}$ & 22.38 & 22.51 & 22.65 & 22.79 & 22.92 & 23.06 & 23.20 & 23.34 & 23.48 & 20.0 \\
\hline 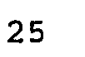 & 23.76 & 23.90 & 24.04 & 24.18 & 24.33 & 24.47 & 24.62 & 24.76 & 24.91 & 25.0 \\
\hline
\end{tabular}


continuação da Tabela 6

\begin{tabular}{|c|c|c|c|c|c|c|c|c|c|c|}
\hline$(t)$ & 0.0 & 0.1 & 0.2 & 0.3 & 0.4 & 0.5 & 0.6 & 0.7 & 0.8 & 0.9 \\
\hline & & & & & & & & & & \\
\hline 26 & 25.21 & 25.36 & 25.51 & 25.66 & 25.81 & 25.96 & 26.12 & 26.27 & 26.43 & 26.58 \\
\hline 27 & 26.74 & 26.90 & 27.06 & 27.21 & 27.37 & 27.54 & 27.70 & 27.86 & 28.02 & 28.19 \\
\hline 28 & 28.35 & 28.51 & 28.68 & 28.85 & 29.02 & 29.18 & 29.35 & 29.53 & 29.70 & 29.87 \\
\hline 29 & 30.04 & 30.22 & 30.39 & 30.57 & 30.75 & 30.92 & 31.10 & 31.28 & 31.46 & 31.64 \\
\hline 30 & 31.82 & 32.01 & 32.19 & 32.38 & 32.56 & 32.75 & 32.93 & 33.12 & 33.91 & 33.50 \\
\hline 31 & 33.70 & 33.89 & 34.08 & 34.28 & 34.47 & 34.67 & 34.86 & 35.06 & 35.26 & 35.46 \\
\hline 32 & 35.66 & 35.87 & 36.07 & 36.27 & 36.48 & 36.68 & 36.89 & 37.10 & 37.31 & 37.52 \\
\hline 33 & 37.73 & 37.94 & 38.16 & 38.37 & 38.58 & 38.80 & 39.02 & 39.24 & 39.46 & 39.68 \\
\hline 34 & 39.90 & 40.12 & 40.34 & 40.57 & 40.80 & 41.02 & 41.25 & 41.48 & 41.71 & 41.94 \\
\hline 35 & 42.18 & 42.41 & 42.64 & 42.88 & 43.12 & 43.36 & 43.60 & 43.84 & 44.08 & 44.32 \\
\hline 36 & 44.56 & 44.81 & 45.05 & 45.30 & 45.55 & 45.80 & 46.05 & 46.30 & 46.56 & 46.81 \\
\hline 37 & 47.07 & 47.32 & 47.58 & 47.84 & 48.10 & 48.36 & 48.63 & 48.89 & 49.16 & 49.42 \\
\hline 38 & 49.69 & 49.96 & 50.23 & 50.50 & 50.77 & 51.05 & 51.32 & 51.60 & 51.88 & 52.16 \\
\hline 39 & 52.44 & 52.73 & 53.01. & 53.29 & 53.58 & 53.87 & 54.16 & 54.45 & 54.74 & 55.03 \\
\hline 40 & 55.32 & 55.61 & 55.91 & 56.21 & 56.51 & 56.81 & 57.11 & 57.41 & 57.72 & 58.03 \\
\hline 41 & 58.34 & 58.65 & 58.96 & 59.27 & 59.58 & 59.90 & 60.22 & 60.54 & 60.86 & 61.18 \\
\hline 42 & 61.50 & 61.82 & 62.14 & 62.47 & 62.80 & 63.13 & 63.46 & 63.79 & 64.12 & 64.46 \\
\hline 43 & 64.80 & 65.14 & 65.48 & 65.82 & 66.16 & 66.51 & 66.86 & 67.21 & 67.56 & 67.91 \\
\hline 44 & 68.26 & 68.61 & 68.97 & 69.33 & 69.69 & 70.05 & 70.41 & 70.77 & 71.14 & 71.51 \\
\hline 45 & 71.71 & & & & & & & & & \\
\hline
\end{tabular}


Figura 15. Histograma de frequencia de $\mathrm{n} / \mathrm{N}$ (em valores).

Histograma de Frequencia de $\mathrm{n} / \mathrm{N}$

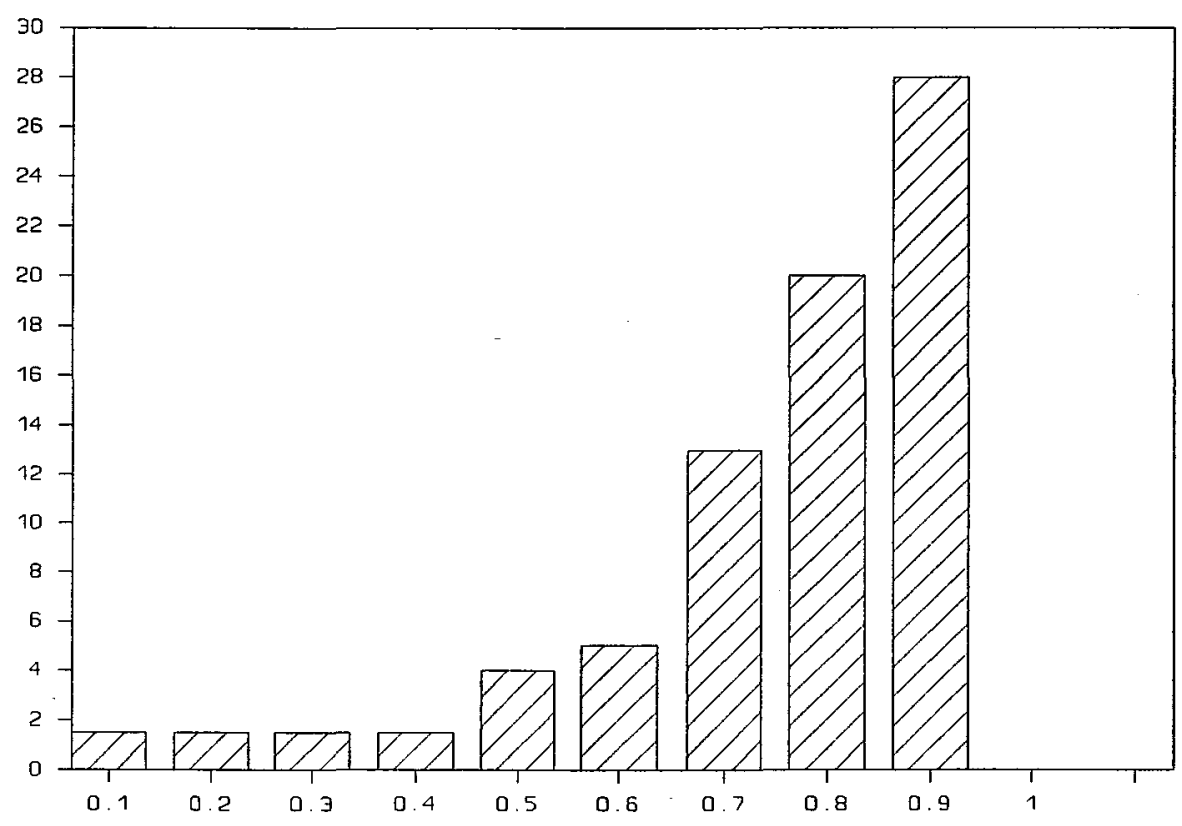

Figura 16. Histograma de frequência $\mathrm{n} / \mathrm{N}$ (percentual).

Histograma de Frequencia de $\mathrm{n} / \mathrm{N}$

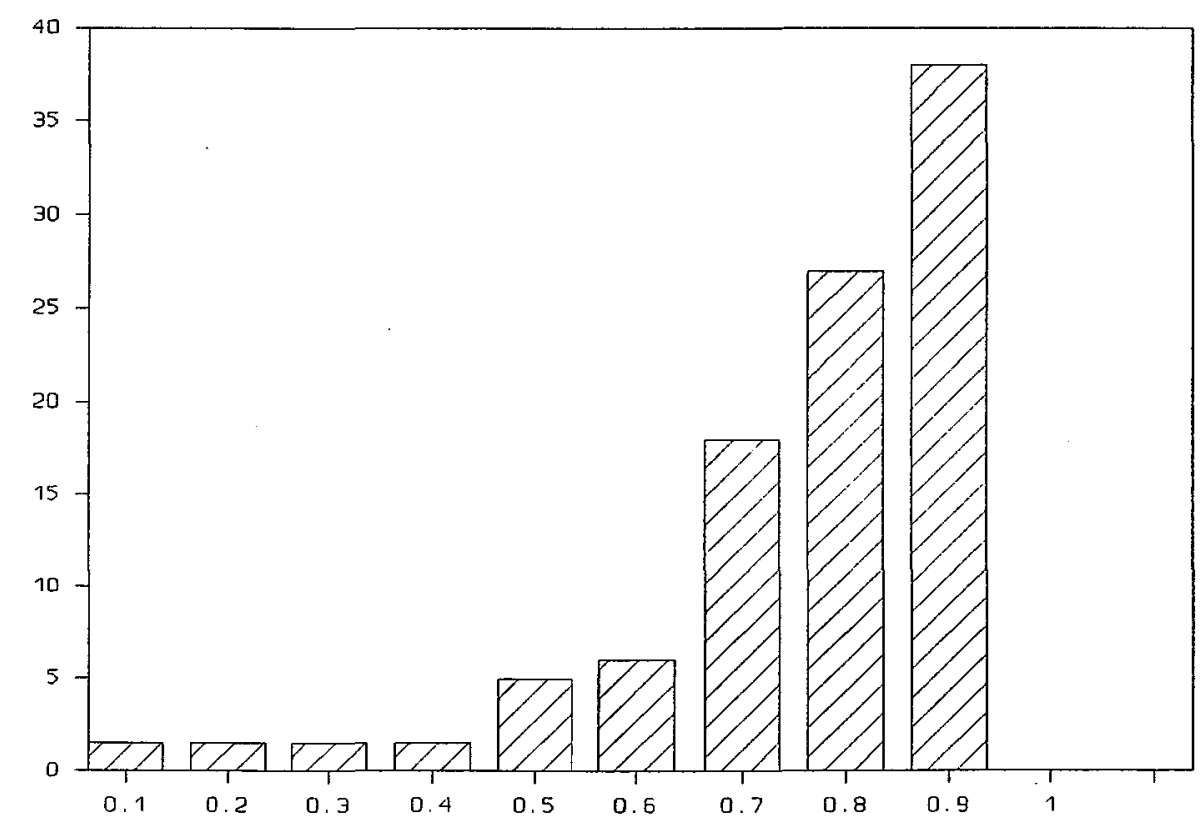


Figura 17. Histograma de frequência de pressão atual de vapor. Histograma de Frequencia de ea

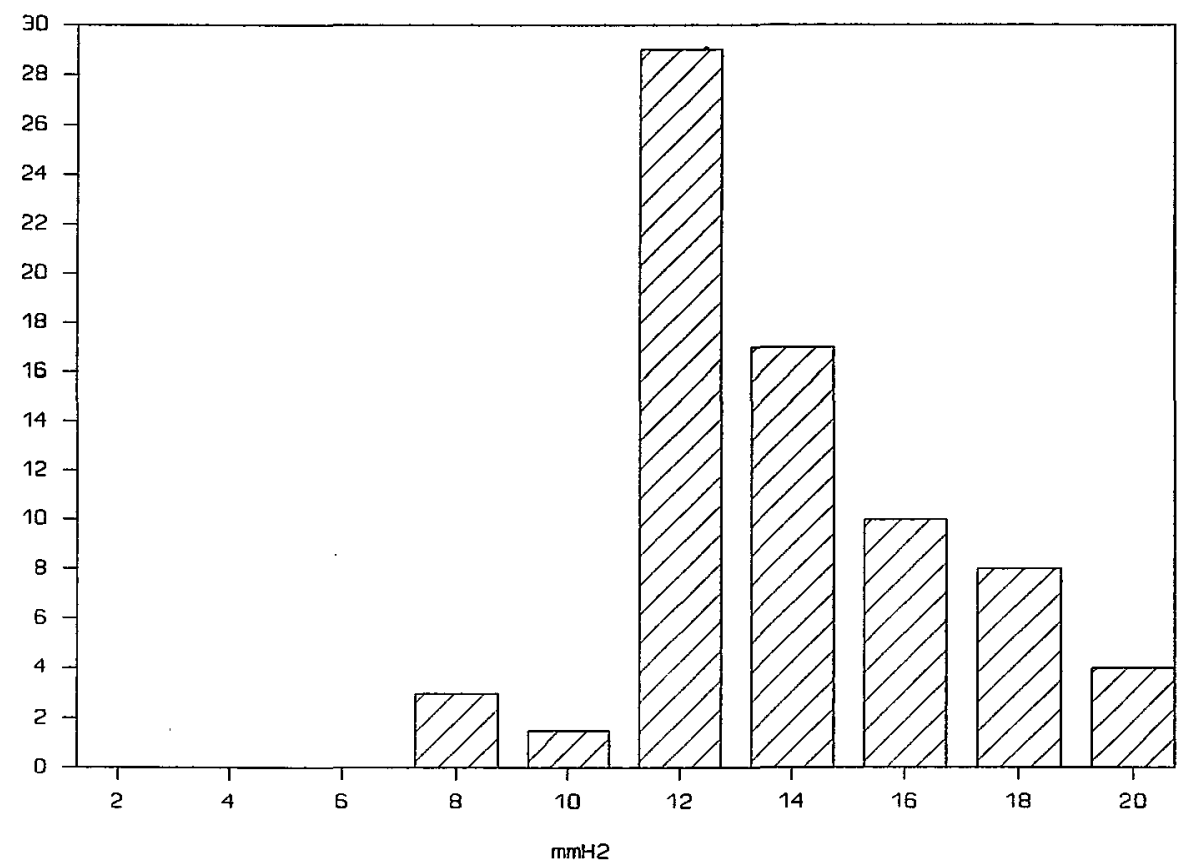

Figura 18. Histograma de frequência de pressão atual de vapor (percentual).

Histograma de Frequencia de ea

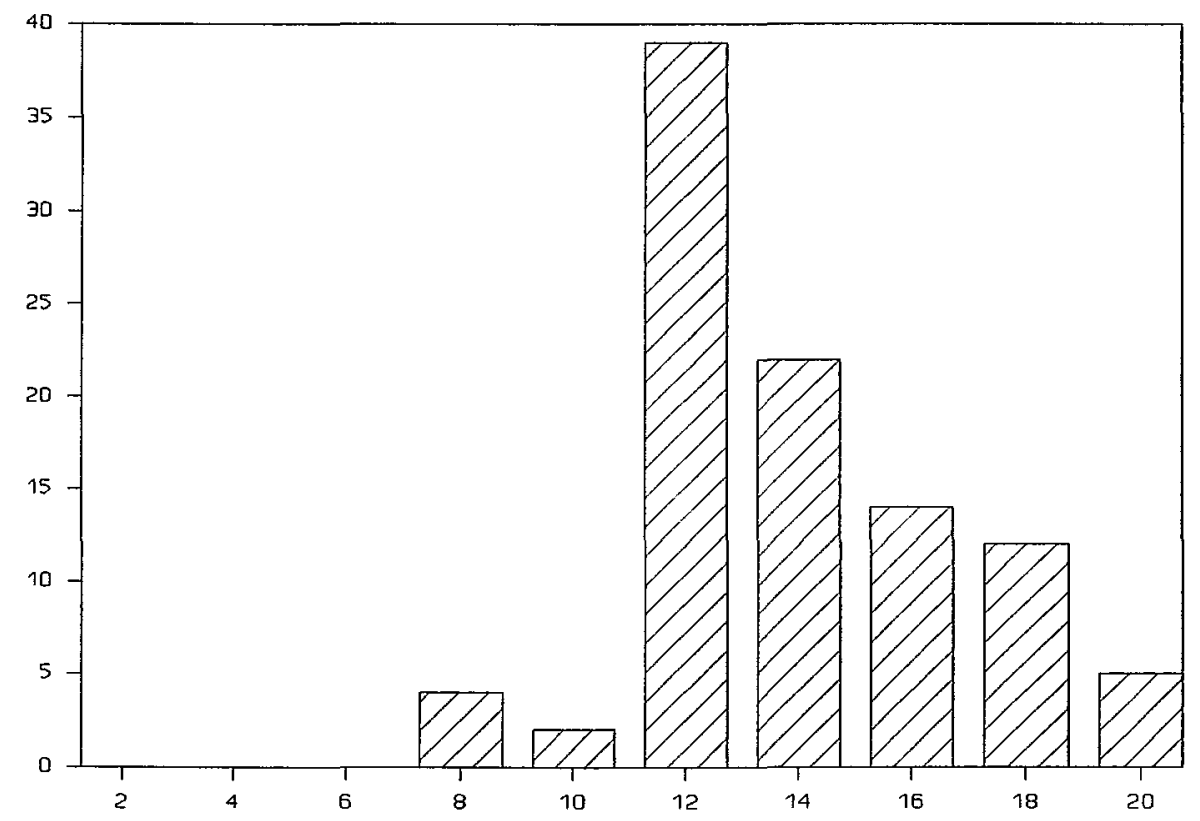

